UNIVERSIDADE DE SÃO PAULO

ESCOLA POLITÉCNICA

DEPARTAMENTO DE ENG. DE ENERGIA E AUTOMAÇÃO ELÉTRICAS.

SISTEMA DE MONITORAMENTO E METODOLOGIA DE ESTIMATIVA DOS TEMPOS DE OPERAÇÃO DO DISJUNTOR

Milthon Serna Silva

SÃO PAULO

2005 
MILTHON SERNA SILVA

\section{SISTEMA DE MONITORAMENTO E METODOLOGIA DE ESTIMATIVA DOS TEMPOS DE OPERAÇÃO DO DISJUNTOR}

Tese apresentada à Escola Politécnica da Universidade de São Paulo, para obtenção do Título de Doutor em Engenharia Elétrica.

Orientador:

Prof. Dr. José Antonio Jardini. 
Este exemplar foi revisado e alterado em relação à versão original, sob responsabilidade única do autor e com a anuência de seu orientador.

São Paulo, 25 de abril de 2005.

Assinatura do autor

Assinatura do orientador

Silva, Milthon Serna.

Sistema de monitoramento e metodologia de estimativa dos tempos de operação do disjuntor I Milthon Serna Silva.

São Paulo, 2005.

$116 p$.

Tese (Doutorado) -- Escola Politécnica da Universidade de São Paulo. Departamento de Energia e Automação Elétricas.

1.Sistemas de Monitoramento 2.Transformada Wavelet.

3.Processamento de sinais I.Universidade de São Paulo.

Escola Politécnica. II.Departamento de Energia e Automação Elétricas. III.t. 
Dedico este trabalho aos meus pais e irmãos.

"A mente que se abre a uma nova idéia jamais voltará ao seu tamanho original".

Albert Einstein. 


\section{AGRADECIMENTOS}

Ao Prof. Dr. José A. Jardini pela orientação, dedicação e por acreditar em nosso trabalho.

Ao Prof. Dr. Luiz A. Bacalá pela colaboração no entendimento da teoria das Transformadas Wavelets.

Aos amigos de todas as horas do “GAGTD”, em especial ao Luiz Carlos Magrini que me acompanharam e participaram diretamente do desenvolvimento deste trabalho. A meu amigo Elcio pelos conselhos e sugestões oferecidas.

À minha querida esposa Edilene pela compreensão, companheirismo e incentivo.

Aos professores e funcionários do Departamento de Engenharia de Energia e Automação Elétricas da POLI-USP que de alguma forma contribuíram para o andamento deste trabalho.

À Coordenadoria de Aperfeiçoamento de Pessoal de Nível Superior - CAPES pela bolsa de estudos concedida.

À Empresa de Transmissão de Energia do Oeste Ltda. - ETEO (nas pessoas de Luis A. Solis, Antonio M. Corvo e Oto A. Behmer) e a Companhia de Eletricidade do Estado da Bahia - COELBA (na pessoa de Francisco Veiga), pela informação proporcionada sobre a operação de seus disjuntores e pelo financiamento dos projetos de Sistemas de Monitoramento de equipamentos em subestações elétricas como parte dos P\&D da Agência Nacional de Energia Elétrica - ANEEL.

Sobretudo a Deus. 


\section{SUMÁRIO}

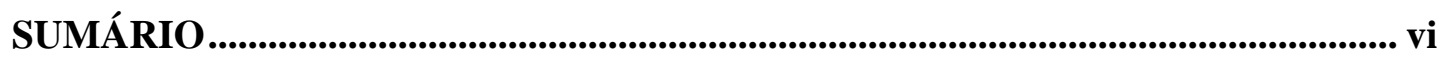

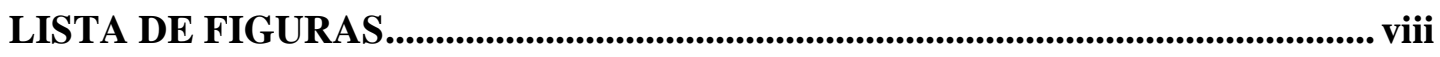

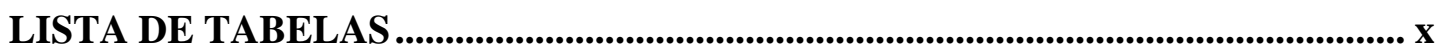

LISTA DE SIGLAS E ABREVIATURAS ...............................................................

LISTA DE SÍMBOLOS ........................................................................................... xii

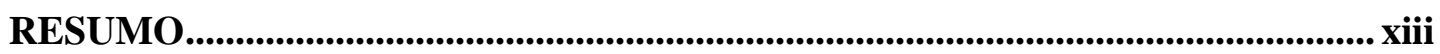

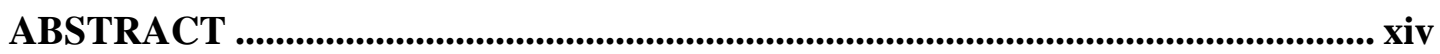

\section{CAPÍTULO 1}

Preâmbulo ........................................................................................................................................................ 1

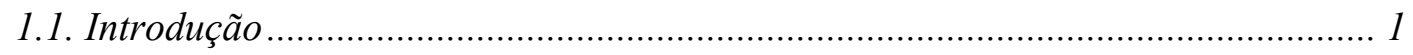

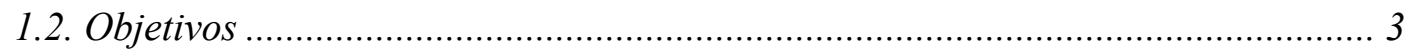

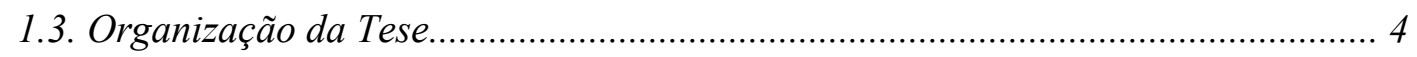

\section{CAPÍTULO 2}

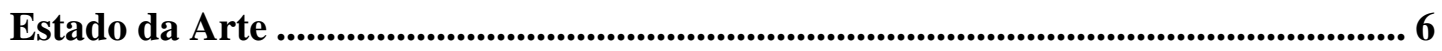

\section{CAPÍTULO 3}

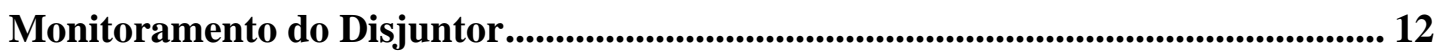

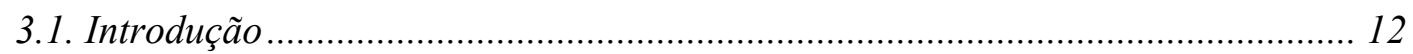

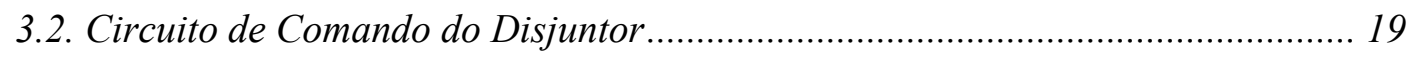

3.3. Sistema de Monitoramento ...................................................................................... 21

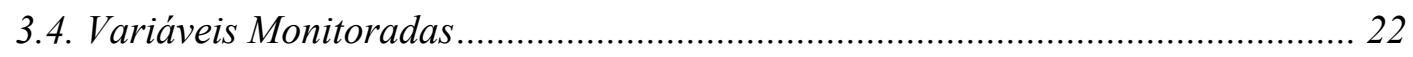

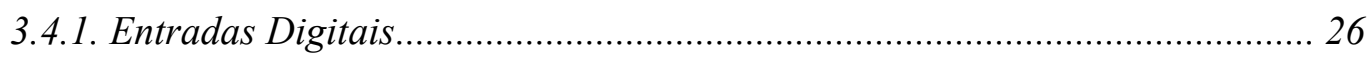

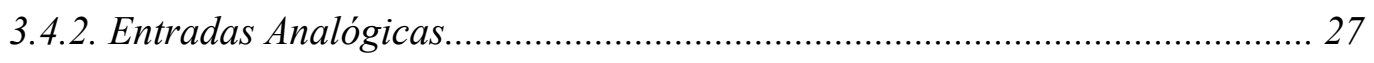

\section{CAPÍTULO 4}

Determinação dos tempos de operação do disjuntor..................................................... 29

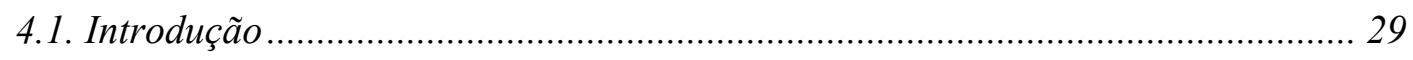

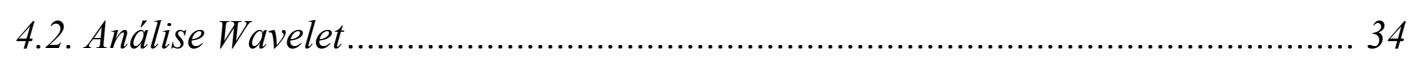

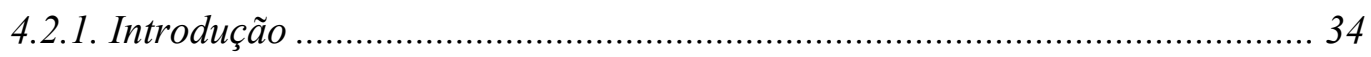




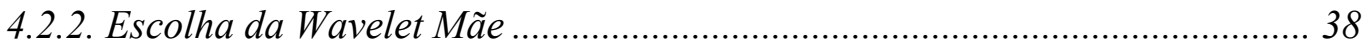

4.2.3. Metodologia utilizada para determinação dos tempos de operação............... 43

4.3. Análise de Fourier............................................................................................... 51

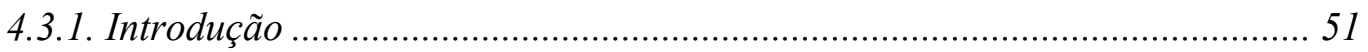

4.3.2. Transformada de Fourier de Curta Duração (STFT) .................................... 52

4.3.3. Metodologia utilizada para determinação dos tempos de operação.............. 52

\section{CAPÍTULO 5}

Medições efetuadas no Protótipo................................................................................... 59

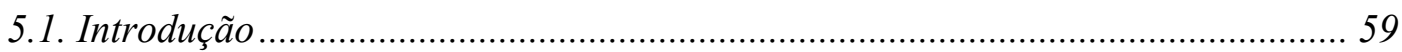

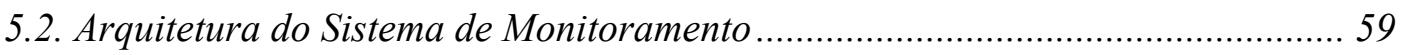

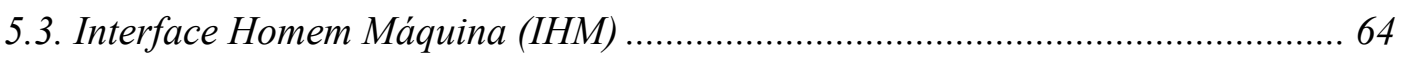

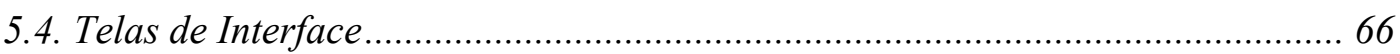

\section{CAPÍTULO 6}

Conclusões, Comentários, Contribuições ................................................................... 80

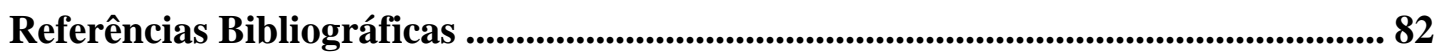

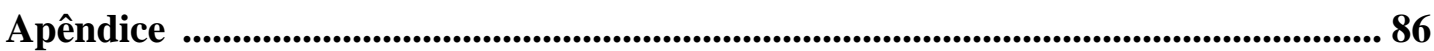

Técnica de Análise de sinal Wavelet e Fourier .............................................................. 86 


\section{LISTA DE FIGURAS}

FIGURA 3.1 - Diagrama esquemático do Disjuntor com isolamento a gás SF6.......... 14

FIGURA 3.2 - Corte esquemático da câmara de interrupção Disjuntor a Gás ............. 15

FIGURA 3.3 - Diagrama esquemático do Disjuntor mecânico...................................... 17

FIGURA 3.4 - Corte esquemático da câmara de interrupção Disjuntor a mola............. 18

FIGURA 3.5 - Circuito de comando do Disjuntor ......................................................... 20

FIGURA 3.6 - Diagrama de Monitoramento da condição do Disjuntor......................... 22

FIGURA 4.1 - Diagrama Unifilar da Subestação Sumaré de ETEO .............................. 31

FIGURA 4.2 - Oscilografia das tensões da linha $(440 x \sqrt{2} / \sqrt{ } 3 \mathrm{kV})$................................ 32

FIGURA 4.3 - Oscilografia das correntes da linha ........................................................ 33

FIGURA 4.4 - Processo de filtragem de um sinal .......................................................... 35

FIGURA 4.5 - Processo de diminuição do número de amostras do sinal ....................... 35

FIGURA 4.6 - Exemplo de filtragem com decimação de um sinal .................................. 36

FIGURA 4.7 - Ilustração do processo sucessivo dedecomposição de um sinal ............. 36

FIGURA 4.8 - Decomposição e recomposição de sinais usando AMR .......................... 37

FIGURA 4.9 - Decomposição da corrente na Fase C usando diferentes WT mãe.......... 39

FIGURA 4.10 - Decomposição da corrente na Fase C durante a abertura................... 42

FIGURA 4.11 - Fluxograma descritivo do algoritmo de cálculo de tempos.................. 44

FIGURA 4.12 - Decomposição da Tensão Fase A (Va), usando db4............................. 45

FIGURA 4.13 - Decomposição da Tensão Fase B (Vb), usando db4............................. 46

FIGURA 4.14 - Decomposição da Tensão Fase C (Vc), usando db4 ............................. 47

FIGURA 4.15 - Decomposição da Corrente Fase A (Ia), usando db4 ........................... 48

FIGURA 4.16 - Decomposição da Corrente Fase B (Ib), usando db4 .......................... 49

FIGURA 4.17 - Decomposição da Corrente Fase C (Ic), usando db4 ........................... 50

FIGURA 4.18 - Oscilografia da corrente na Fase $C$, com intervalos ............................ 52

FIGURA 4.19 - Espectro de frequências da Tensão Fase A (Va), usando STFT ............ 53

FIGURA 4.20 - Espectro de frequências da Corrente Fase A (Ia), usando STFT ......... 54

FIGURA 4.21 - Espectro de frequências da Tensão Fase B (Vb), usando STFT ............ 54

FIGURA 4.22 - Espectro de frequências da Corrente Fase B (Ib), usando STFT .......... 55

FIGURA 4.23 - Espectro de frequências da Tensão Fase C (Vc), usando STFT ........... 55

FIGURA 4.24 - Espectro de frequências da Corrente Fase C (Ic), usando STFT ......... 56

FIGURA 5.1 - Arquitetura geral do Sistema de Monitoramento de Disjuntores ........... 60 
FIGURA 5.2 - Esquema geral do funcionamento do Sistema. 65

FIGURA 5.3 - Diagrama geral de distribuição da informação 66

FIGURA 5.4 - Telas principais da ferramenta de monitoramento 67

FIGURA 5.5 - Tela de parâmetros disjuntor. 68

FIGURA 5.6 - Medição da pressão do SF6. 72

FIGURA 5.7 - Medição da pressão do óleo 73

FIGURA 5.8 - Medição de temperatura interna e do ambiente . 74

FIGURA 5.9 - Oscilografia das tensões na linha do disjuntor. 75

FIGURA 5.10 - Curvas geradas no momento da operação do disjuntor. 76

FIGURA 5.11 - Determinação de limiares nas curvas caracteristicas ... 77

FIGURA 5.12 - Tela de Histórico de Eventos .... 78

FIGURA 5.13 - Tela de Alarmes. 79 


\section{LISTA DE TABELAS}

TABELA 3.1 - Descrição das partes do disjuntor a SF6 14

TABELA 3.2 - Descrição das partes da Câmara de interrupção 15

TABELA 3.3 - Descrição das partes do disjuntor mecânico 17

TABELA 3.4 - Descrição das partes da Câmara de interrupção 18

TABELA 3.5 - Formas de ondas do disjuntor em operação. 20

TABELA 3.6 - Formas de ondas defeituosas de corrente nas bobinas. 21

TABELA 3.7 - Entradas Digitais Monitoradas 27

TABELA 3.8 - Entradas Analógicas Monitoradas 28 


\section{LISTA DE SIGLAS E ABREVIATURAS}

\begin{tabular}{|c|c|}
\hline ANSI & - American National Standards Institute \\
\hline AMR/MRA & - Análise Multiresolução / Multi resolution Analysis \\
\hline $\mathrm{AC} / \mathrm{AC}$ & - Alternate Current / Corrente Alternada \\
\hline CoifP & - Wavelet Mãe de Coiflets de Ordem P \\
\hline COELBA & - Companhia de Eletricidade do Estado da Bahia \\
\hline $\mathrm{dbN}$ & - Wavelet Mãe de Daubechies de Ordem N \\
\hline $\mathrm{DC} / \mathrm{CC}$ & - Direct Current / Corrente Contínua \\
\hline DFT/TDF & - Discrete Fourier Transform / Transformada Discreta de Fourier \\
\hline DWT/TWD & - Discrete Wavelet Transform / Transformada Wavelet Discreta \\
\hline ED & - Estimativa da Duração \\
\hline EPRI & - Electric Power Research Institute \\
\hline ETEO & - Empresa de Transmissão de Energia do Oeste Ltda. \\
\hline FFT/TRF & - Fast Fourier Transform / Transformada Rápida de Fourier \\
\hline IEEE & - Institute of Electrical and Electronic Engineering \\
\hline PLC & - Programmable Logic Controller \\
\hline RNA & - Redes Neurais Artificiais \\
\hline SEP & - Sistema Elétrico de Potência \\
\hline SF & - Série de Fourier \\
\hline \multirow[t]{2}{*}{ STFT/TFCD } & - Short Time Fourier Transform / Transformada de Fourier de \\
\hline & Curta Duração \\
\hline SymM & - Wavelet Mãe de Symlet de Ordem M \\
\hline $\mathrm{TF}$ & - Transformada de Fourier \\
\hline TQ & - Transformada Quadrática \\
\hline TW & - Transformada Wavelet \\
\hline TWC & - Transformada Wavelet Contínua \\
\hline WDFT & - Windowed Discrete Fourier Transform \\
\hline
\end{tabular}




\section{LISTA DE SÍMBOLOS}

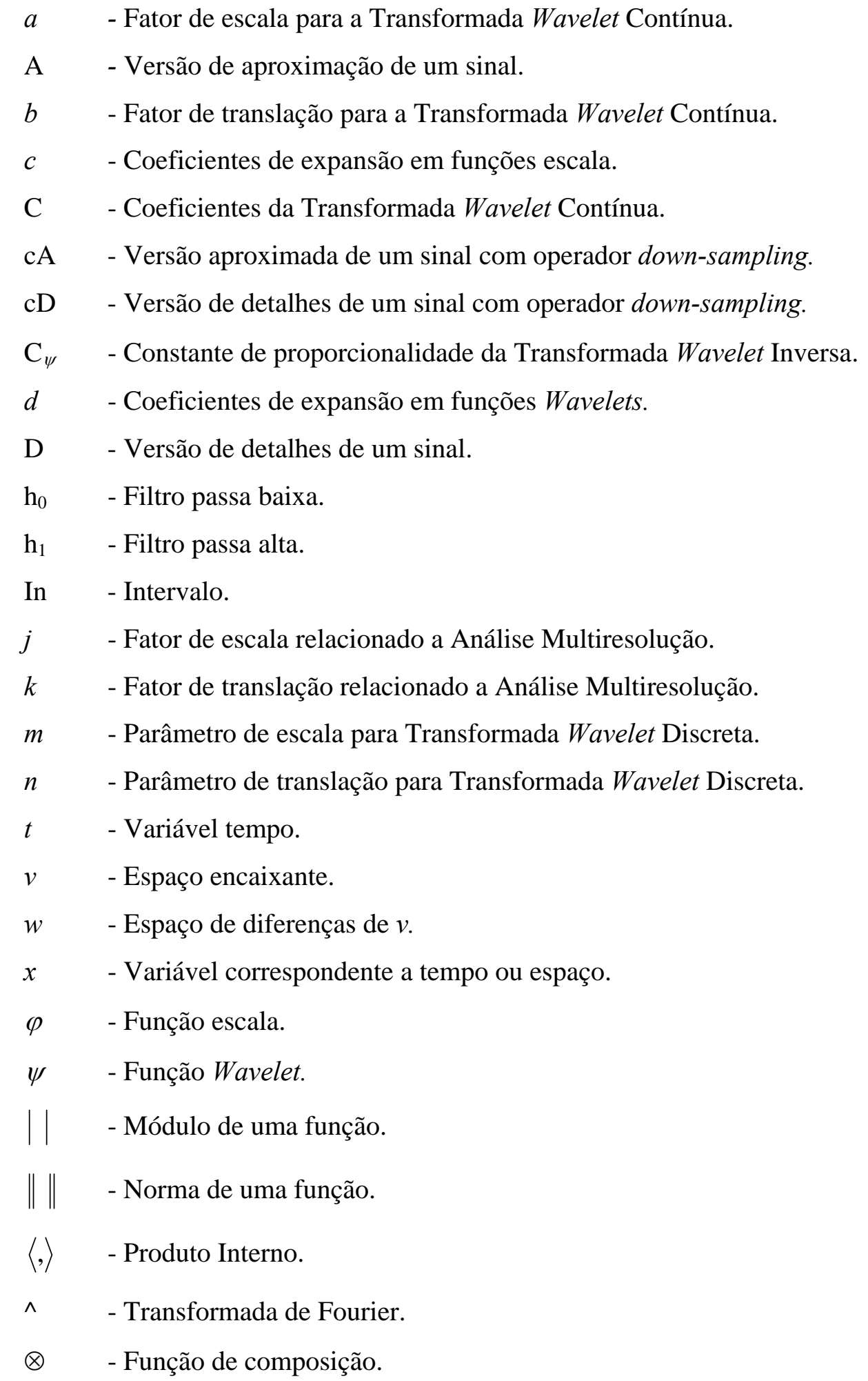




\section{RESUMO}

SILVA, M. S. Sistema de Monitoramento e Metodologia de estimativa dos Tempos de Operação do Disjuntor. São Paulo, 2005. 112p. Tese (Doutorado) - Escola Politécnica da Universidade de São Paulo.

O presente trabalho visa o desenvolvimento de um sistema de monitoramento de disjuntor voltado a coletar informações para manutenção preditiva. São analisadas as características das variáveis que são monitoradas através de sensores ligados ao disjuntor, sua aquisição e o tratamento das informações.

Um protótipo foi desenvolvido e instalado na subestação de Sumaré $440 \mathrm{kV}$ de ETEO (Empresa de Transmissão de Energia do Oeste Paulista).

Um assunto importante para a manutenção é a avaliação dos tempos envolvidos na movimentação dos contatos principais do disjuntor principalmente na operação de abertura do curto circuito. Para tal é proposto um sistema não intrusivo que analise a oscilografia das tensões e correntes no disjuntor sincronizado com as correntes no circuito de disparo deste equipamento.

A Transformada de Fourier aplicada no sinal de corrente/tensão sem perturbação permite determinar o valor do componente fundamental desse sinal. Com esse valor pode-se gerar uma senóide que superposta com o sinal coletado pelo oscilógrafo permite visualizar a alteração.

A Transformada Wavelet é realizada através de filtros decompondo-se o sinal de corrente ou tensão em Análise Multiresolução, em diferentes estágios obtendo-se em cada, uma versão chamada aproximação (baixas freqüências) e uma de detalhes (altas freqüências), sendo assim, os distúrbios podem ser detectados e localizados no tempo em função do seu conteúdo de freqüência.

Palavras Chave: Monitoramento de Disjuntores, Processamento de Sinais, Transformada Wavelet, Transformada Fourier. 


\begin{abstract}
SILVA, M. S. Monitoring System and Methodology to Estimation of Circuit Breaker Operation Times. Sao Paulo, 2005. 112p. (Doctorate). Escola Politécnica da Universidade de São Paulo.
\end{abstract}

The present work addresses the development of a circuit breaker monitoring system so as to collect information for predictive maintenance. The characteristics of the variables that are monitored through certain sensors linked to the circuit breaker, its acquisition and the treatment of the information, are analyzed.

A prototype was developed and installed at the $440 \mathrm{kV}$ Sumaré substation of ETEO (Empresa de Transmissão de Energia do Oeste Paulista) a Brazilian Transmission Company. An important aspect for the maintenance is the evaluation of the times involved in the movement of the circuit breaker main contacts, mainly at the opening operation for example during a short circuit. On this respect, a nonintrusive system that analyzes the oscillography of both voltages and currents in the circuit breaker synchronized with the currents in the tripping circuit of this equipment is proposed.

The Fourier Transform applied to the current or voltage signal with no disturbance allows to determine the value of the fundamental component of this signal. With that value, it can be generated a pure sine wave which when overlapped to the signal collected by the oscillograph allows to visualize alterations.

The Wavelet Transform is realized through filters and decomposing the current or voltage signal through the Multiresolution Analysis at different levels, in this way, obtaining in each level, a version called approximation (low frequencies) and another with details (high frequencies), thus, the disturbances can be detected and located in the time and as a function of its frequency content.

Key Words: Circuit Breaker Monitoring, Signal Processing, Wavelet Transform and Fourier Transform. 


\section{CAPÍTULO 1}

\section{PREÂMBULO}

\subsection{Introdução}

A manutenção de equipamentos em subestações de concessionárias de energia elétrica tem sido tradicionalmente baseada no tempo. Esse critério tem sido o principal determinante desde o inicio até épocas mais recentes, quando as subestações possuíam equipes permanentes e o equipamento podia ser monitorado regularmente, com a visita periódica das equipes de manutenção para inspecionar os equipamentos, fazer uma revisão geral, executar medições, registrar dados e extrair amostras para análise. Os equipamentos são revisados regularmente com base numa programação considerando o histórico de falhas, número de operações, idade, etc., ou que tenha sido determinado um mau funcionamento ou uma falha iminente.

Os custos de manutenção baseados no tempo são significativos. As despesas com inspeções periódicas, revisão geral do equipamento e levantamento de dados têm sido efetuadas, embora a atividade possa não ter sido em resposta a uma necessidade imediata de manutenção preventiva. Para um sistema de manutenção baseado no tempo, um aumento na freqüência de inspeções e revisões gerais do equipamento resulta num aumento de custos. A realidade de hoje reconhece a ineficiência inerente à manutenção desta forma.

O disjuntor é um dos mais importantes e complexos de todos os equipamentos da subestação. Ele possui um sistema de interrupção de corrente e é utilizado para manobra e proteção de circuitos; isto devido a sua alta capacidade de isolamento e interrupção de 
correntes de carga acima do valor nominal assim como de correntes de curto circuito. De acordo com pesquisas anteriores, pode-se afirmar que mais de $40 \%$ do custo de manutenção dos equipamentos de pátio de uma subestação é gasta em disjuntores, e 60\% desse total é destinado para revisão geral [6] e [7]. Assim os sistemas de manutenção preditiva baseados no monitoramento contínuo de variáveis do disjuntor podem proporcionar reduções significativas nesses custos.

O desafio dos sistemas de manutenção preditiva (monitoramento) para disjuntores é o reconhecimento de que a manutenção é direcionados àqueles já em operação vindos de diferentes fabricantes e que utilizam diferentes tecnologias de interrupção e acionamento. Em contraste, por exemplo, com os transformadores de potência, cujos princípios operacionais e exigências de monitoramento são essencialmente os mesmos, independentemente do fabricante.

Ao se projetar um sistema de monitoramento do disjuntor deve-se fazer aquisição de dados de variáveis relativas: ao isolamento interno (Ex: pressão de gás SF6); ao sistema de acionamento (Ex: pressão de óleo no sistema hidráulico); e nos circuitos de comando (Ex: verificação do estado da bobina de acionamento).

Uma constatação importante é a determinação dos tempos envolvidos nos vários estágios do acionamento do disjuntor (Ex: comando de abertura, ação da bobina de disparo, inicio da abertura do contato principal, arco interno, fim da abertura do contato principal e interrupção da corrente).

Os tempos relativos à movimentação dos contatos são obtidos pela instalação de sensores especiais, internamente ao disjuntor para serem eficazes. Este método, por ser intrusivo pode diminuir a confiabilidade do disjuntor e precisar calibrações futuras. Assim um método não intrusivo que faça a determinação dos tempos através das correntes e tensões no disjuntor, é de alto interesse.

A técnica de processamento de sinais baseada no uso da Transformada Wavelet (TW) é uma nova ferramenta para análise das correntes que existem no momento da operação do disjuntor. 
Uma das propriedades mais importantes das Wavelets é sua capacidade de identificar particularidades de um sinal tanto no tempo quanto na freqüência. Esta propriedade é de extrema utilidade na análise de sinais que possuam as seguintes características: não-estacionário, componentes transitórios de curta duração e singularidades em várias escalas diferentes. Sendo assim, a Transformada Wavelet é capaz de revelar aspectos em um sinal que não foram possíveis de serem obtidos através de outras técnicas de processamento, aspectos estes como: tendências, pontos de descontinuidade, descontinuidades em derivadas superiores e auto-similaridade.

Com estas características singulares e bem adaptadas à análise de sinais, a Transformada Wavelet mostra-se como uma técnica com grande potencialidade no estudo de correntes e tensões da linha presentes no disjuntor, visando determinar os tempos envolvidos no funcionamento do disjuntor.

\subsection{Objetivos}

Uma motivação deste trabalho é a aplicação de Ferramentas Matemáticas (Transformada Wavelet e Fourier) na análise dos tempos envolvidos na operação do disjuntor. A pesquisa feita sobre o assunto na literatura atual disponível é bastante extensa e com muitas aplicações destas ferramentas em áreas tão diversas como matemática, geofísica, física, economia, estatística, música, processamento de sinais e imagens, engenharia elétrica, medicina, entre outras. Entretanto, a bibliografia tem mostrado que a quantidade de trabalhos publicados especificamente aplicados à Engenharia Elétrica está ainda em ascensão, não se tendo encontrado nenhuma relacionada com os tempos de operação do disjuntor. Buscou-se, então a utilização e a adaptação de aplicações existentes que resultou numa importante contribuição do trabalho.

O objetivo maior deste trabalho, entretanto, foi o desenvolvimento de um sistema de monitoramento de disjuntores que proporcione informação de variáveis úteis para a manutenção preditiva. Tal sistema foi implementado para o disjuntor do bay de reator de 150MVAr, 440kV na subestação Sumaré da ETEO e no disjuntor de linha de 69kV na subestação Federação da COELBA. 
Embora o conceito deste tipo de sistema tenha sido descrito em algumas publicações, o desenvolvimento realizado contribuiu com soluções inéditas dos detalhes tecnológicos podendo citar: O sensoriamento para medição de corrente no circuito de comando do disjuntor; a implementação de placas de entradas analógicas para aquisição de dados com resolução de 1ms; o estabelecimento de protocolos de comunicação aderentes as mais importantes normas mundiais (IEC, ANSI, EPRI).

A instalação e testes do sistema comprovaram a adequacidade do projeto para os objetivos estabelecidos de monitorar o disjuntor e adicionalmente outros equipamentos: transformador e acionamento de seccionadoras.

\subsection{Organização desta Tese}

A presente tese está organizada da seguinte forma: o Capítulo 1 apresenta as razões que motivaram este trabalho, expondo os objetivos pretendidos e contribuições.

O Capítulo 2 traz a revisão bibliográfica que focaliza trabalhos referentes ao monitoramento de disjuntores, e os que fazem uso de ferramentas matemáticas (TW e $\mathrm{TF}$ ), assim como trabalhos relevantes aplicados ao processamento de sinais genéricos e em problemas de tratamento de sinais de corrente e tensão delineando as tendências cientificas no que tange a análise de distúrbios.

No Capitulo 3 trata-se de um estudo descritivo, exploratório e experimental de um sistema de Monitoramento de Disjuntor para ser instalado com a finalidade de identificação dos principais defeitos, presentes e potenciais, no equipamento durante sua operação como: alterações nos tempos de operação, perda de pressões (gás, óleo), desgastes dos contactos. Ele está baseado em um conjunto de dispositivos instalados que permitem observar de forma ininterrupta a condição de operação do disjuntor, estando este energizado ou não, de maneira manual ou automática (on-line), com variação de tempo periódica ou continua, que permite antecipar e prevenir danos cujas conseqüências demandariam, além das paralisações, elevados custos de reparos.

Os fundamentos teóricos da Análise Wavelet, assim como a comparação da mesma com outros métodos clássicos usualmente aplicados em processamento de sinais 
dentre eles, a Transformada de Fourier Clássica (TF) e a Transformada de Fourier de Curta Duração ou STFT, além da apresentação da metodologia usada para o cálculo dos tempos envolvidos na operação do disjuntor está contida no Capítulo 4.

No Capítulo 5 é detalhado o sistema de monitoramento protótipo instalado na subestação Sumaré $440 \mathrm{kV}$ de ETEO.

Finalmente no Capítulo 6, são apresentados os comentários e conclusões finais com respeito aos sistemas e algoritmos desenvolvidos.

Completa-se com as referências bibliográficas e um apêndice com as técnicas de análise de sinal Wavelet e Fourier. 


\section{CAPÍTULO 2}

\section{ESTADO DA ARTE}

Com o propósito de conhecer os estudos referentes aos sistemas de monitoramento de disjuntores e à aplicação das Ferramentas Matemáticas para análise dos tempos envolvidos na operação do disjuntor, foram levantados alguns dos principais trabalhos realizados. Este Capítulo busca abordar os principais pontos no que se refere a estas aplicações.

No disjuntor a complexidade do sistema de monitoramento está diretamente relacionada com as características das variáveis que se desejam medir sejam estas mecânicas ou elétricas. Em recentes décadas, duas grandes investigações dirigidas pelo grupo de trabalho SC13 da CIGRE e do CEA [12] e [10] respectivamente, com respeito ao funcionamento do disjuntor foram feitas chegando às seguintes conclusões:

- Relativo às solicitações mecânicas, concluiu-se que aproximadamente $90 \%$ de todos os disjuntores são operados menos de 80 vezes por ano. Exceções são os disjuntores de reator, banco de capacitores ou disjuntores conectados diretamente aos circuitos de geração das centrais elétricas, estes são operados até duas vezes por dia.

- Com respeito às características elétricas concluiu-se que as condições de operação do disjuntor estão sempre dentro da faixa da corrente nominal, 90\% destes disjuntores têm que interromper correntes de apenas 35\% de seu valor de corrente de curto circuito. Dado todas estas considerações, pode-se concluir que só é importante monitorar disjuntores estrategicamente localizados e de alta importância. 
De acordo com investigações adicionais [20] e [17] aplicando o método FMECA - "Failure mode Effect and Criticality Analysis", indica-se que 70\% de todas as falhas principais do disjuntor são de origem mecânica e que só 19\% são de origem elétrica. Além disso, 37\% de todas as falhas são devidas ao mau funcionamento dos mecanismos de operação, enquanto que só $11 \%$ correspondem à falha do dielétrico da parte ativa do disjuntor. Desta forma, fica claro que no caso do disjuntor, o sistema de monitoramento não deveria concentrar-se só nos contatos, mas também, em todo o mecanismo de atuação mecânica. Não obstante a tudo isso, a capacidade de interrupção elétrica da câmara do disjuntor ainda é de importância central.

LEE et al. [23] utilizaram as Wavelets e redes neurais para a análise dos dados da vibração de disjuntores com o objetivo de detecção de faltas incipientes. As Transformadas Wavelets são usadas para explorar os dados de medições de vibração tanto de um disjuntor em operação normal como de um disjuntor com operação defeituosa, possibilitando a determinação de características de mau funcionamento sendo estes colocados dentro de redes neurais para sua classificação. Testes foram feitos em três disjuntores de $66 \mathrm{kV}$ com simulação de faltas, tendo sido comprovado que a precisão na detecção é melhor que a obtida por outras técnicas clássicas como a Transformada de Fourier Discreta, sistemas especialistas ou redes neurais isoladas. A precisão na detecção de falhas pode chegar a 100\% em alguns casos dependendo do tipo de falta.

YU et al. [43] apresenta o uso das Transformadas Wavelets para a determinação de falhas mecânicas através da medição de mudanças na vibração, tendo sido usada a transformada Hilbert para juntar em pacotes os sinais de vibração.

JEFFREY et al. [21], fazem uma descrição resumida de todas as considerações que devem ser tomadas no momento da instalação de um sistema de monitoramento no disjuntor, assim como o detalhamento de quais equipamentos estão atualmente disponíveis para tal finalidade. Além disso, o autor lista as informações disponíveis para determinar o que monitorar e as expectativas e benefícios como resultado da implantação de um sistema de monitoramento no disjuntor. Também foi considerado no artigo os objetivos desejados pela concessionária no momento de instalar um CMS (Condition Monitoring System). 
BERGMAN et al. [6] e [7] indicam o que monitorar em um disjuntor para obter maior confiabilidade, extensão da vida útil, maximização da segurança e retorno do investimento.

Os trabalhos de POELT et al. [27] e DUPRAZ et al. [15] e [16] são exemplos de sistemas de monitoramento instalados em disjuntores da $\mathrm{ABB}$ de $500 \mathrm{kV}$ e em disjuntores da ALSTOM de 345kV respectivamente. Em ambos casos faz-se menção a utilização de equipamentos específicos CMU (Condition Monitoring Unit) e CBWatch para realizar o monitoramento integral do disjuntor. São também indicados os diferentes problemas encontrados na utilização de um determinado sensor, sendo suas instalações ilustradas através de fotografias.

Destaca-se, referindo-se a aplicação da teoria de Wavelet (TW) na análise de sinais, o trabalho de SANTOSO et al. [34] voltado ao monitoramento da qualidade de energia (Power Quality) utilizando a Análise Multiresolução (AMR), com a Daubechies de ordem quatro (db4) como Wavelet mãe, para detectar e localizar vários tipos de distúrbios que estão relacionados com alterações no sinal. A idéia chave do trabalho está na decomposição de um dado sinal distorcido em outros sinais que representam uma versão de "aproximação" (conteúdo de baixa freqüência) e uma versão de "detalhes" (conteúdo de alta freqüência) do sinal original. Os autores descreveram também a base de um possível esquema de classificação de distúrbios utilizando coeficientes quadráticos da Transformada Wavelet, extraindo as características dos diferentes distúrbios.

ANGRISANI et al. [1] apresenta um método para análise de sinais (tensão) combinando o uso da TW e a AMR. A TW foi implementada usando a função Wavelet de Morlet como função base, bem como suas propriedades de módulo máximo. A técnica de AMR foi realizada tendo como função base a Wavelet de Daubechies com 16 coeficientes. A deteç̧ão do distúrbio é feita com a utilização da ferramenta TW e o uso da propriedade de módulo máximo se faz necessária para a estimação do tempo de duração do distúrbio. A técnica de AMR é usada para extrair a componente fundamental do sinal que contém o distúrbio. Com este método, os autores afirmam que os distúrbios mais relevantes no sistema elétrico de potência podem ser detectados, localizados e estimados automaticamente mesmo na presença de ruídos, e ainda, as características dos 
distúrbios podem ser extraídas usando um número menor de parâmetros quando comparado com os métodos até então desenvolvidos.

A técnica de AMR, com a Wavelet mãe de Daubechies db4, foi também utilizada por GAOUDA et al. [19] para detectar e localizar diferentes problemas de qualidade de energia, sendo a base de sua aplicação focada na decomposição de um dado sinal em versões de aproximação e de detalhes. Os autores introduzem um método de classificação de distúrbios relacionando a energia do sinal distorcido com a energia de cada componente da decomposição em AMR (teorema de Parseval). A energia do sinal pode ser dividida através dos coeficientes da decomposição que é feita em diferentes intervalos de freqüência, fornecendo assim informações sobre o conteúdo de freqüência do sinal e possibilitando classificar diferentes fenômenos. Características únicas dos diferentes distúrbios podem então ser extraídas utilizando-se curvas de desvio padrão em diferentes níveis de resolução.

POISSON et al. [28] e [29] fazem comparação entre a Transformada de Fourier (TF), a TW, a AMR e a Transformada Quadrática (TQ) que são ferramentas de representação tempo-freqüência. A utilização da TW teve como base (Wavelet mãe) uma função complexa similar à função base de Morlet e implementada usando um algoritmo recursivo que é descrito pelos autores. A AMR teve como Wavelet mãe a função Feauveau. Tais comparações são feitas na análise de distúrbios (qualidade de energia) relacionados com a tensão e corrente tais como afundamento, flicker e distorções harmônicas. Através deste trabalho os autores concluem ser o AMR e TQ ferramentas seguras para detectar distúrbios e indicar o conteúdo de freqüência existente em tais distúrbios. Apresentam ainda, a TW como ferramenta mais segura para detecção e estimação da amplitude de afundamentos, elevações e flicker comparada com as ferramentas AMR e TQ.

A técnica proposta por SANTOSO et al. [35] tem por finalidade extrair características únicas de distúrbios (qualidade de energia) caracterizando-os como eventos, bem como elaborar metodologias para extraí-los das formas de onda original usando como ferramentas a união de uma importante transformada matemática na engenharia de potência, a TF, com a TW. A TF é usada para caracterizar fenômenos de estado permanente, enquanto que a TW, usando a Wavelet mãe de Daubechies db4, é 
aplicada para fenômenos transitórios. Outras técnicas matemáticas de análise, tais como técnicas de curvas permanentes para estimar mudanças repentinas de tensão são também usadas pelos autores. Estes caracterizam também eventos comuns em sistemas de distribuição afirmando que estes formam as bases para futuras caracterizações de outros eventos.

A TW foi utilizada por YANG et al. [41] para a extração de ruídos de um dado sinal para então ser analisado. Tal análise tem como objetivo a classificação de defeitos em sistemas elétricos de potência. Uma vez que a presença de ruídos pode vir a causar dificuldades na detecção de distúrbios, a extração deste é de grande valia. A TW junto com a técnica (AMR) é usada, pelos autores, para eliminar a presença de ruído do sinal que contém o distúrbio, podendo desta forma ser criada uma ferramenta de monitoramento do sistema para detectar e localizar com maior eficiência distúrbios como afundamento, elevação e transitórios de tensão e corrente.

A tese apresentada por REIS [33], apresenta um algoritmo digital para a proteção da interligação concessionária - industria operando em sistemas de cogeração através de uma proteção multi-função com uma visão sistêmica das principais condições operativas. Sob o ponto de vista matemático, a impossibilidade do uso de uma só janela de observação dos fenômenos apresentados durante a interligação por suas características de freqüências altas e baixas motivou a verificação do conceito de energia através da utilização da Transformada Wavelet, obtendo bons resultados.

Na dissertação de mestrado a ser apresentada por MARTINEZ [24], far-se-á um estudo completo do disjuntor e seus tipos, características de operação, principais falhas, sendo um trabalho complementar a tese aqui apresentada.

Procurou-se através das publicações citadas, apresentar alguns dos principais trabalhos realizados sobre monitoramento de disjuntores, assim como a utilização das ferramentas matemáticas (TW e TF) para a análise de sinais voltado aos problemas nos sistemas de potência como: qualidade de energia, classificação de defeitos e a análise de ruídos. Estes eventos embora não estejam diretamente relacionados com a determinação dos tempos que caracterizam a abertura e fechamento do disjuntor mostram o potencial das técnicas TW e TF. 
Com base nesta análise do estado da arte a proposta deste trabalho consiste em:

- Analisar os tempos de deslocamento de contatos principais presentes na câmera do disjuntor (separação física), disparo de abertura e fechamento, monitorando variáveis externas ao disjuntor.

- Utilizar técnicas TW, TF para a identificação destes fenômenos.

- Implementação de um protótipo que foi instalado na Subestação de Sumaré de ETEO, 440kV no disjuntor do bay do reator.

- Analisar o desempenho do sistema, sobretudo na avaliação de deslocamento dos contatos principais do disjuntor.

- Além evidentemente de propor um sistema geral de monitoramento do disjuntor. 


\section{CAPÍTULO 3}

\section{MONITORAMENTO DO DISJUNTOR}

\subsection{Introdução}

Os disjuntores junto com os transformadores são os equipamentos mais importantes na subestação. Considerando sua função de manobra pode-se dizer que um disjuntor está geralmente num estado inativo, isto devido a que normalmente permanece aberto ou fechado por longos períodos de tempo, até que aconteça alguma alteração das condições normais de operação do sistema, momento no qual ele deve operar para mudar de estado. Entretanto quando um disjuntor tem de funcionar, uma operação errada ou uma falha na interrupção podem dar origem a uma perturbação severa no sistema, razão pela qual deve ter um sistema bem projetado e altamente seguro.

O sistema de monitoramento de disjuntor é um sistema em tempo real de supervisão de dados dos parâmetros principais do disjuntor (corrente, tensão, pressões, temperaturas, contatos, etc.). Esta supervisão é feita por meio de equipamentos digitais e sensores especiais que são instalados próximos ao disjuntor. Os dados são coletados e processados em uma unidade de aquisição de dados e controle (UAC), para posteriormente através de uma rede de comunicação, usando desejavelmente um protocolo padrão (definido por norma), serem enviados a um computador central localizado na sala de comando da subestação e depois aos centros de operação permitindo assim uma supervisão remota.

A seguir será feita uma descrição de dois tipos diferentes de disjuntores com o objetivo de se visualizar como conhecer o monitoramento: 
A) Disjuntor marca Siemens modelo 3AT4 EI mostrado na Figura 3.1, e Tabela 3.1 possui acionamento monopolar, ou seja, painel de comando independente para cada fase. Cada pólo possui uma coluna isolante montada sobre uma base (6), uma câmara de interrupção (1) com duplo acionamento; tanto a coluna isolante como a câmara de interrupção são preenchidas com gás SF6 usado como meio extintor do arco. Desta forma a massa do gás precisa ser controlada sendo feita através de um densimetro ou um pressóstato (14).

O cárter de transmissão (5) transforma o movimento vertical da haste de manobra em um movimento horizontal do contato móvel (3) que se conecta ao contato fixo (2). O capacitor (4) equaliza a tensão através da câmara quando o disjuntor está aberto. A haste de manobra (7) é acionada pelo mecanismo de acoplamento de tipo eletro-hidráulico (8).

A energia para acionamento do disjuntor (acionador hidráulico (10)) é produzida pelo gás nitrogênio, comprimido no interior do acumulador de óleo (11). Tubos (12) saindo deste conduzem o óleo pressurizado ao mecanismo de acoplamento em cada coluna isolante e ao painel de comando (17) no qual é efetuada a supervisão e controle do meio (óleo/ $\mathrm{N}_{2}$ ). Contatos auxiliares (9) normalmente fechados (NF) e normalmente abertos (NA) mudam de estado com o acionamento da haste. 


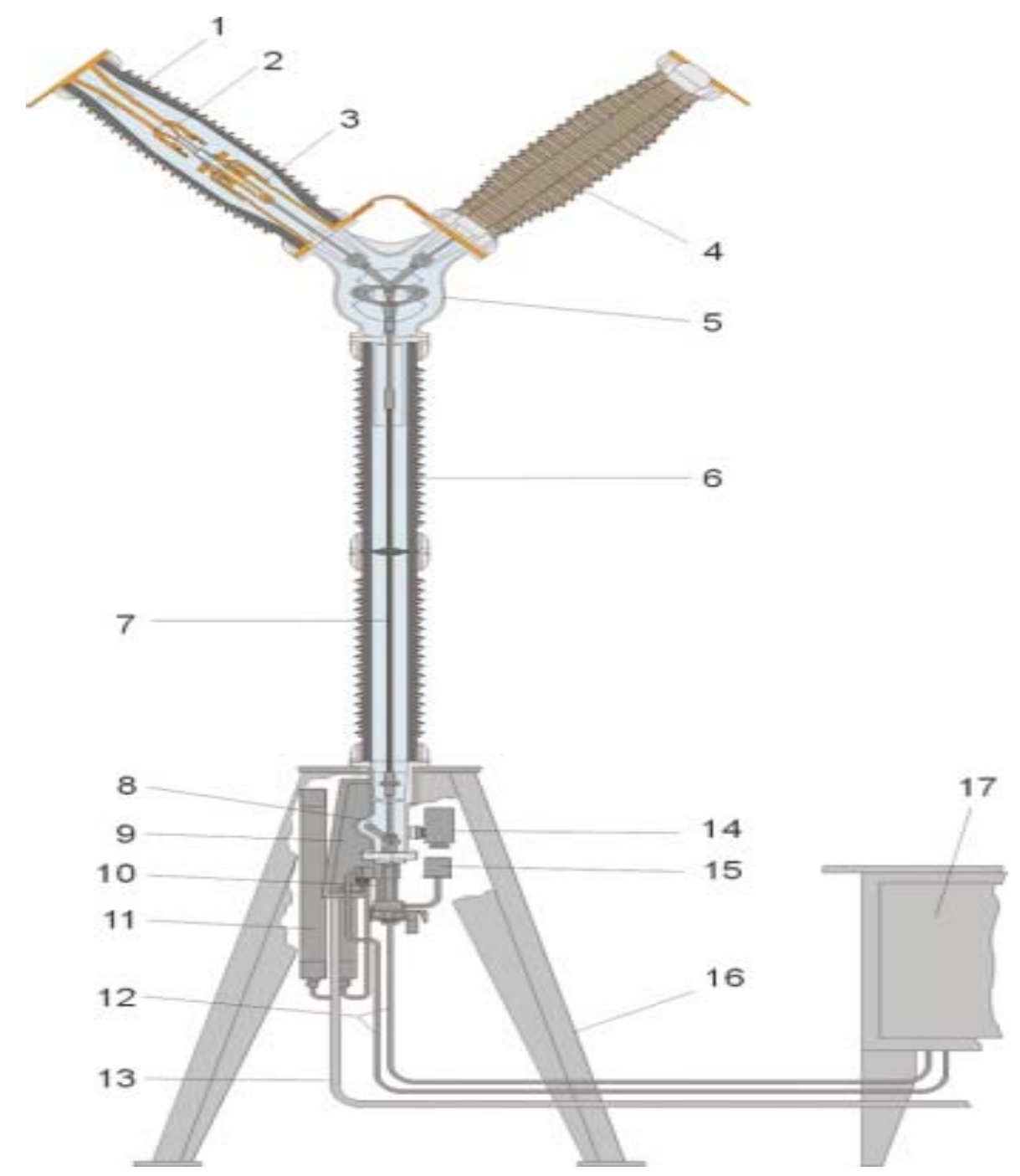

Figura 3.1 - Diagrama Esquemático do Disjuntor com isolamento a gás SF6.

Tabela 3.1 - Descrição das partes do disjuntor a SF6.

\begin{tabular}{c|c|c|c}
\hline Item & Descrição & Item & Descrição \\
\hline 1 & Câmara de interrupção & 10 & Acionador hidráulico \\
\hline 2 & Contato fixo & 11 & Acumulador de óleo \\
\hline 3 & Contato móvel & 12 & Tubulação hidráulica \\
\hline 4 & Capacitor equalizador & 13 & Cabos de conexão elétrica \\
\hline 5 & Cárter de transmissão & 14 & Manodensostato \\
\hline 6 & Coluna isolante & 15 & Tanque de expansão \\
\hline 7 & Biela isolante & 16 & Estrutura suporte \\
\hline 8 & Mecanismo de acoplamento & 17 & Painel de comando \\
\hline 9 & Painel de contatos auxiliares & & \\
\hline
\end{tabular}


A parte mais importante de um disjuntor é a câmera de interrupção, cujo principio de funcionamento será descrito a seguir. Uma única peça movimenta-se dentro de um volume pressurizado com gás SF6 à baixa pressão, ver Figura 3.2 e Tabela 3.2.

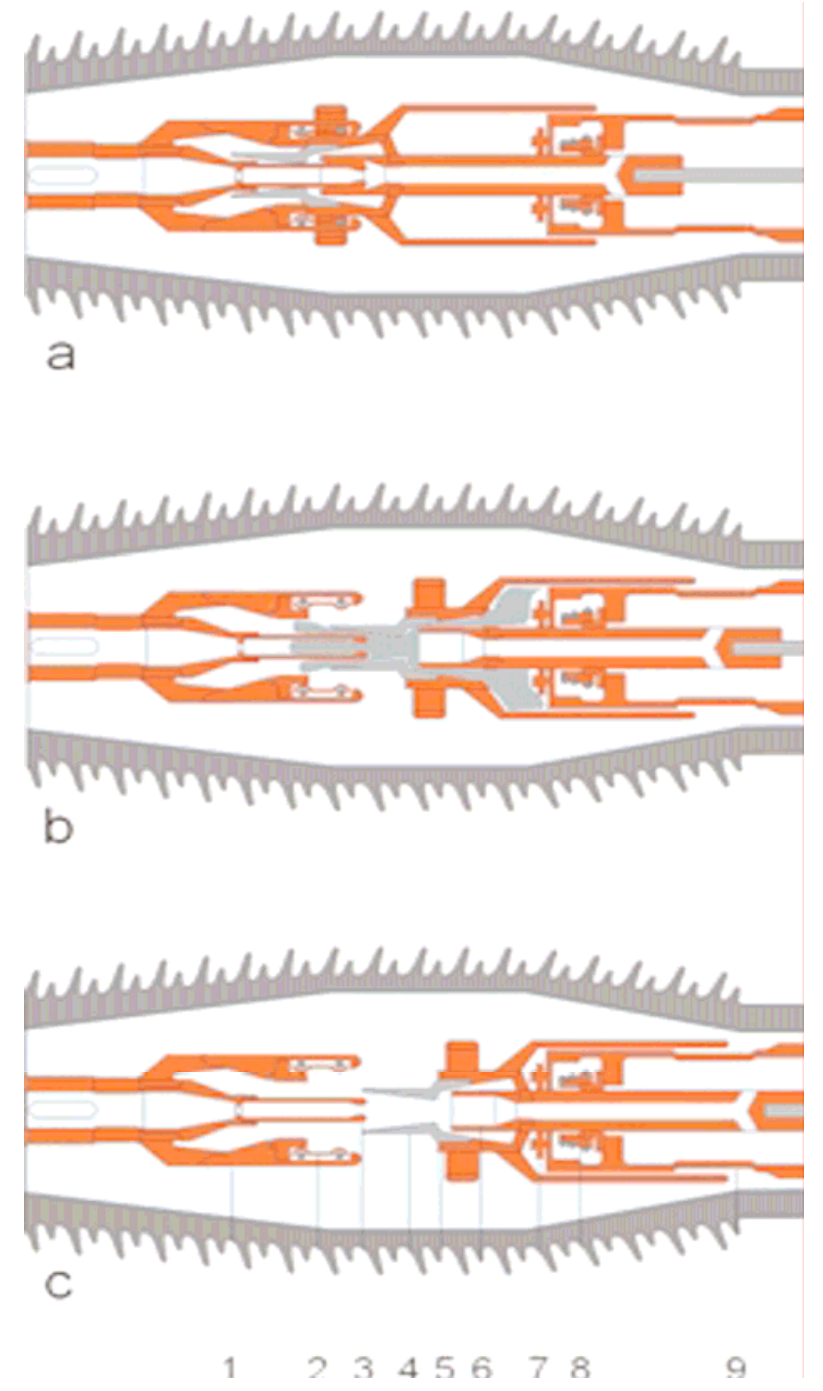

Figura 3.2 - Corte esquemático da câmara de interrupção Disjuntor a gás SF6.

Tabela 3.2 - Descrição das partes da Câmara de interrupção.

\begin{tabular}{c|c|c|c}
\hline Item & Descrição & Item & Descrição \\
\hline a & Disjuntor posição "fechado" & 5 & Contato e cilindro móvel \\
\hline b & Disjuntor durante interrupção & 6 & Contato de arco móvel \\
\hline c & Disjuntor posição "aberto" & 7 & Válvula \\
\hline 1 & Contato fixo & 8 & Pinça de contato móvel \\
\hline 2 & Pinça do contato fixo & 9 & Pistão fixo \\
\hline 3 & Contato de arco fixo & 10 & Biela de comando da câmera \\
\hline 4 & Bocal do sopro & & \\
\hline
\end{tabular}


No momento de uma abertura, o deslocamento do contato móvel (5) solidário a um cilindro, comprime o gás SF6 compreendido entre o cilindro e o pistão fixo (9). O contato móvel separa-se do contato fixo (1) e das pinças (2) que quando o disjuntor está na posição “fechado” assegura a passagem permanente de corrente. A corrente é então conduzida pelos contatos de arco (3) e (6), na seqüência o contato de arco móvel (6) separa-se do contato de arco fixo (3). O cilindro (5) continua a se deslocar e o SF6 comprimido escapa por um orifício (bocal de sopro (4)), soprando SF6 sobre o arco. Na passagem pelo zero de corrente, o arco se extingue e a desionização da região é obtida pelo SF6 sob pressão, garantindo a rigidez dielétrica entre os contatos abertos.

No momento do fechamento, a válvula (7) abre, evitando a formação de uma descompressão no interior do cilindro. Isto permite no caso de religamento rápido, restabelecer o equilíbrio de pressão assegurando as boas condições do sopro quando de uma segunda abertura.

B) Disjuntor marca Merlin Gerin (Schneider) modelo SB6-72 com acionamento tripolar (um só painel de comando), que utiliza a técnica do arco rotativo associado à auto-expansão. A corrente a ser interrompida percorre uma bobina (4) concêntrica ao eixo dos contatos. O campo magnético então criado, induz o arco a realizar rotações rápidas sobre a superfície dos contatos de arco, possibilitando que o aquecimento dos contatos seja distribuído. A elevação da pressão pela operação, provoca o sopro de gás SF6 sobre o arco para sua extinção.

O sistema de acionamento é mecânico, composto por um conjunto de alavancas, com acumulação de energia por molas acionadas através de um motor. A liberação da mola produz a energia para abertura/fechamento do disjuntor.

A Figura 3.3 ilustra um disjuntor mecânico com todos seus componentes identificados na Tabela 3.3. 


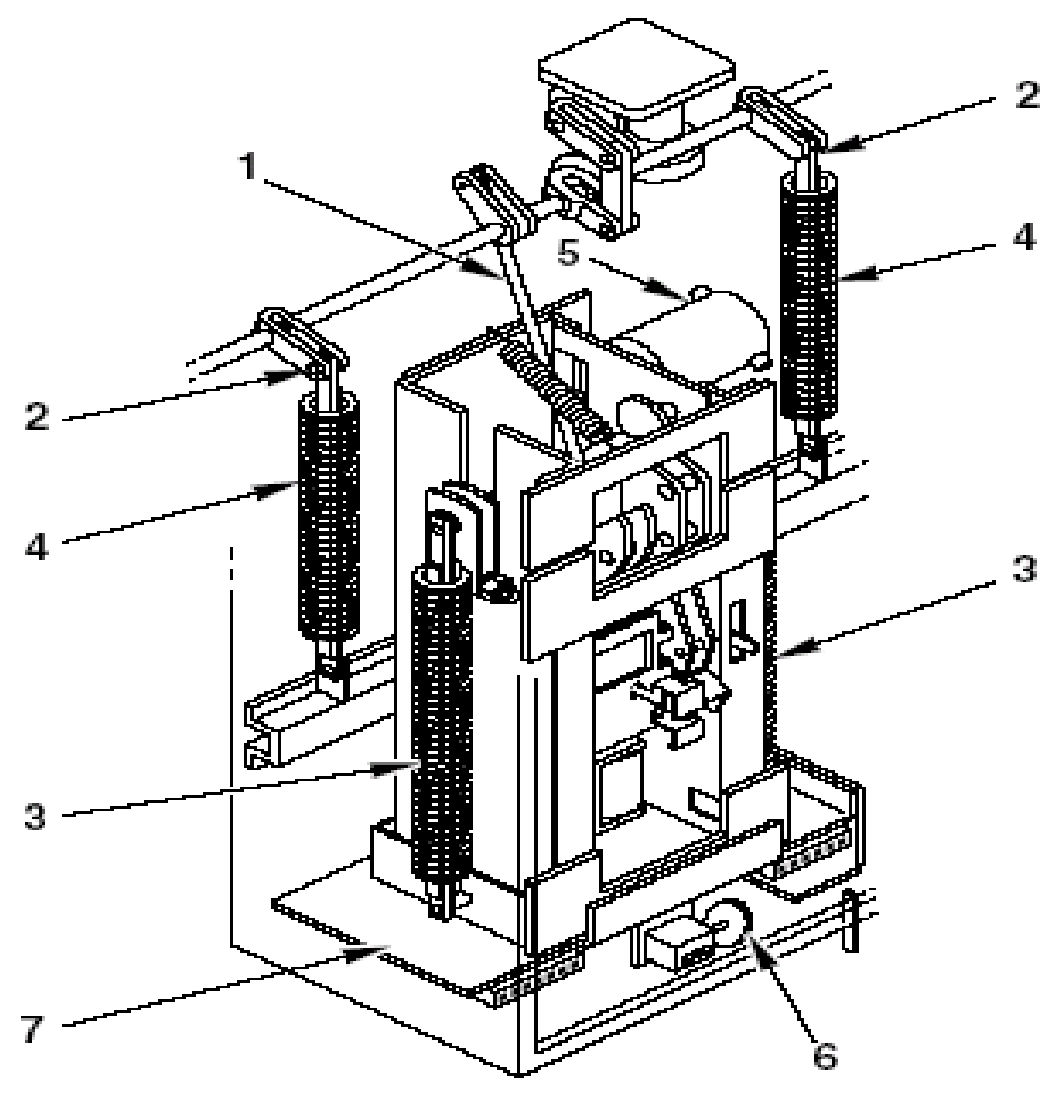

Figura 3.3 - Diagrama esquemático do Disjuntor mecânico.

Tabela 3.3 - Descrição das partes do Disjuntor mecânico.

\begin{tabular}{c|c|c|c}
\hline Item & Descrição & Item & Descrição \\
\hline 1 & Haste de fechamento & 5 & $\begin{array}{c}\text { Mecanismo de carregamento da } \\
\text { mola }\end{array}$ \\
\hline 2 & Manivela de abertura & 6 & Indicador de posição \\
\hline 3 & Bobina de fechamento & 7 & Suporte mecanismo operação \\
\hline 4 & Bobina de abertura & & \\
\hline
\end{tabular}

Na Figura 3.4 está apresentada um corte da câmara de extinção e na Tabela 3.4 estão indicadas as partes. 


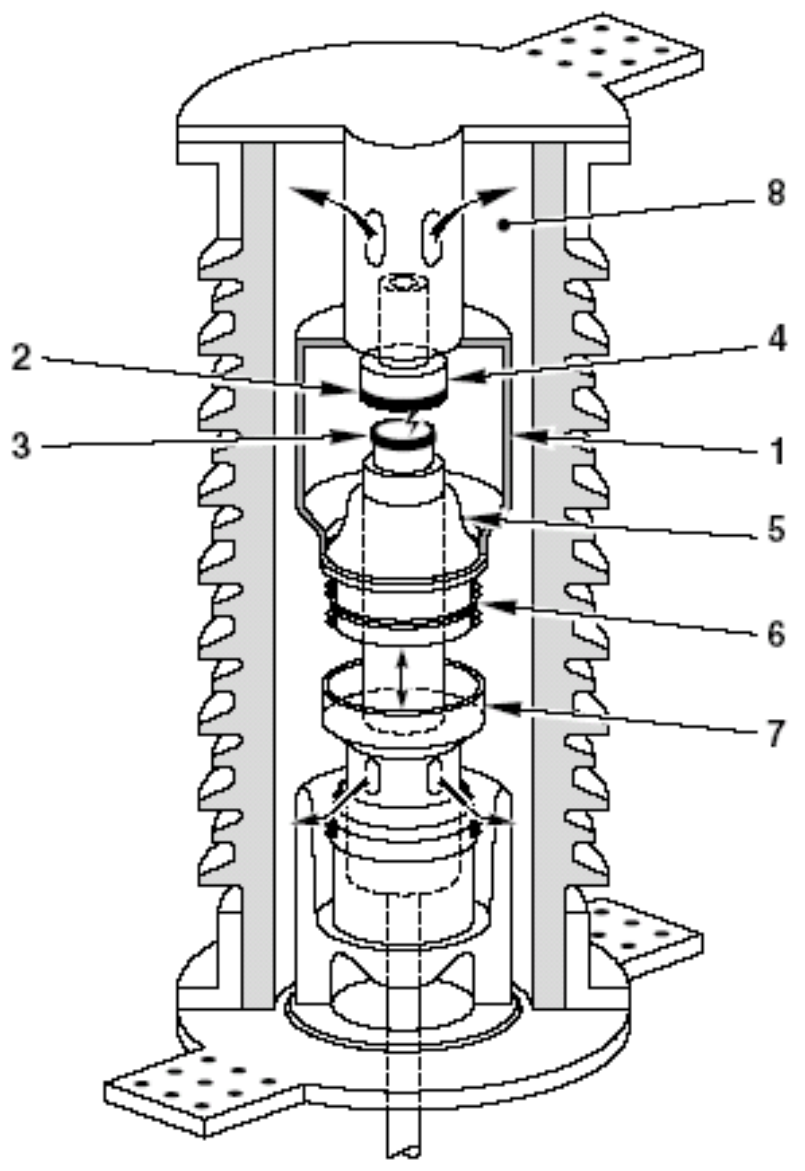

Figura 3.4 - Corte esquemático da câmera de interrupção Disjuntor a mola.

Tabela 3.4 - Descrição das partes da Câmera de interrupção.

\begin{tabular}{c|c|c|c}
\hline Item & Descrição & Item & Descrição \\
\hline 1 & Cilindro de expansão & 5 & Espaçador de isolamento \\
\hline 2 & Contato de arco fixo & 6 & Contato principal fixo \\
\hline 3 & Contato de arco móvel & 7 & Contato principal móvel \\
\hline 4 & Bobina & 8 & Cilindro exaustor \\
\hline
\end{tabular}

Em ambos tipos de disjuntores para abrir ou fechar o disjuntor é preciso energizar as bobinas.

Normalmente existe duas bobinas de abertura (segurança no caso de uma estar danificada) e uma de fechamento. 
C) Comentários.

Alguns comentários são apresentados voltados ao aspecto de monitoração:

$\checkmark$ A pressão (massa) do SF6 é crucial e seu monitoramento é desejável para a identificação de vazamentos;

$\checkmark$ O esforço para a operação de fechamento/abertura é efetuado pelas hastes que pode sofrer flambagem;

$\checkmark$ Os contatos auxiliares indicam por via indireta se o disjuntor esta aberto ou fechado podendo resultar em informações erradas;

$\checkmark$ O carregamento da mola e a pressão nitrogênio / óleo, são importantes pontos de supervisão;

$\checkmark \quad \mathrm{O}$ arco desgasta os contatos e este efeito afeta a manutenção;

$\checkmark$ Monitora-se a continuidade do circuito de disparo (abertura) principalmente.

\subsection{Circuito de Comando do Disjuntor}

Para poder avaliar melhor os resultados do sistema de monitoramento precisa-se primeiro entender o modo de operação de um disjuntor real, para isso é mostrado na Figura 3.5 o circuito de comando de um disjuntor. Como pode-se observar este compreende de dois circuitos, um de abertura e outro de fechamento, com suas respectivas bobinas (TC e CC), contatos principais (Trip e Close) e contatos auxiliares (52a) .

De acordo com o tipo de disjuntor este poderia estar em estado normalmente aberto (NA) ou normalmente fechado (NF). Caso o disjuntor esteja fechado o contato auxiliar 52a do circuito de fechamento estará fechado e o contacto auxiliar 52a do circuito de abertura estará fechado. A operação do disjuntor se inicia quando é energizado o circuito de abertura por ação de um operador do edifício de comando, de um relé de proteção ou através de um dispositivo de controle. Este sinal (Trip) energiza a bobina de abertura (TC) a qual possui um mecanismo que ativa um solenóide quando a mesma está totalmente energizada liberando dessa maneira a energia armazenada em uma mola ou em um compressor hidráulico que movimenta as alavancas, portanto os contatos principais do disjuntor permitindo assim a sua abertura. 


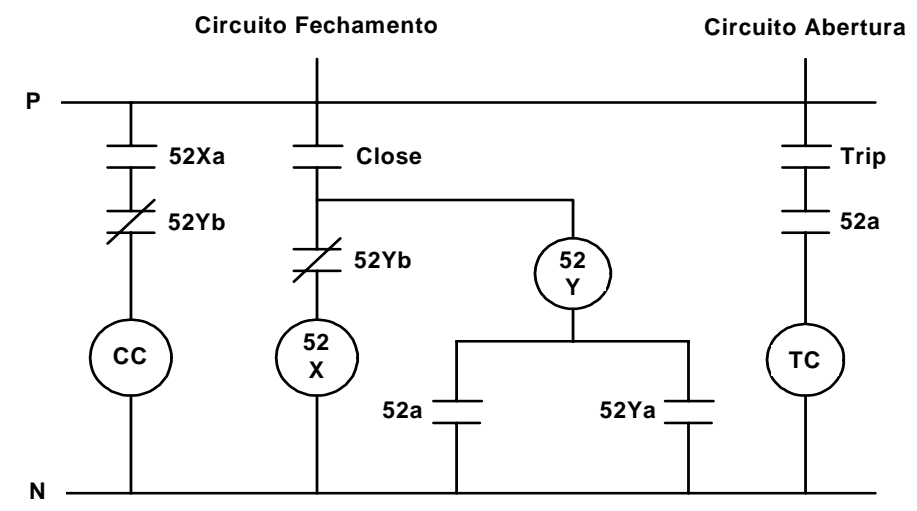

Figura 3.5 - Circuito de comando do Disjuntor.

A operação de fechamento é iniciada quando é emitido um sinal (Close) que alimenta o circuito de fechamento, sendo primeiro energizada a bobina 52X e imediatamente depois é alimentada a bobina de fechamento (CC), que possui um mecanismo parecido com a bobina de abertura, efetuando-se assim a operação de fechamento do disjuntor. Os contatos $52 \mathrm{Yb}$ trabalham em conjunto com a bobina $52 \mathrm{Y}$ e permitem temporizar a operação de fechamento gerando um pequeno atraso.

A Tabela 3.5 ilustra as diferentes formas de ondas presentes no disjuntor no momento da operação de abertura e fechamento. Como pode-se observar existem semelhanças entre as mesmas.

Tabela 3.5 - Formas de ondas do Disjuntor em operação.

\begin{tabular}{|c|c|c|}
\hline \multirow{2}{*}{$\begin{array}{l}\text { TIPO DE } \\
\text { SINAL }\end{array}$} & \multicolumn{2}{|c|}{ FORMAS DE ONDA } \\
\hline & OPERAÇÃO DE ABERTURA & OPERAÇÃO DE FECHAMENTO \\
\hline $\begin{array}{l}\text { Contatos } \\
\text { Trip e Close }\end{array}$ & Trip & Close \\
\hline $\begin{array}{l}\text { Contatos } \\
\text { Auxiliares }\end{array}$ & $52 a$ & 52 \\
\hline $\begin{array}{l}\text { Corrente } \\
\text { Bobinas }\end{array}$ & C & \\
\hline $\begin{array}{l}\text { Corrente } \\
\text { em XeY }\end{array}$ & NENHUMA & \begin{tabular}{l|l}
\cline { 2 - 2 } & \\
\cline { 2 - 2 } & $52 \mathrm{Ya}$ \\
\end{tabular} \\
\hline $\begin{array}{l}\text { Corrente } \\
\text { Fases }\end{array}$ & & $\dagger$ \\
\hline $\begin{array}{l}\text { Tensão CC } \\
\text { circuito }\end{array}$ & & \\
\hline
\end{tabular}


Dependendo da forma de onda de um determinado sinal, pode-se detectar anomalias ou prováveis falhas que no futuro poderiam danificar o disjuntor, causando prejuízos econômicos à concessionária.

A Tabela 3.6 ilustra alguns exemplos de formas de onda defeituosas e suas prováveis causas. A linha tracejada representa a curva de operação normal do disjuntor.

Tabela 3.6 - Formas de ondas defeituosas de corrente nas bobinas.

\begin{tabular}{|c|c|c|}
\hline $\begin{array}{c}\text { TIPO } \\
\text { DEFEITO }\end{array}$ & ILUSTRAÇÃo & $\begin{array}{c}\text { PROVÁVEL } \\
\text { PROBLEMA }\end{array}$ \\
\hline $\begin{array}{c}\text { Extinção } \\
\text { Lenta }\end{array}$ & & \\
\hline $\begin{array}{c}\text { Corrente } \\
\text { Distorcida }\end{array}$ & Friç̧ão \\
Travamento
\end{tabular}

\subsection{Sistema de Monitoramento}

No computador de supervisão está instalado um programa de base de dados que armazena o histórico das informações coletadas da operação do disjuntor. Um programa SCADA (Supervisory Control And Data Acquisition) permite fazer a Interface Homem Máquina (IHM) entre o sistema de monitoramento e o operador da subestação. Um programa dedicado de supervisão permite transformar os dados coletados pelo sistema de monitoramento em informação, continuamente calculando e apresentando o estado dos componentes do disjuntor monitorado, na forma de curvas, gráficos, ou diagramas, de forma a possibilitar uma avaliação e análise objetiva da condição real do disjuntor, o que irá permitir assim a adequada programação de sua manutenção. É objetivo fundamental do sistema a minimização da quantidade de falhas dos equipamentos e a redução do número de manutenções programadas durante a vida útil.

O disjuntor pode ser dividido em três partes, para identificar como fazer seu monitoramento:

* O circuito de potência - Por onde a corrente flui ou é interrompida, que é composto por um espaço fechado que contém um contato fixo, um contato móvel 
(contatos principais) e um meio interruptor que permite extinguir o arco elétrico no momento da abertura dos contatos. Dependendo da aplicação tem-se também um resistor de inserção que permite reduzir os transitórios de tensão que se produzem no momento que o disjuntor opera.

* O mecanismo de operação - Que permite a operação dos contatos principais (abertura - fechamento), mediante a utilização de dispositivos chamados acumuladores de energia, sendo os mais comuns mecanismos de operação: mecânico, hidráulico, e pneumático.

* O controle - Para fazer operar o disjuntor é necessário um impulso elétrico que é iniciado por contatos de acionamento ou pelo sistema de proteção.

Na Figura 3.6 apresenta-se uma primeira visão do monitoramento [10].

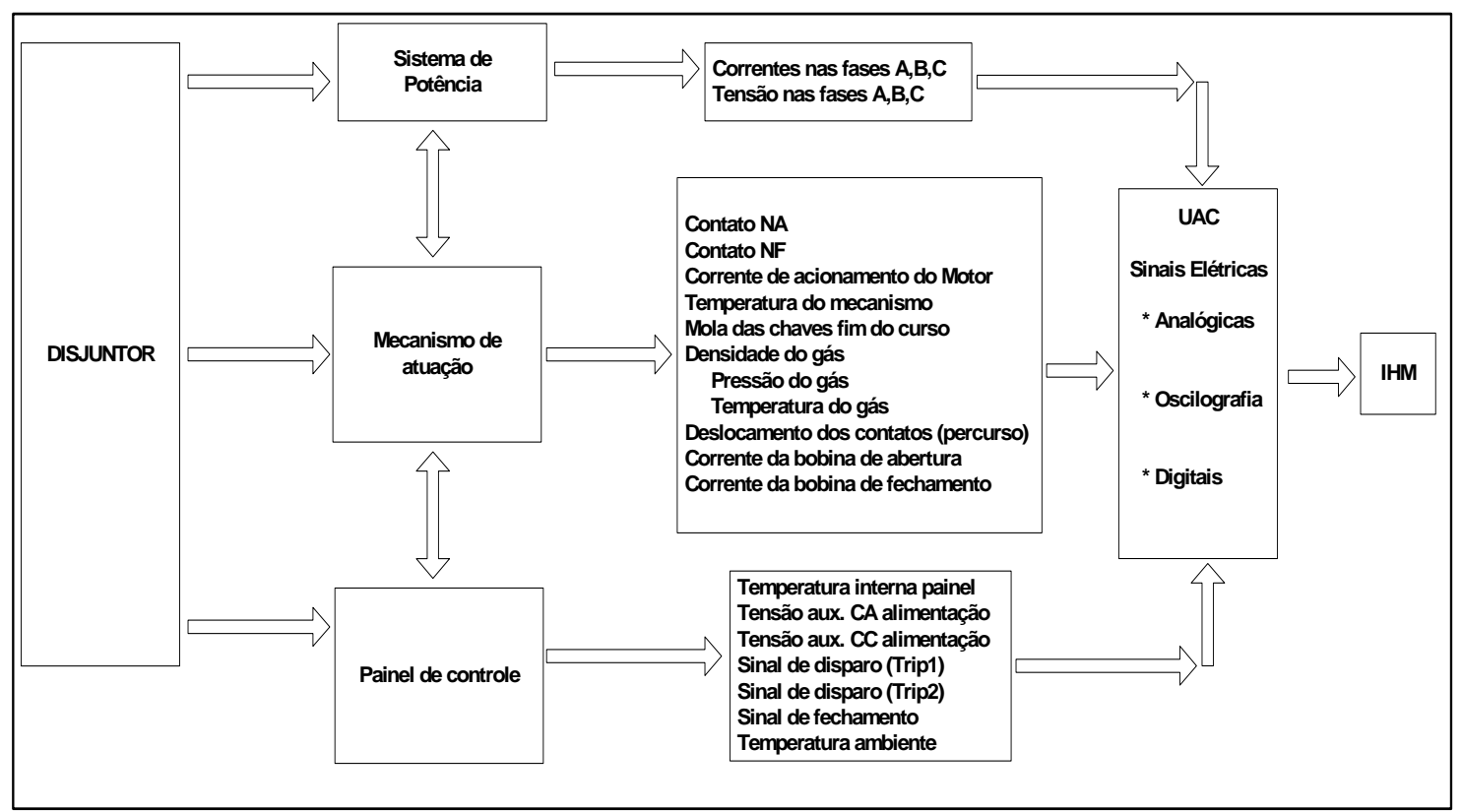

Figura 3.6 - Diagrama de Monitoramento da condição do Disjuntor.

\subsection{Variáveis Monitoradas}

Que variáveis precisam-se monitorar é uma pergunta importante que a concessionária tem que responder antes de implementar um sistema de monitoramento. 
O grupo de trabalho do IEEE “High Voltage Circuit Breaker Subcommittee Working Group on Quality \& Reliability of Circuit Breaker" preparou um guia de recomendações básicas de um sistema de monitoramento de disjuntores denominado de norma IEEE C37.10.1-2000 [20] e responde a pergunta anterior.

\section{a) Correntes dos circuitos de fechamento e disparo}

Os circuitos de disparo (trip) e fechamento (close) podem ser monitorados (Figura 3.5) para detectar o comportamento e funcionamento das bobinas de abertura e fechamento. Para isso normalmente se aplicam dois métodos: um através de transdutores de corrente de efeito hall e outro usando resistores. Este segundo método pode provocar atuações indevidas e por isso ultimamente não tem sido uma prática bem aceita pelas concessionárias. Destaca-se que o circuito de abertura é critico para a operação do disjuntor, sendo seu tempo total de resposta muito mais rápido em relação ao circuito de fechamento, que pode ser considerado como elemento menos critico para o monitoramento.

\section{b) Correntes nas fases no circuito principal}

O monitoramento das correntes das fases com amostragem menor que um milissegundo (oscilografia), permite detectar uma perturbação ou variação dos valores das correntes em cada fase, cuja informação tanto antes quanto depois da operação do disjuntor pode ser armazenada. A oscilografia das correntes permitirá saber o instante aproximado do acontecimento da falta e o tempo total de operação do disjuntor, além de possibilitar o calculo do desgaste dos contatos do disjuntor mediante a relação $\mathrm{I}^{2} \mathrm{~T}$ (sendo I a corrente e T o tempo).

\section{c) Tensões Auxiliares de alimentação (CA e CC)}

São também monitoradas as tensões auxiliares CA e CC no disjuntor, permitindo utilizar seus valores para determinar possíveis alterações decorrentes de algum tipo de falha, assim como supervisionar a adequada tensão de alimentação do mecanismo de acionamento e dos circuitos de controle do painel de comando. No protótipo desenvolvido junto com a pesquisa aqui descrita, as tensões supervisionadas foram 125 
Vcc como tensão de alimentação do painel de comando, e 440 Vca como suprimento do motor de acionamento. Cabe indicar que em geral os motores usados são de acionamento universal e que podem trabalhar em diferentes níveis de tensão, em Vcc ou/e Vca, cuja seleção depende da padronização da concessionária.

\section{d) Tensões nas fases no circuito principal}

Podem ser monitoradas as tensões das fases através da oscilografia do sinal proporcionado pelos TP's (Transformadores de Potencial) de cada fase do circuito principal, para registrar uma perturbação ou sobretensão que possa originar a operação do disjuntor. Embora este parâmetro não seja imprescindível dentro dos sistemas de monitoramento o uso de medidores digitais e módulos condicionadores permitem sua avaliação.

\section{e) Sistema de acionamento}

Em disjuntores com mecanismos de atuação mecânico ou pneumático é importante monitorar a pressão da mola que funciona como acumulador de energia de acionamento, cujo monitoramento permitirá verificar o ciclo de abertura do disjuntor. Além disso, a excessiva compressão ou carga da mola, algumas vezes pode indicar um problema no mecanismo de compressão. Não é recomendável a instalação de forma direta de um sensor de pressão na mola, porque poderia reduzir a confiabilidade no momento de sua operação. Alternativamente pode-se monitorar todos os demais componentes auxiliares do sistema de compressão, permitindo assim estimar de forma indireta a pressão da mola.

No caso dos sistemas protótipos o sistema de acionamento do disjuntor da ETEO é eletro - hidráulico (motor/bomba) sendo monitorado a pressão hidráulica (nitrogênio / óleo).

\section{f) Deslocamento dos contatos moveis principais no disjuntor}

Com o uso de sensores de percurso, seja por uma medição semidireta (instalado na haste da coluna polar do disjuntor) ou indireta (instalado nas alavancas do mecanismo de acionamento), é possível cronometrar o tempo de movimentação dos contatos a cada 
operação do disjuntor. Entretanto a colocação do sensor de percurso na haste poderia significar acrescentar um elemento a mais de risco na operação interna do disjuntor. Além do fato, deste sensor sofrer descalibração a cada operação do disjuntor criando um novo problema de manutenção. Portanto a maneira mais recomendável da medição do deslocamento dos contatos principais seria através de métodos não intrusivos.

Neste trabalho procurou-se efetuar esta determinação pela oscilografia das tensões e correntes do circuito principal e da corrente no circuito de disparo e no motor de acionamento. A confrontação do tempo gasto nas seqüências da operação pode identificar um possível problema no mecanismo de atuação.

\section{g) Desgaste dos contatos do disjuntor}

Baseados no monitoramento do número de operações, do tempo de operação e da corrente de interrupção, pode-se aplicar a expressão matemática $\mathrm{I}^{\mathrm{n}} \mathrm{T}$ (n valor entre 1 e 2) de acordo com o tipo de disjuntor, para se estimar a condição de desgaste dos contatos principais. Isto permite programar adequadamente sua manutenção preditiva.

\section{h) Massa do gás da câmara principal}

Nos disjuntores com sistemas de extinção do arco a gás (SF6), o monitoramento permite detectar variações limites na pressão do gás (ou densidade) que afetam a isolação interna diminuindo a capacidade de interrupção do disjuntor. Possibilita também estimar a taxa de diminuição do gás no tempo, permitindo, portanto que a equipe de manutenção possa atuar na hora oportuna antes que seja atingido um nível crítico de pressão. Esta variação pode ocorrer devido a vazamentos indesejados.

\section{i) Pressão do óleo / $N_{2}$ isolante}

Para disjuntores que utilizam sistemas de acionamento baseados na combinação óleo/ $\mathrm{N}_{2}$ é possível instalar um sensor de pressão que registre a variação do sistema motor-bomba durante a operação, permitindo identificar algum defeito no momento da atuação. Todas essas informações podem ser usadas para formular um plano de manutenção baseados na pressão do óleo/ $\mathrm{N}_{2}$ e não em tempos programados como é feito tradicionalmente. 


\section{j) Temperatura}

A medição da temperatura ambiente permite corrigir o valor da pressão interna do gás (na realidade calcular a densidade do gás), através do uso das curvas parametrizadas para cada disjuntor. Além disso, a supervisão da temperatura do gabinete permite alertar sobre o aumento provável da corrente do motor pelo aumento de temperatura do mecanismo de acionamento fora do limite normal de operação.

\section{k) Sinais Discretos}

Diferentes sinais são coletados com a finalidade de serem usados como alarmes ou eventos dentro do sistema de monitoramento. Esses sinais são informações de estado das grandezas (valores máximos e mínimos ultrapassados), estágios de alarme de algumas grandezas como pressões de óleo e gás. Estes sinais são obtidos do circuito de controle do disjuntor e das caixas de junção de cada pólo.

Em resumo para a aquisição das grandezas e estado dos eventos do disjuntor no protótipo foram considerados os sinais descritos a seguir:

\subsubsection{Entradas Digitais}

São sinais a serem coletados no momento da operação do disjuntor. Dependendo da utilização que se deseja deles, podem ser coletados com resolução rápida "Fast Resolution” (FR) ou lenta “Low Resolution” (LR). A FR (resolução menor ou igual a 1 ms) é usada quando se vai fazer o sequenciamento de eventos, que permite determinar e ordenar os tempo de operação e uma comparação com valores obtidos de outros sinais do sistema de monitoramento do disjuntor. Os sinais LR são geralmente usados como alarmes, informação do estado dos estágios das pressões e níveis de tensões de alimentação CC e CA, (resolução da ordem de segundos). Na Tabela 3.7 encontra-se a relação de entradas digitais instaladas no disjuntor protótipo. 
Tabela 3.7 - Entradas Digitais Monitoradas.

\begin{tabular}{c|l|c}
\hline Sinal & \multicolumn{1}{|c}{ Descrição } & Resolução \\
\hline $\mathrm{A}$ & Status do contato normalmente Fechado do disjuntor & $\mathrm{FR}$ \\
\hline $\mathrm{B}$ & Status do contato normalmente Aberto do disjuntor & $\mathrm{FR}$ \\
\hline $\mathrm{CB}$ & Status do relé de bloqueio geral do disjuntor & $\mathrm{LR}$ \\
\hline Oil-1 & Status baixa pressão de óleo 1 ${ }^{\circ}$ estágio (alarme) & $\mathrm{LR}$ \\
\hline Oil-2 & Status baixa pressão de óleo 2 ${ }^{\circ}$ estágio (bloqueio) & $\mathrm{LR}$ \\
\hline SF6-1 & Status baixa pressão de SF6 1 ${ }^{\circ}$ estágio (alarme) & $\mathrm{LR}$ \\
\hline SF6-2 & Status baixa pressão de SF6 2 ${ }^{\circ}$ estágio (bloqueio) & $\mathrm{LR}$ \\
\hline Vol-1 & Status do relé de falta de tensão do circuito Vcc & $\mathrm{LR}$ \\
\hline Vol-2 & Status do relé de falta de tensão do circuito Vca & $\mathrm{LR}$ \\
\hline $\mathrm{M}-2$ & Status do motor de acionamento (ligado/desligado) & $\mathrm{FR}$ \\
\hline $\mathrm{M}-\mathrm{FC}$ & Status do relé de fim de curso do motor & $\mathrm{FR}$ \\
\hline $\mathrm{D}-\mathrm{P}$ & Status do relé de discordância de pólos & $\mathrm{FR}$ \\
\hline $\mathrm{R}$ & Status do relé de Auto-religamento & $\mathrm{LR}$ \\
\hline
\end{tabular}

\subsubsection{Entradas Analógicas}

O monitoramento de disjuntores envolve grandezas analógicas também agrupadas em dois tipos: uma com resolução lenta de tempo (LR), sendo necessário e suficiente coletá-la em intervalos de segundos, geralmente usados para grandezas relativas a condições de operação (temperatura, pressão, etc.); e a outra com resolução rápida (FR) coletada durante a operação do disjuntor na forma de oscilografia (correntes das fases do circuito principal, corrente do motor, etc.). Esses últimos eventos são rápidos e a alta taxa de amostragem, permite fazer uma correta oscilografia da variável e dessa forma observar qualquer tipo de alteração dentro do padrão normal de operação. A Tabela 3.8 lista as diferentes entradas analógicas do disjuntor. 
Tabela 3.8 - Entradas Analógicas Monitoradas.

\begin{tabular}{c|l|c}
\hline Sinal & \multicolumn{1}{|c|}{ Descrição } & Resolução \\
\hline $\mathrm{TA}$ & Temperatura ambiente & $\mathrm{LR}$ \\
\hline $\mathrm{TI}$ & Temperatura interna painel de comando & $\mathrm{LR}$ \\
\hline $\mathrm{PG}$ & Pressão do gás (SF6) & $\mathrm{LR}$ \\
\hline $\mathrm{PO}$ & Pressão do óleo/N2 & $\mathrm{LR}$ \\
\hline $\mathrm{C}$ & Corrente da bobina de fechamento (Close) & $\mathrm{FR}$ \\
\hline $\mathrm{T}-1$ & Corrente da bobina de abertura (Trip1) & $\mathrm{FR}$ \\
\hline $\mathrm{T}-2$ & Corrente da bobina de abertura (Trip2) & $\mathrm{FR}$ \\
\hline $\mathrm{M}$ & Corrente de acionamento do motor & $\mathrm{FR}$ \\
\hline $\mathrm{P}$ & Corrente das fases da linha & $\mathrm{FR}$ \\
\hline $\mathrm{V}$ & Tensões das fases da linha & $\mathrm{FR}$ \\
\hline
\end{tabular}

A quantidade de entradas analógicas vai depender se o acionamento do disjuntor é monofásico ou trifásico, da necessidade de comparação entre os valores de cada fase, do tipo de mecanismo de acionamento, entre outros. 


\section{CAPÍTULO 4}

\section{DETERMINAÇÃO DOS TEMPOS DE OPERAÇÃO DO DISJUNTOR}

\subsection{Introdução}

O objetivo principal deste capítulo é discutir a possibilidade de usar-se a transformada Wavelet (TW), na detecção dos tempos de operação do disjuntor (abertura e fechamento) usando para isso a oscilografia das correntes e tensões no disjuntor.

Para cumprir com o objetivo mencionado, necessitou-se da obtenção de dados de situações reais anteriores à construção do protótipo, ou seja, distúrbios que ocasionaram a operação do disjuntor dentro do sistema elétrico. Para tanto, foi utilizada uma informação proporcionada pelo osciloperturbógrafo, marca Siemens, modelo SIMEAS $\mathrm{R}$, junto com o programa "Comtrade Viewer", tomando-se os dados referentes à operação do disjuntor do Bay de Linha, Siemens 3AT4-SF6, de 440kV instalado na subestação de Sumaré do sistema de transmissão da ETEO. Nas oscilografias coletadas foi utilizada uma taxa de amostragem de $15,4 \mathrm{kHz}$, ou seja, 256 amostras/ciclo a $60 \mathrm{~Hz}$ com possibilidade de escolher um número variável de ciclos pré e pós-disparo.

Ressalta-se que para uma análise mais definitivamente conclusiva do processo, seria necessário examinar mais oscilografias com diferentes tipos de curto, de instantes de ocorrência do curto e da distancia destes a subestação.

Entretanto a ETEO por ser um sistema de transmissão novo, não dispõe de um conjunto de informações completas . 
Outro ponto necessário para o desenvolvimento do trabalho foi a pesquisa do método a ser utilizado para desenvolver o algoritmo determinador dos tempos, tendo sido escolhidas duas ferramentas matemáticas: a Transformada de Fourier de Curta Duração (STFT); e a Transformada Wavelet Discreta (DWT) sob a forma de Análise Multiresolução (AMR).

Uma questão natural foi: Qual será a Função base (Wavelet mãe) a ser utilizada para a análise DWT/AMR? Para responder tal pergunta, foram desenvolvidos estudos com diversas funções bases, devendo ser escolhida uma Wavelet mãe que fosse capaz de extrair características pertinentes dos diferentes distúrbios envolvidos no período de atuação do disjuntor. Desta forma uma Wavelet mãe foi escolhida e a AMR foi empregada para analisar e determinar os tempos envolvidos. Para tais análises foram utilizados algoritmos, desenvolvidos no software Matlab, que explorassem as diferentes curvas (corrente e tensão) e permitissem calcular os tempos de abertura e fechamento do disjuntor estudado.

Inicialmente, é apresentado na Figura 4.1 o sistema elétrico onde está localizado o disjuntor a ser monitorado (circulo verde) pelo protótipo desenvolvido. Apresenta-se a seguir o estudo efetuado com cada uma das ferramentas matemáticas. 


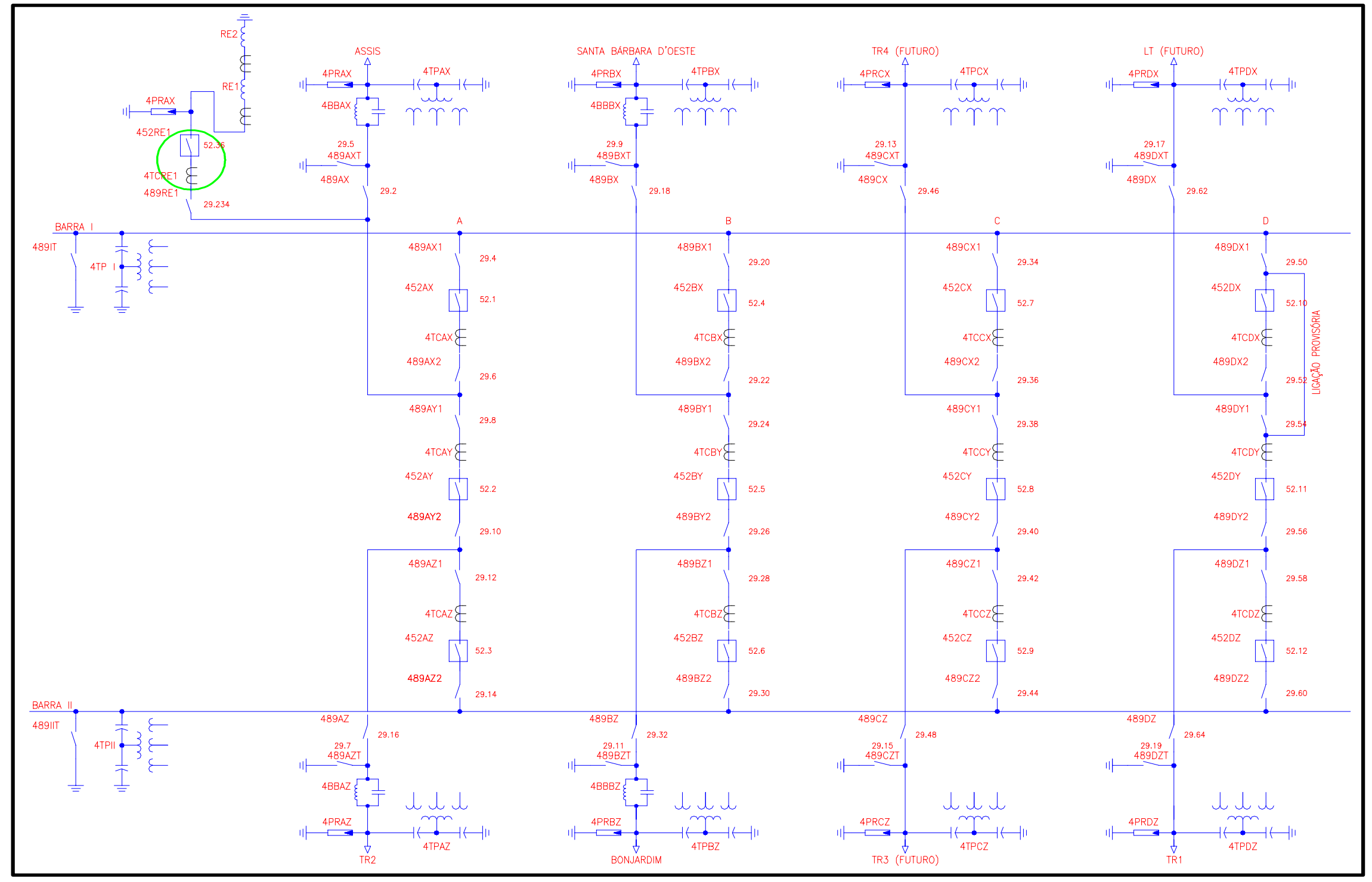

Figura 4.1 - Diagrama unifilar da Subestação Sumaré (ETEO) 
Para a realização de testes nos algoritmos é necessária a utilização de um conjunto de casos ocorridos. As Figuras 4.2 e 4.3 apresentam a oscilografia de tensão e corrente devido a um curto monofásico, na fase C que levou ao acionamento de um disjuntor da subestação. Este caso será usado para análise investigatória da viabilidade da metodologia de determinação dos instantes característicos do transitório.

\section{SUMARE EH1}

$09 / 20 / 02$

04:15:29.555

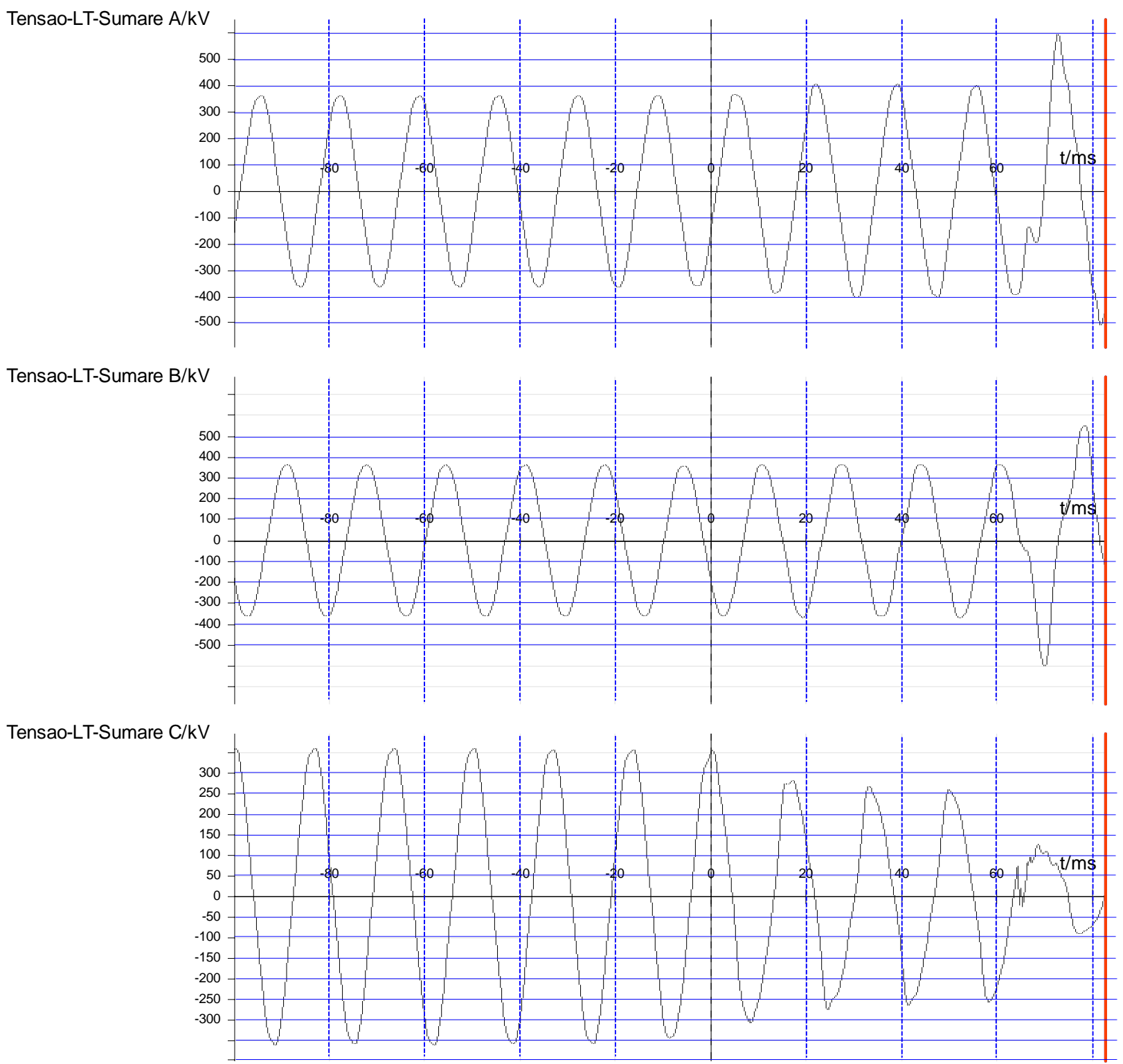

Figura 4.2 - Oscilografia das Tensões de linha $(440 x \sqrt{ } 2 / \sqrt{ } 3 k V)$ 
SUMARE EH1

09/20/02

04:15:29.555

Corrent-LT-Sumar A/kA

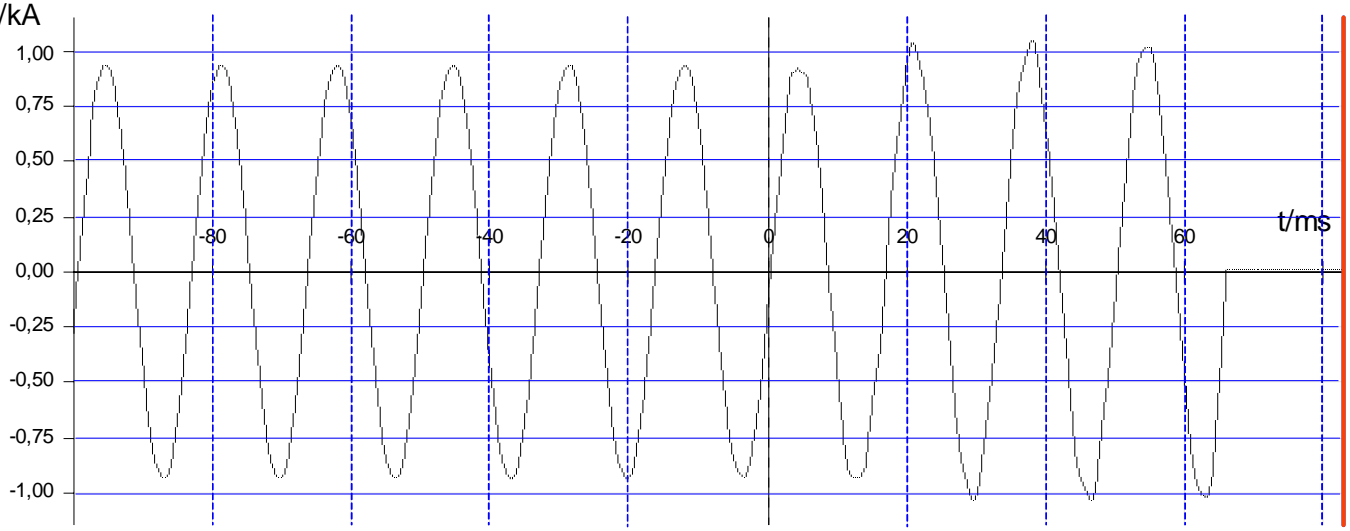

Corrent-LT-Sumar B/kA

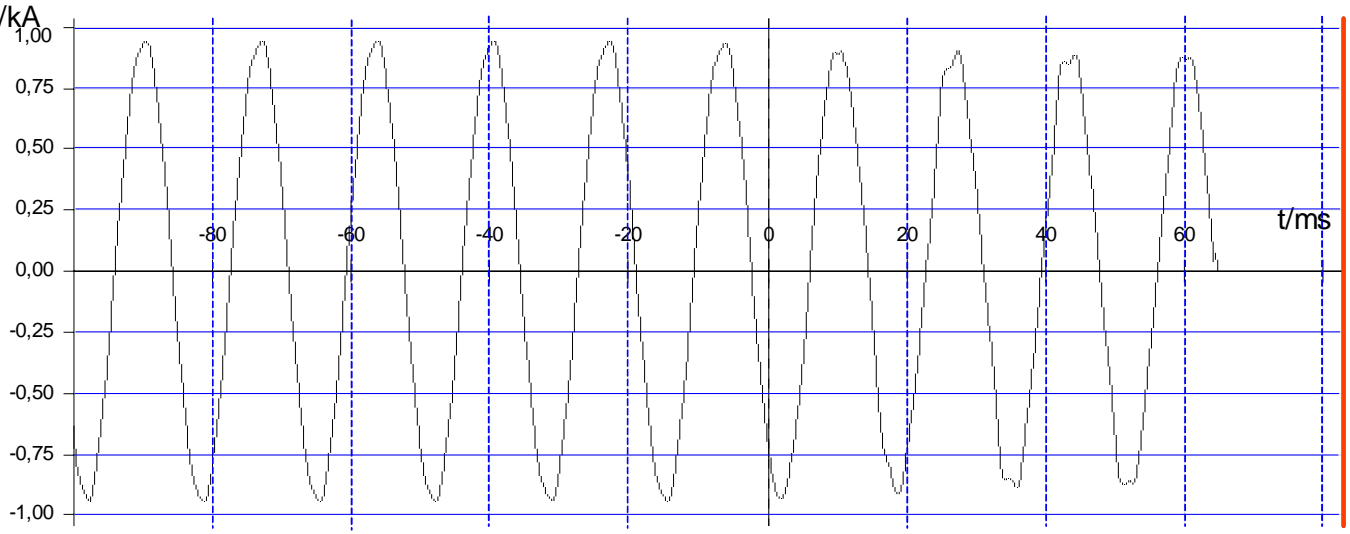

Corrent-LT-Sumar C/kA

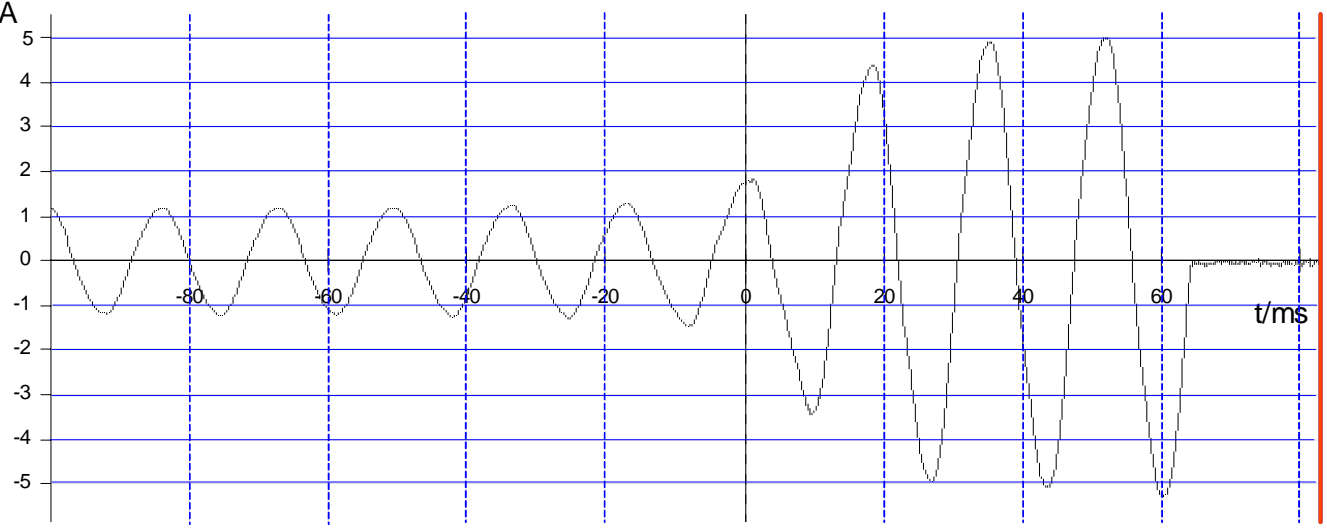

* Observar a mudança de escalas no eixo da ordenada.

Figura 4.3 - Oscilografia das Correntes de linha. 
O instante de disparo da oscilografia, comandado pelo relé de proteção, foi 04:15:29.555 (instante zero). Observa-se pelas modificações das tensões e correntes na fase C que o curto provavelmente iniciou-se cerca de 8 a $15 \mathrm{~ms}$ antes do referido instante. Em particular observa-se que o pico negativo da tensão a -10 ms é menor que os anteriores, e que o sinal de corrente é maior.

Considerando que os relés de proteção atuam em 0,5 a 1 ciclo após o curto infere-se que no instante zero da oscilografia a bobina de disparo do disjuntor já estaria energizada.

No instante aproximadamente a 65ms (4 ciclos a 60Hz) ocorre a interrupção da corrente no disjuntor.

\subsection{Análise Wavelet}

\subsubsection{Introdução}

No Apêndice A encontra-se uma introdução à Transformada Wavelet. Está fora do escopo deste trabalho uma abordagem matemática mais detalhada sobre essa ferramenta, podendo a mesma ser encontrada, por exemplo, em [22, 25 e 26].

Será usada nesta aplicação a Análise Multi-Resolução (AMR) também sumarizada no Apêndice A.

Neste trabalho, os sinais de tempo discreto, os quais serão analisados usando o algoritmo AMR, são as correntes e tensões nas fases (A, B e C), amostradas com uma resolução de 256 amostras/ciclo a $60 \mathrm{~Hz}$. O processo baseia-se na filtragem de um sinal a ser analisado através de filtros passa alta e passa baixa, fornecendo versões do sinal original relativa aos coeficientes de funções Wavelets e funções escala, respectivamente.

O processo de filtragem é ilustrado abaixo, na Figura 4.4, em uma forma simplificada, considerando-se somente o primeiro nível de decomposição: 


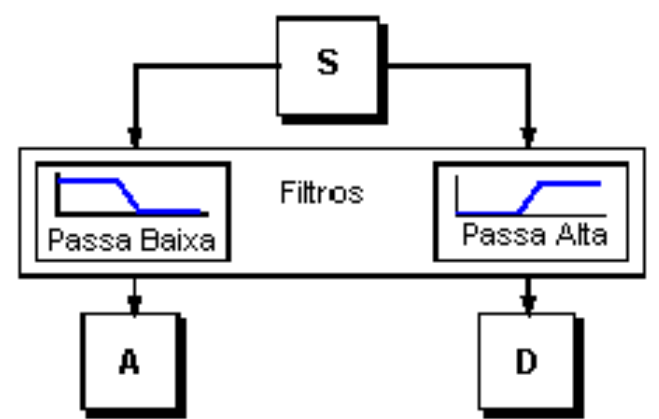

Aproximação Detalhe

Figura 4.4 - Processo de filtragem de um sinal

O sinal original, S, passa através de dois filtros complementares que fornecem como saída dois sinais. Ao utilizar esse esquema em um sinal digital, potencialmente terse-ia duas vezes mais a quantidade de dados em relação aos dados iniciais. Suponha que o sinal original S consista de 1000 amostras de dados. Sendo assim as versões de aproximação (A) e de detalhes (D) do sinal original poderiam vir a ter 1000 amostras cada um, totalizando 2000 amostras.

Para modificar este fato, é introduzido um operador que diminui o número de amostras (operador decimação, down-sampling), [26], que considera dados intercalados, ou seja, considera o primeiro dado, rejeita o segundo, e assim por diante. A Figura 4.5 ilustra a operação do operador down-sampling, representado por $(\downarrow)$, onde é mostrado o processo de filtragem com e sem o estágio de diminuição do número de amostras.

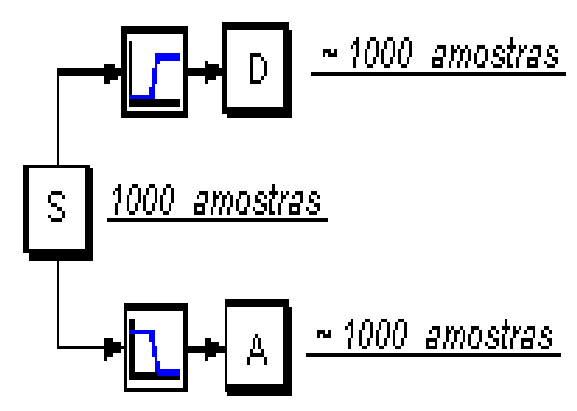

a) Sem decimação

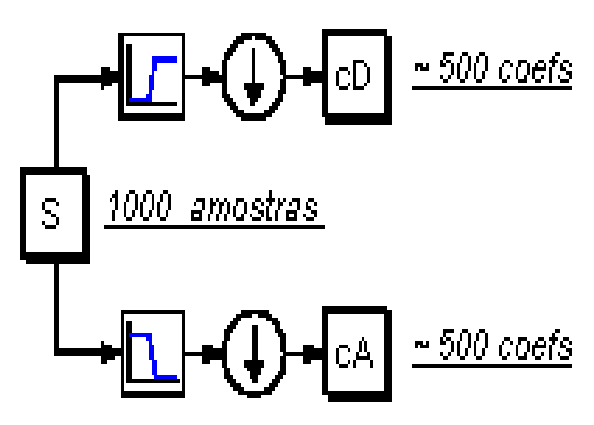

b) Com decimação

Figura 4.5 - Processo de diminuição do número de amostras do sinal. 
O processo que inclui decimação, produz os coeficientes $\mathrm{cD}$ e cA referentes a TW. Para se obter uma maior apreciação deste processo, é apresentado um exemplo, Figura 4.6, com desenvolvimento ilustrativo da TW de um sinal. O sinal utilizado para análise consiste em uma senóide com ruído de alta freqüência adicionado a ela [25].

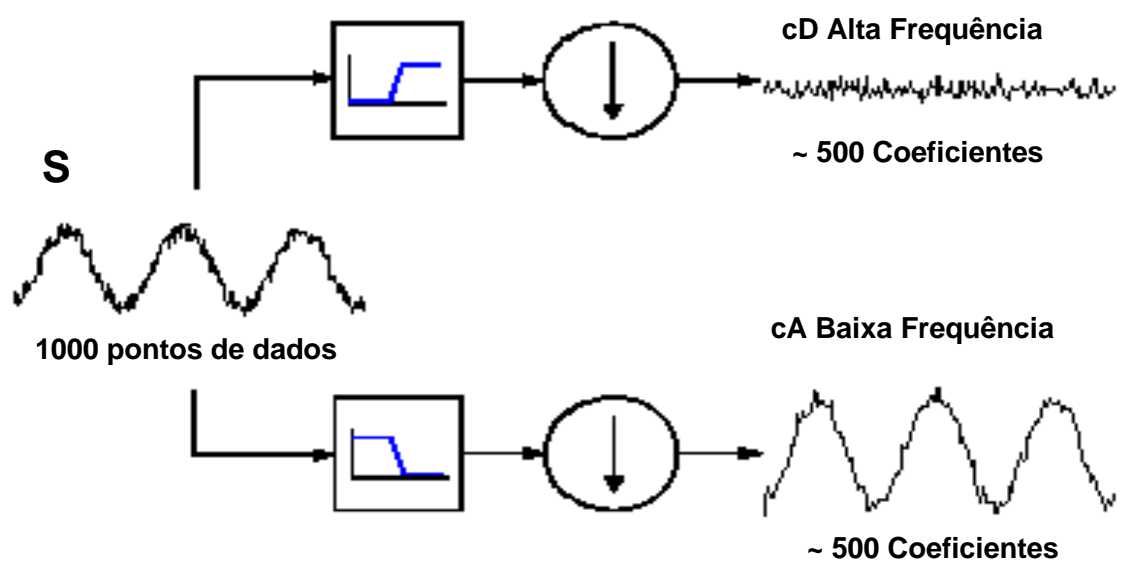

Figura 4.6 - Exemplo de filtragem com decimação de um sinal senoidal com ruído.

O coeficiente de detalhe $\mathrm{cD}$, Figura 4.6, consiste principalmente de ruídos de alta freqüência, enquanto que os coeficientes cA contém muito menos ruído que o sinal original.

O processo de decomposição pode ser repetido, com aproximações de decomposição sucessivas, como mostrado na Figura 4.7.

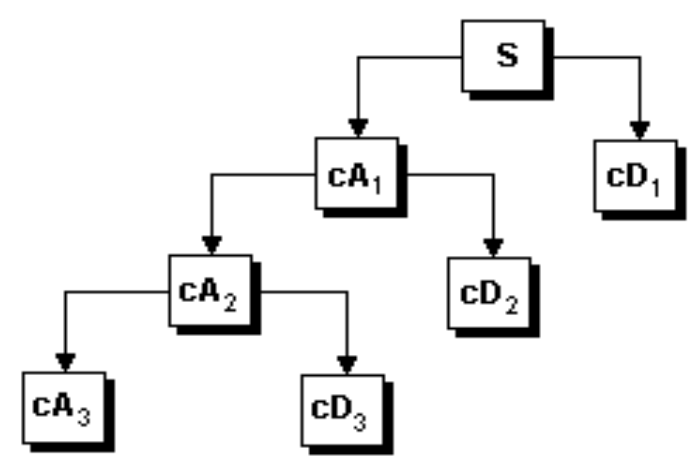

Figura 4.7 - Ilustração do processo sucessivo de decomposição de um sinal. 
A decomposição pode proceder até o detalhe individual consistir em somente uma amostra. Na prática, seleciona-se um número satisfatório de níveis baseado na natureza do sinal.

A análise multi-resolução (AMR) é uma estratégia de processamento de sinais em que é utilizado um conjunto de filtros especializados em extrair as informações do sinal, como as freqüências presentes nesse e sua localização no tempo no transcurso do sinal, em diferentes resoluções.

No AMR, a aproximação é descrita utilizando-se o conceito de resolução ou níveis, nos quais resoluções mais finas (níveis iniciais) possuem mais amostras por unidade de tempo. A passagem para um nível mais alto implica em uma maior resolução freqüêncial, porém à custa de uma menor resolução temporal. Por estas razões o uso desta ferramenta faz-se útil em sistemas de classificação de sinais.

A Figura 4.8 ilustra como é o processo de decomposição e recomposição, usando a AMR com filtros passa alta e passa baixo de decomposição (Lo-D, Hi-D) e (Lo-R, Hi-R) de recomposição, de um determinado sinal amostrado.

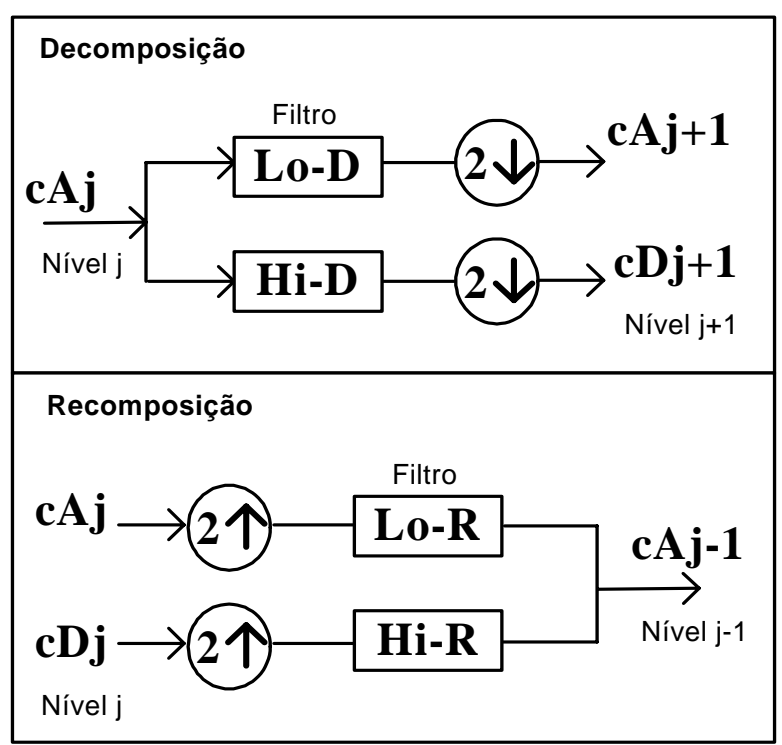

Figura 4.8 Decomposição e recomposição de sinais usando AMR 


\subsubsection{Escolha da Wavelet Mãe}

Com o objetivo de selecionar uma função base Wavelet que melhor se condicione à análise dos tempos de operação do disjuntor, testes foram realizados com várias destas. Tais testes consistiram em submeter a oscilografia da corrente (Fase C) mostrada neste capitulo, para análise, utilizando-se diversas funções bases.

Na Figura 4.9 são ilustrados os resultados obtidos com algumas das bases utilizadas (Haar, Daubechies, Coiflet, Symlet, etc). 

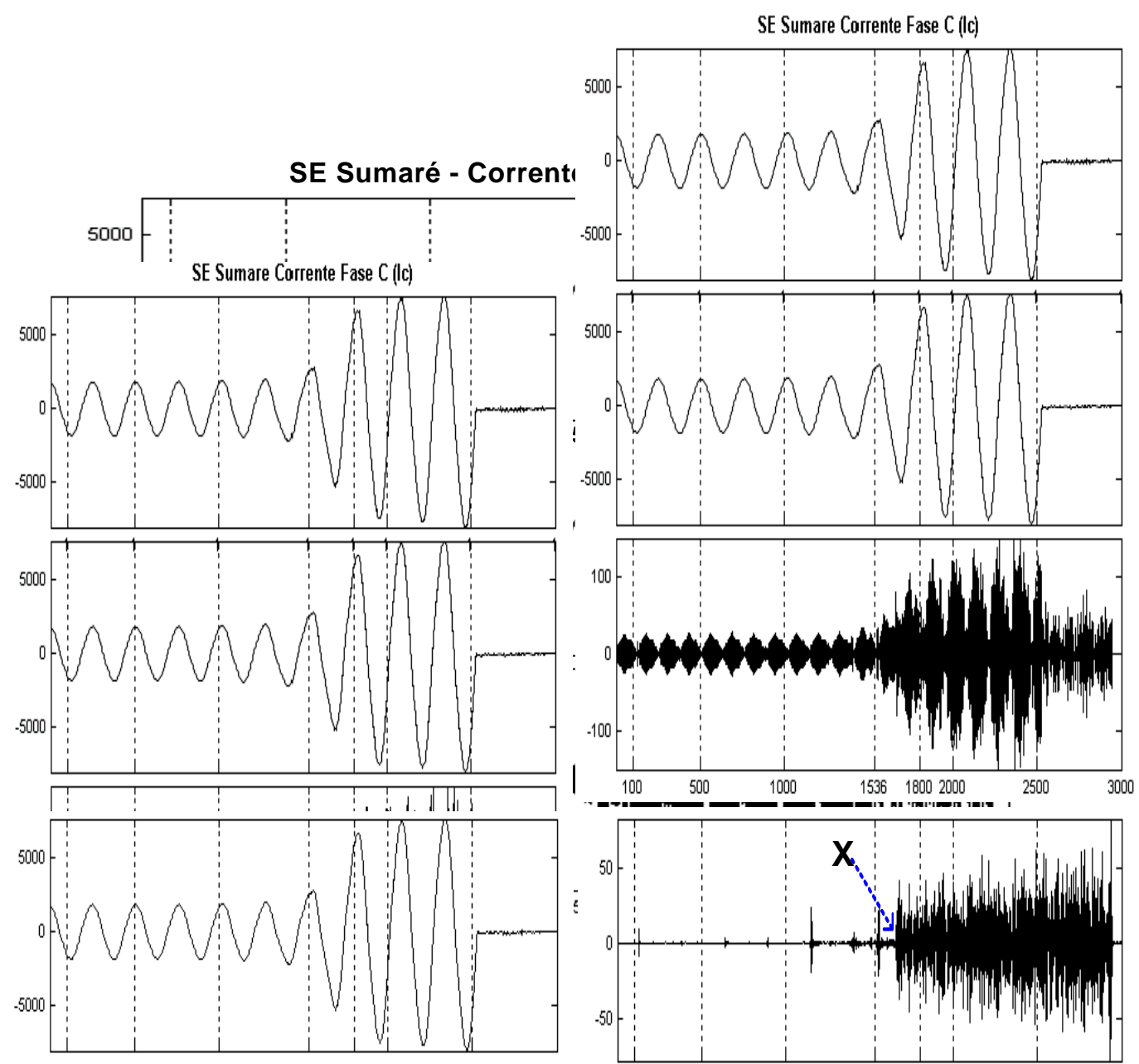

HAAR
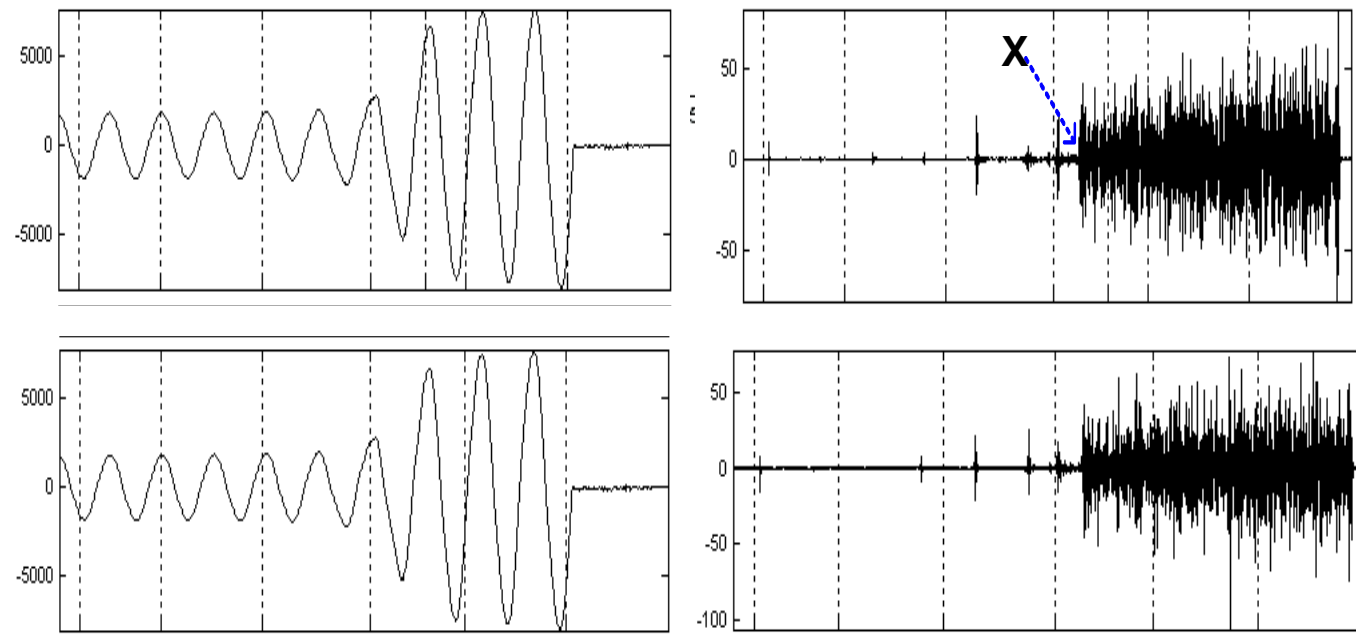

DB4
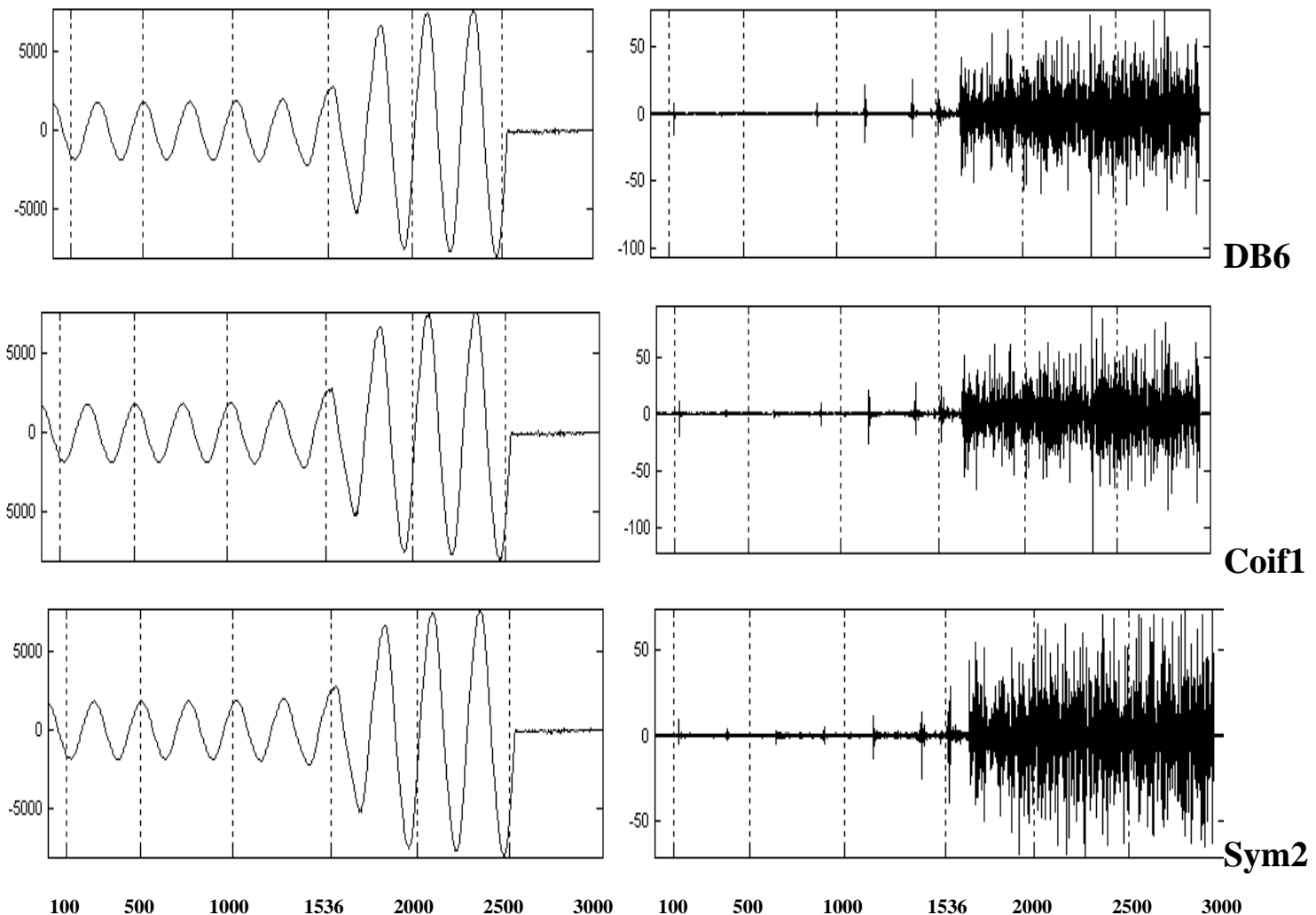

Figura 4.9 - Decomposição da corrente na Fase C, usando diferentes Wavelets Mãe. 
Não se observa indicação do fim de separação dos contatos na d1 (embora apareça o inicio), sendo necessário decompor em outros níveis. Este tempo também pode ser determinado pela mudança de posição dos contatos auxiliares (52a e 52b), mas essa informação não proporciona a exatidão desejada.

Geralmente, Wavelets mais suaves indicam melhor resolução em freqüência que Wavelets que possuem variações bruscas como a Wavelet de Haar, sendo o oposto aplicado para resolução no domínio do tempo.

Salienta-se que o objetivo da análise foi a de escolher uma função base adequada para o desenvolvimento de um algoritmo capaz de detectar, localizar e determinar os tempos envolvidos nos distúrbios. Para tanto, uma função base será adequada quando esta for capaz de diferenciar todos os distúrbios do sinal senoidal através de características ilustradas nas versões de detalhes em seus níveis de decomposição (a; d).

Pela literatura [25] e [30], aumentando a ordem das Wavelets mães, seus comportamentos em suavidade oferecem melhor resolução em freqüência. Sendo assim, as Wavelets de Daubechies, Coiflets e Biortogonal de ordem superior a quatro e Symlet de ordem superior a cinco oferecem melhores resultados na análise para a detecção do tempo final da operação de abertura do disjuntor. Tal conceito e os resultados da Figura 4.9, associado à facilidade de cálculos que a envolve, justifica a utilização da Wavelet de Daubechies de quarta ou sexta ordem (db4 e db6) para o cálculo dos tempos de operação através da análise das correntes e tensões.

Para a determinação dos tempos de abertura e fechamento do disjuntor (contatos principais) vai ser usada a informação indicada na Figura 4.9 onde são estabelecidos os seguintes tempos:

Amostra 1536, o relé informa ao oscilógrafo a existência de curto, através do fechamento de um contato.

* Amostra 1536 menos 4 a 15 ms, provável inicio do curto.

* Aproximadamente na amostra 2600 é interrompida a corrente. 
Questão: Quando iniciou-se a separação dos contatos principais do disjuntor e quando estão completamente separados?. Está compreendida na faixa entre a amostra 1536 até a amostra 2600 esta informação.

Pela análise dos valores detalhe (d1) o início de separação dos contatos seria 0 ponto (X), indicado na Figura 4.9 db4 (amostra 1614) e o final perto da amostra 2500.

Deve-se notar que ao iniciar o curto aparecem altas freqüências na tensão e corrente (ondas viajantes). Junto com o curto pode ocorrer assimetria na corrente (DC Offset) com conseqüente aparecimento de freqüências baixas ( 0 a 6 pu em relação a nominal $60 \mathrm{~Hz}$ ). Na separação dos contactos principais do disjuntor ocorre um arco interno, que fará surgir freqüências superiores a $60 \mathrm{~Hz}$ e de amplitude considerável.

Entende-se que estas freqüências devido ao arco, indicarão os instantes procurados. De fato o detalhe (d1) mostra alterações no fim da onda, 130 amostras (1/2 ciclo a $60 \mathrm{~Hz}$ ) após o instante zero, que permanece até o fim.

A Figura 4.10 ilustra o processo de decomposição da corrente na fase C em 4 sinais sucessivos, depois do disparo do comando de abertura do disjuntor nos últimos quatro ciclos antes de sua extinção total, sendo usado a Wavelet db4 onde pode-se observar as alterações detectadas e os prováveis tempos inicial e final (setas) da operação de abertura do disjuntor. A TW indica o provável instante do inicio da separação dos contatos (TI1). O tempo final interrupção de corrente na passagem pelo zero poderá ser o indicado por uma maior alteração no sinal de decomposição do detalhe (d4), que é mostrado na decomposição (TF1).

A aparição de freqüências diferentes de $60 \mathrm{~Hz}$ no momento da operação do disjuntor pode indicar que as variações no detalhe 1 (d1) da transformada Wavelet (db4) indicam o inicio físico da separação dos contatos principais, dentro da câmera do disjuntor.

Notar que após a interrupção, continua aparecendo os sinais nos detalhes d1. Acredita-se que se deve a ruídos de medições (uma vez que a corrente instantânea deveria ser zero). 


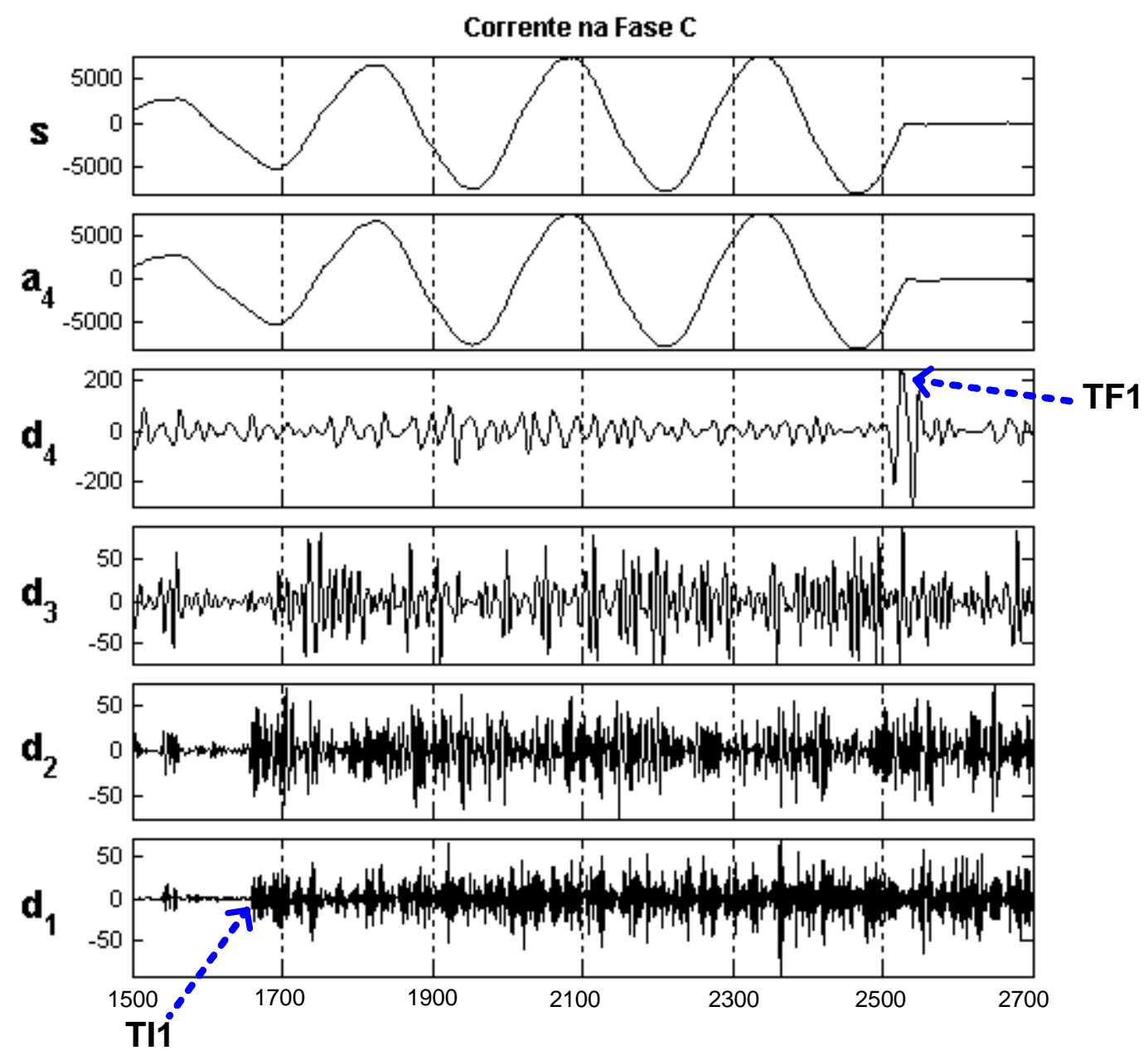

Figura 4.10 - Decomposição da corrente Fase C durante a abertura do disjuntor.

Pode-se também observar que as alterações são mais visíveis no detalhes 1 (d1) da decomposição.

Deve-se salientar entretanto que, para uma análise mais definitiva, pensou-se em efetuar testes num disjuntor provido de sensor de excursão de contatos, com aquisição de informações sincronizada com a oscilografia de correntes e tensões. Não foi possível esta realização por não se dispor de um sistema adequado para tal fim nas concessionárias elétricas brasileiras (FURNAS, CTEEP, CEMIG). 


\subsubsection{Metodologia utilizada para determinação dos tempos de operação}

O sinal de entrada que será submetido ao algoritmo de cálculo de tempos consiste de "vetores" que compreende os pontos amostrados da oscilografia das correntes e tensões no disjuntor, para cada uma das fases. Estes sinais, como já mencionado, foram gerados a uma freqüência de amostragem de 15,4 kHz.

Nota: Não foi proposta deste trabalho uma análise e determinação automática destes instantes de separação dos contatos principais visto que esta informação será usada apenas para a engenharia de manutenção não necessitando de determinação extremamente rápida como seria o caso se fosse utilizada para alguma forma de controle em tempo real. Assim a análise proposta é visual.

Como forma de entender melhor a análise, serão tomados como base os passos ilustrados pelo fluxograma apresentado na Figura 4.11. 


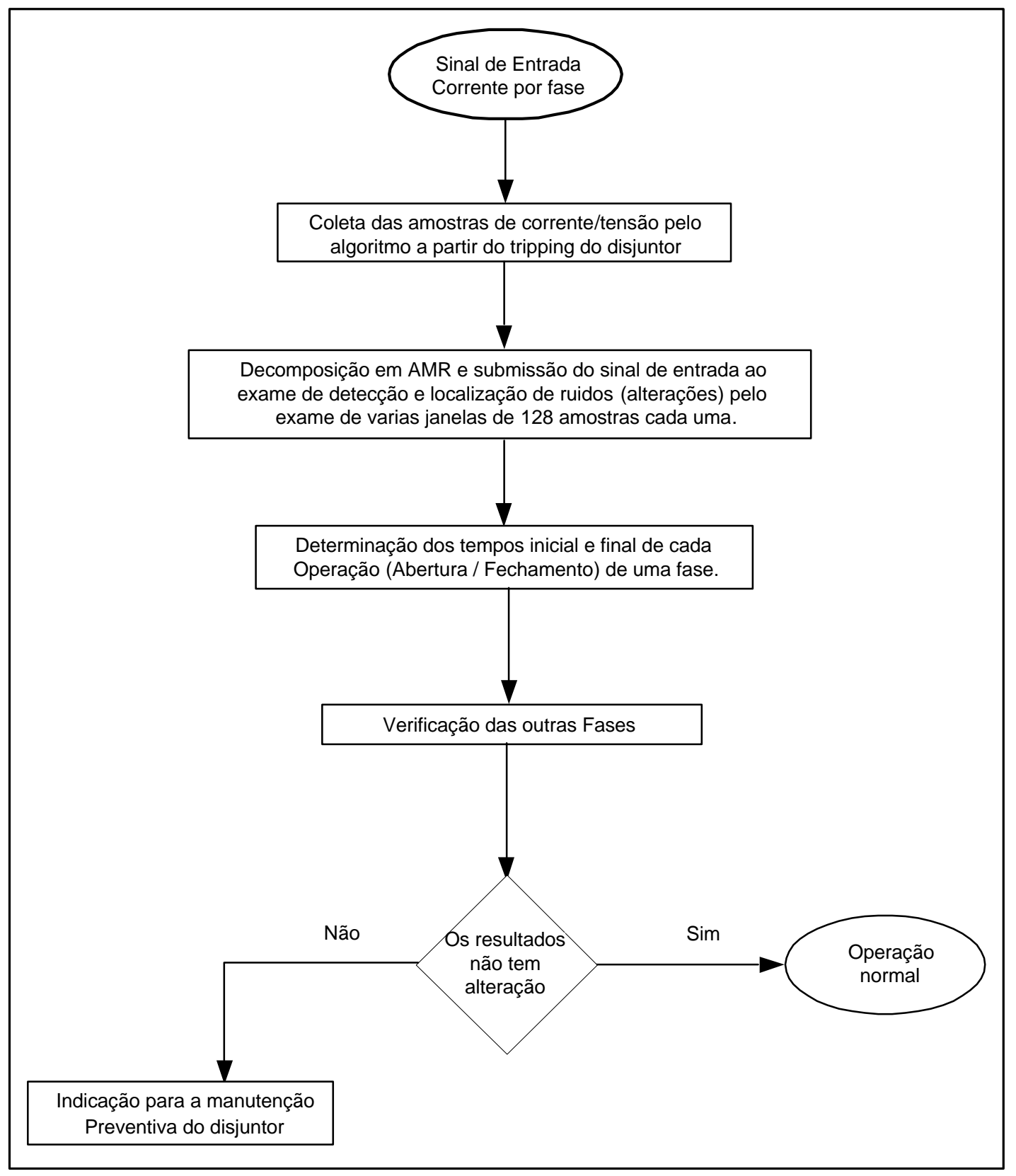

Figura 4.11 - Fluxograma descritivo do algoritmo de cálculo de tempos de operação.

Nas Figuras 4.12 até 4.17 são ilustradas as decomposições: primeira, segunda, terceira e quarta (a1....a4 e d1....d4), usando a wavelet mãe db4 das tensões (Va, Vb e Vc), e das correntes (Ia, Ib e Ic) respectivamente, sendo mostrados a aproximação e detalhe para cada caso. 


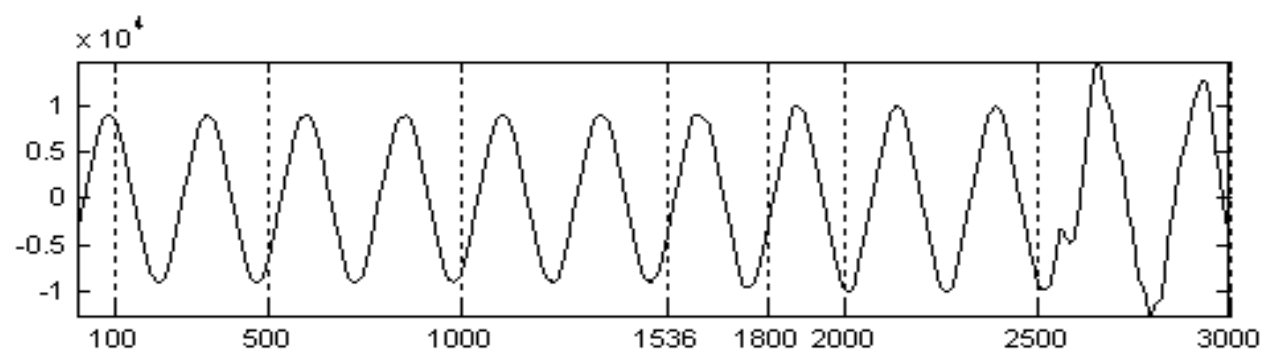

Aproximação (a1)

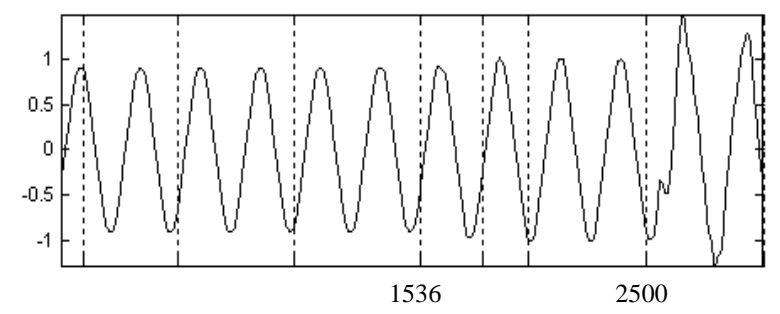

Aproximação (a2)

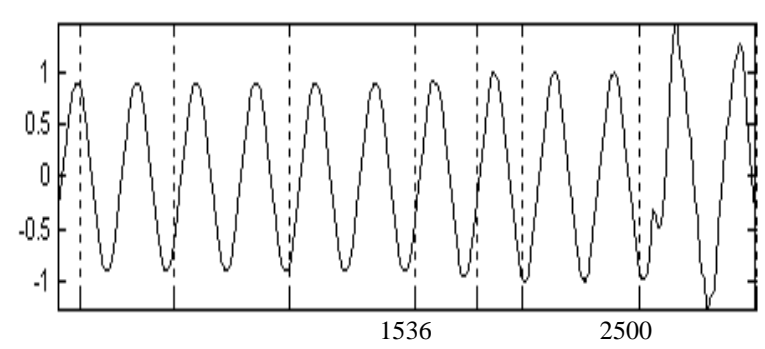

Aproximação (a3)

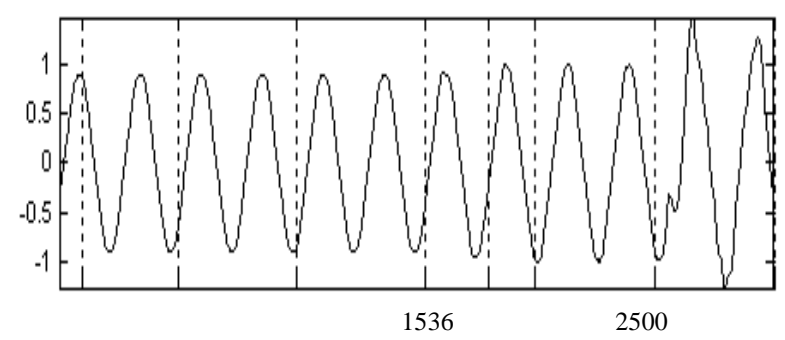

Aproximação (a4)

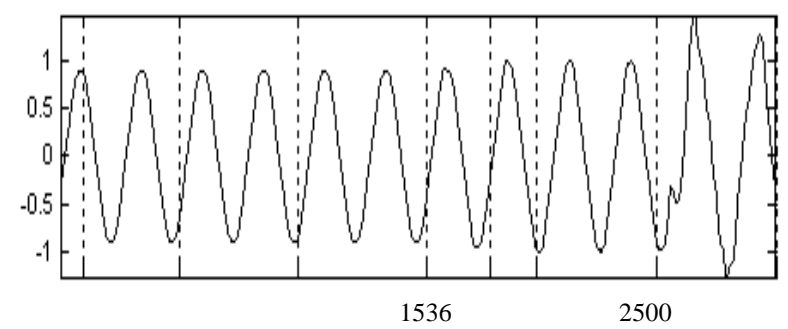

Detalhe (d1)

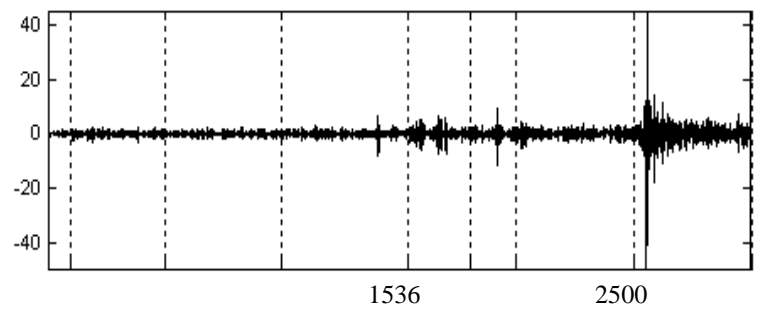

Detalhe (d2)

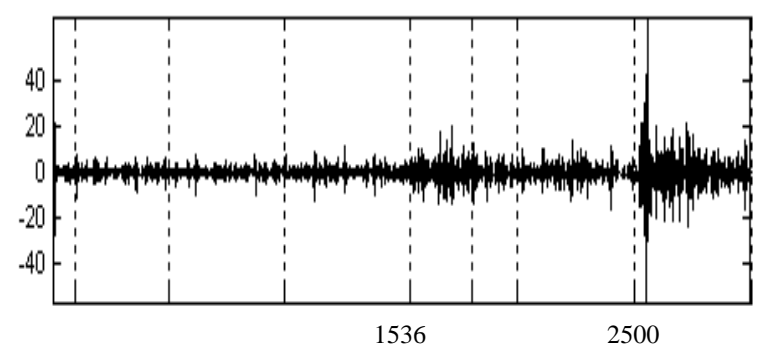

Detalhe (d3)

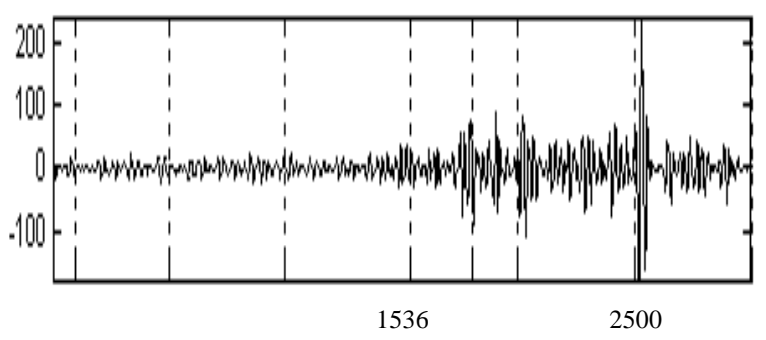

Detalhe (d4)

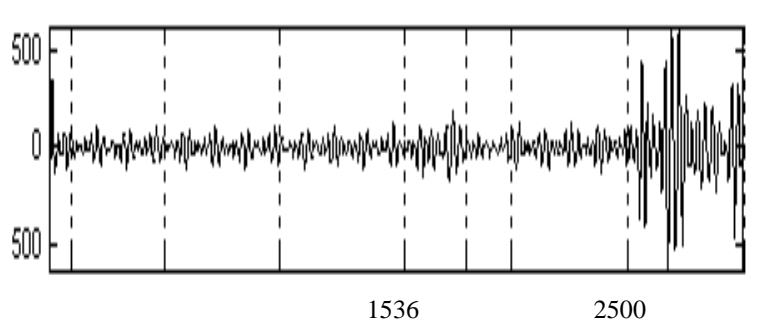

Figura 4.12 - Decomposição da Tensão Fase A (Va), usando db4. 


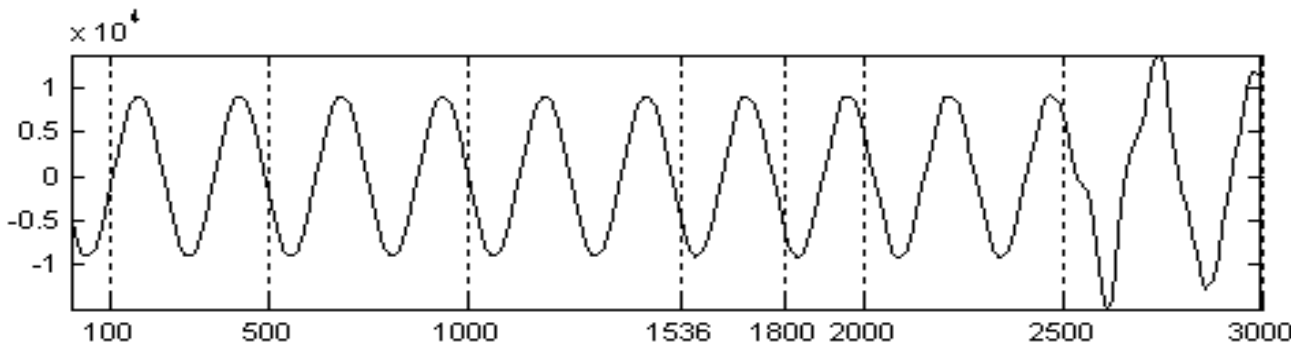

Aproximação (a1)

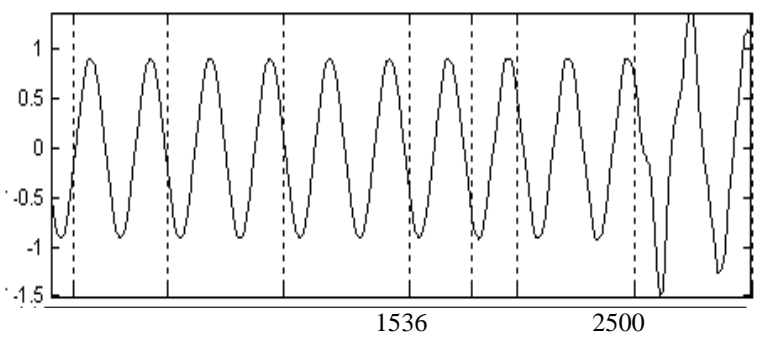

Aproximação (a2)

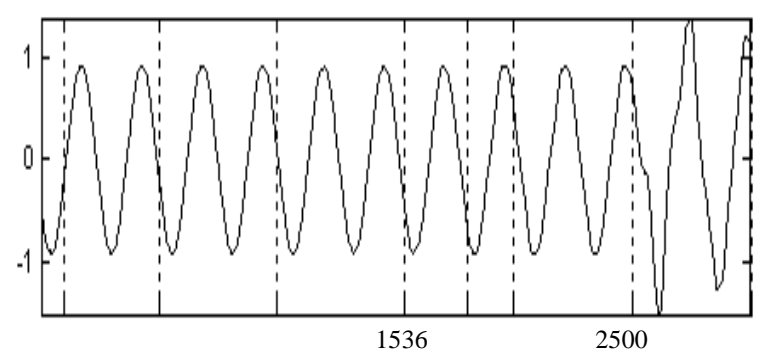

Aproximação (a3)

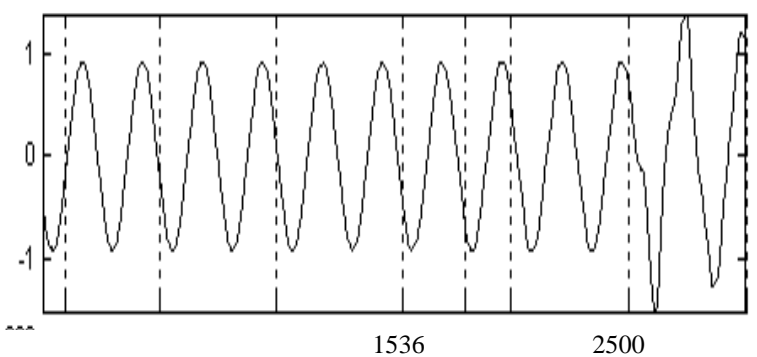

Aproximação (a4)

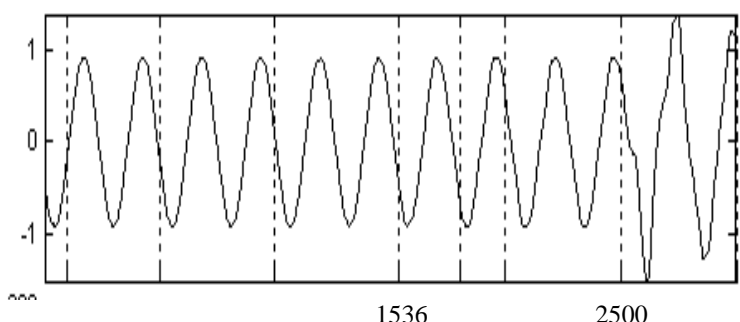

Detalhe (d1)

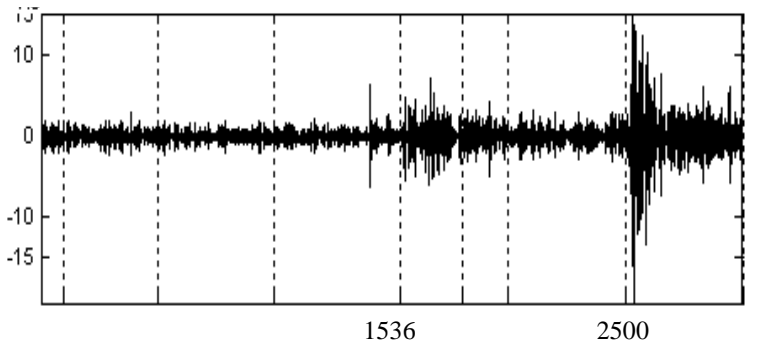

Detalhe (d2)

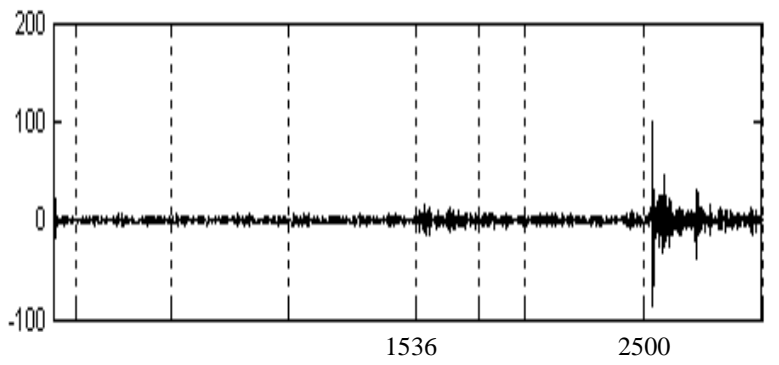

Detalhe (d3)

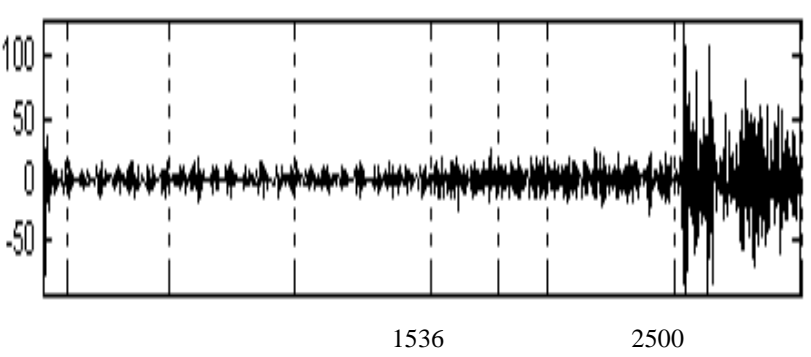

Detalhe (d4)

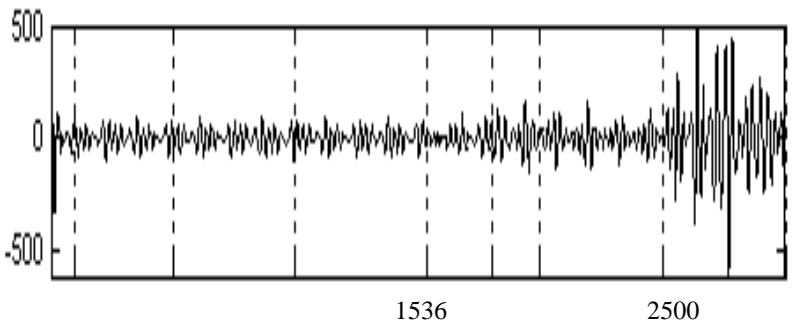

Figura 4.13 - Decomposição da Tensão Fase B (Vb), usando db4. 


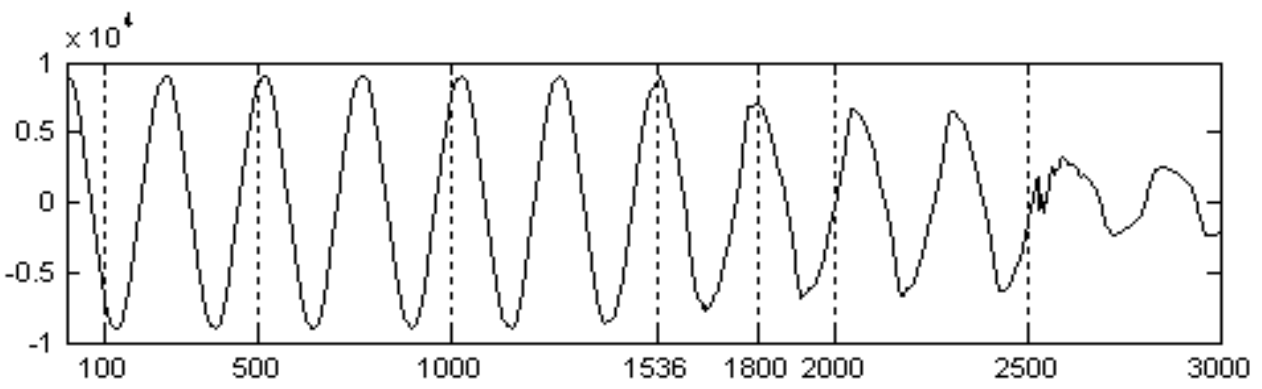

Aproximação (a1)

Detalhe (d1)
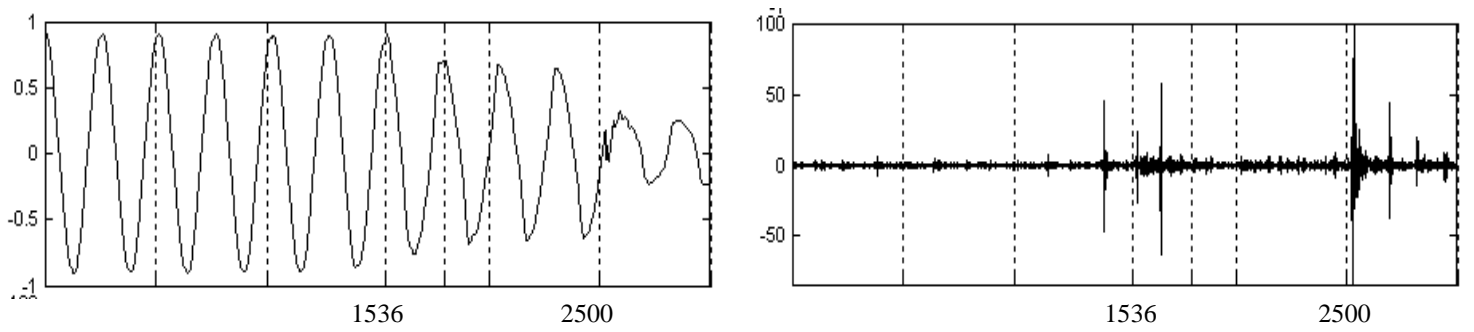

Aproximação (a2)

Detalhe (d2)

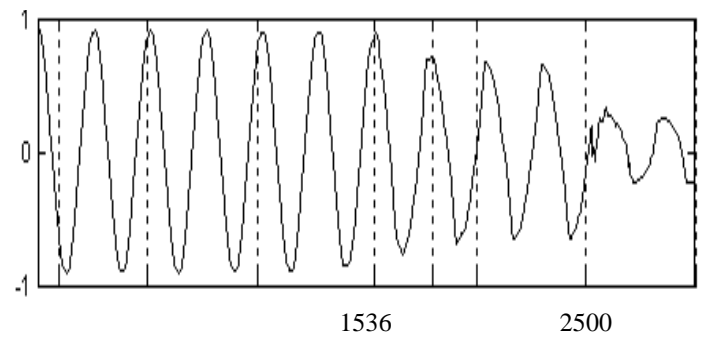

Aproximação (a3)

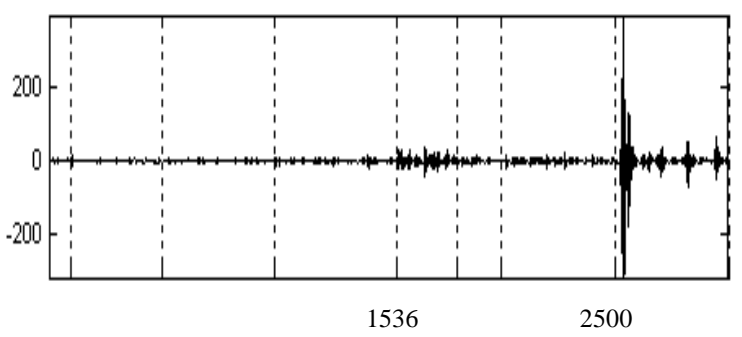

Detalhe (d3)

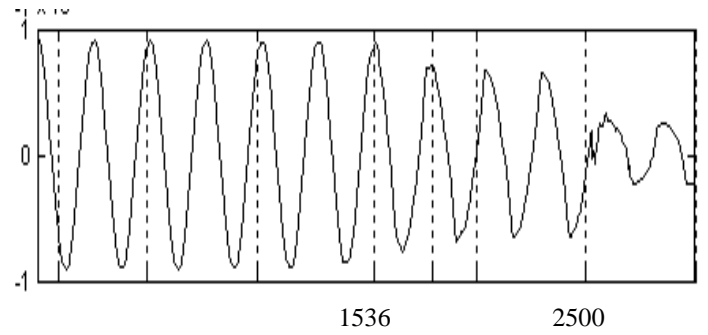

Aproximação (a4)

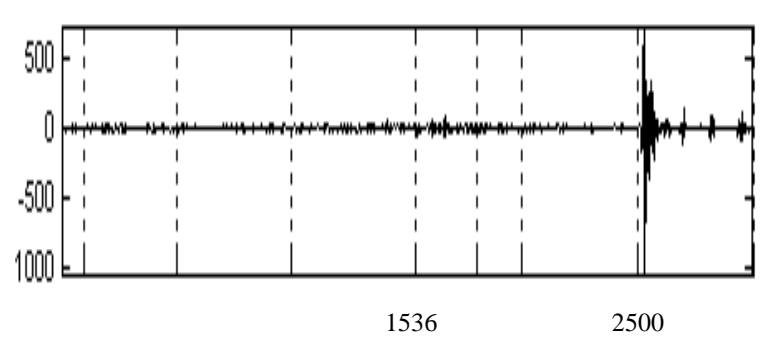

Detalhe (d4)
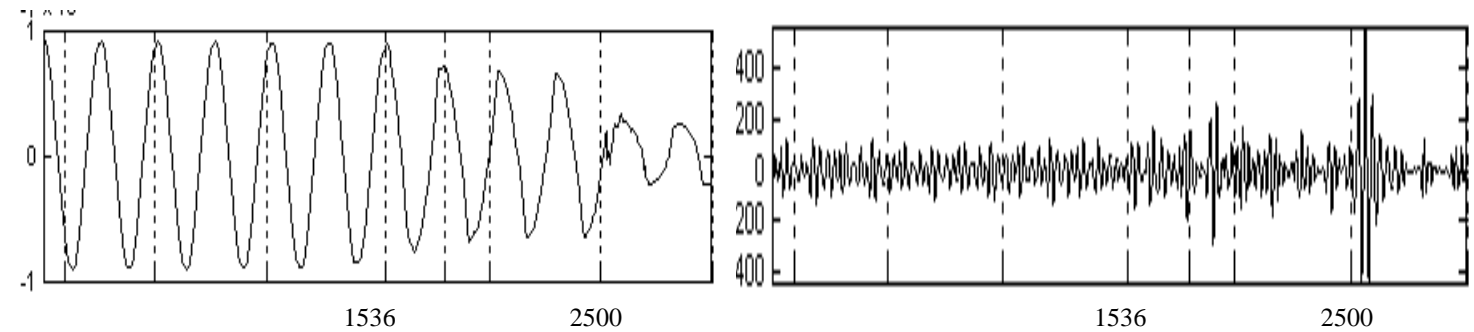

Figura 4.14 - Decomposição da Tensão Fase C (Vc), usando db4. 


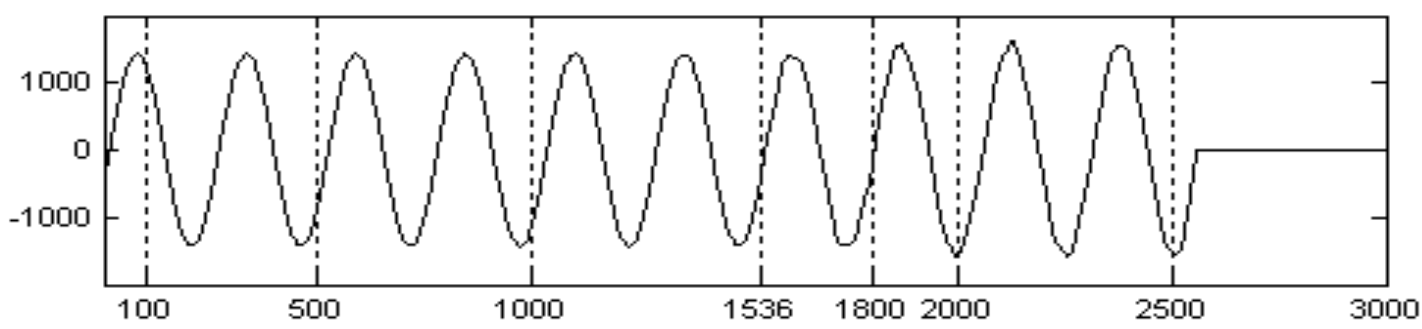

Aproximação (a1)

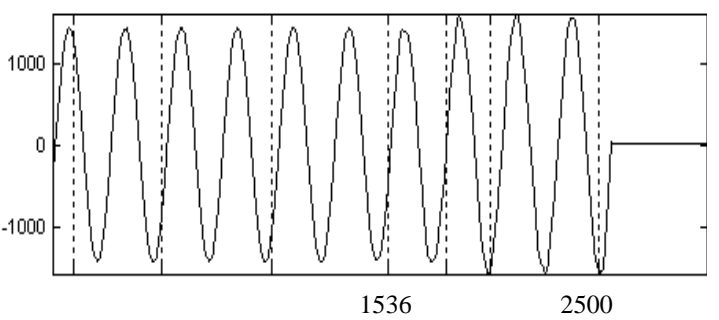

Aproximação (a2)

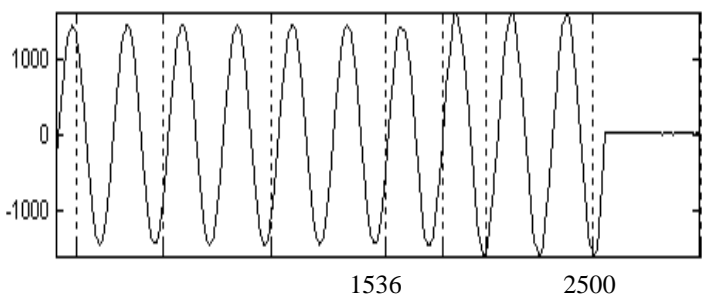

Aproximação (a3)

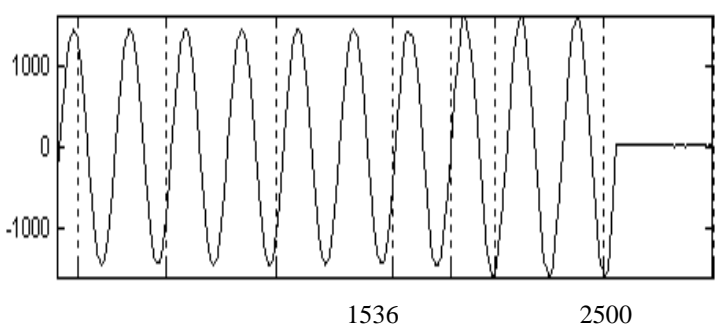

Aproximação (a4)

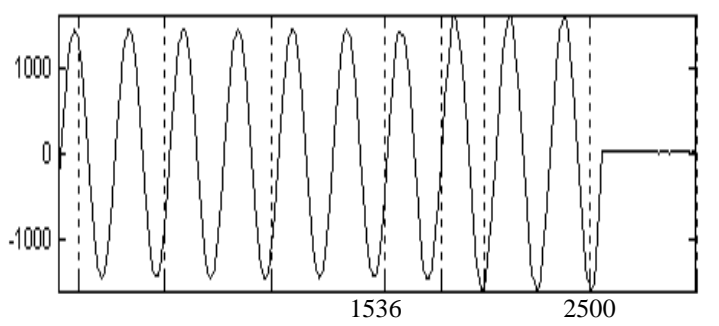

Detalhe (d1)

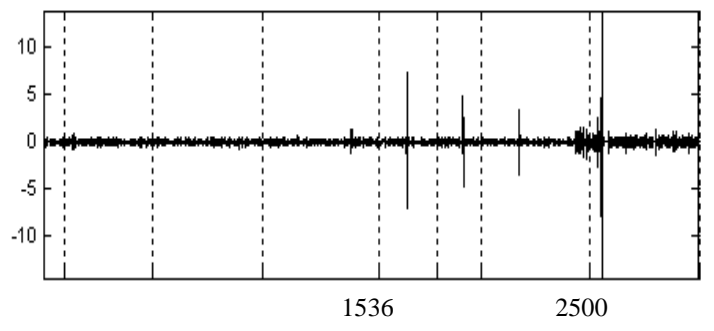

Detalhe (d2)

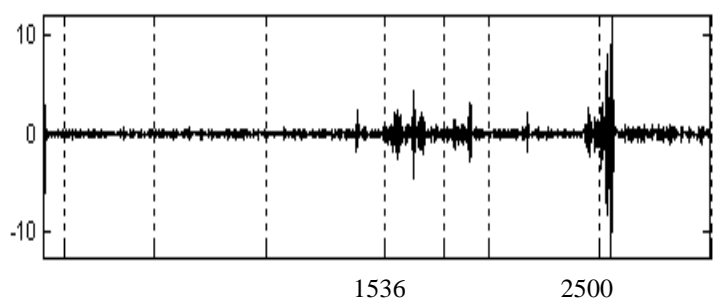

Detalhe (d3)

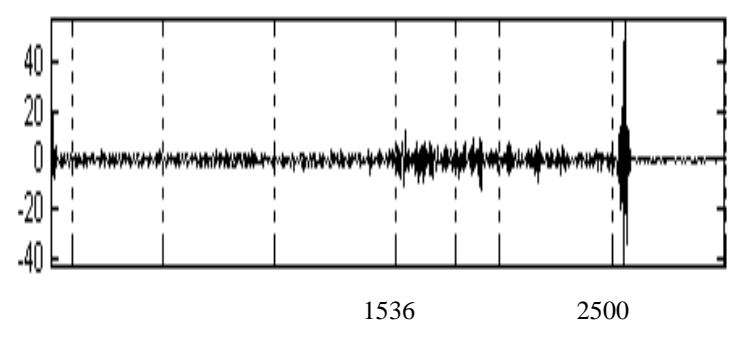

Detalhe (d4)

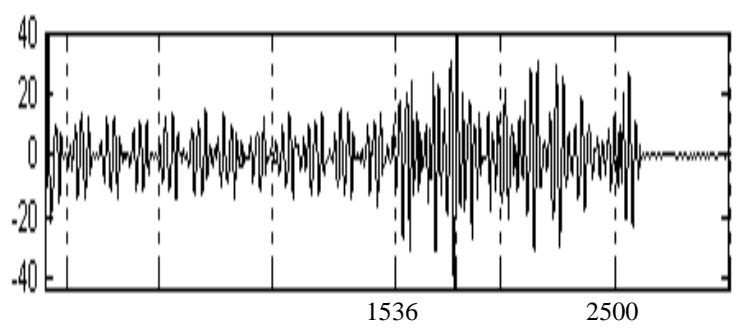

Figura 4.15 - Decomposição da Corrente Fase A (Ia), usando db4. 


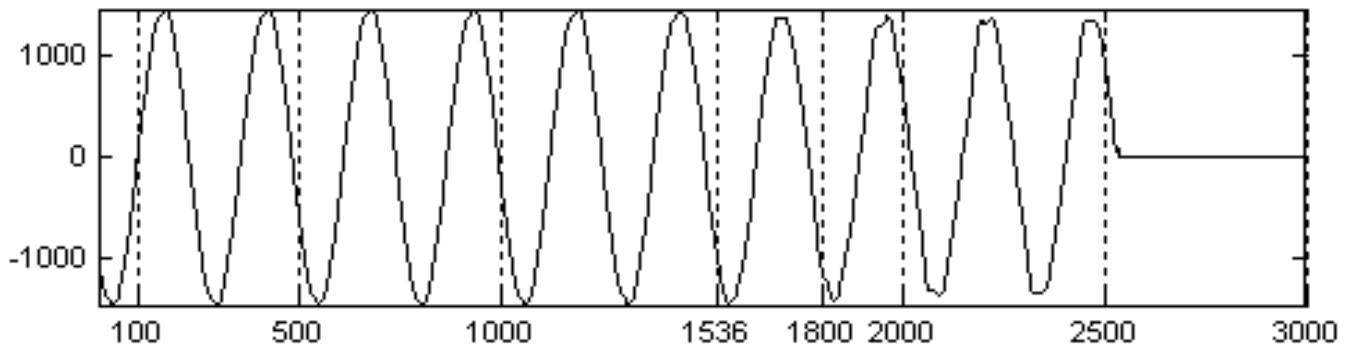

Aproximação (a1)

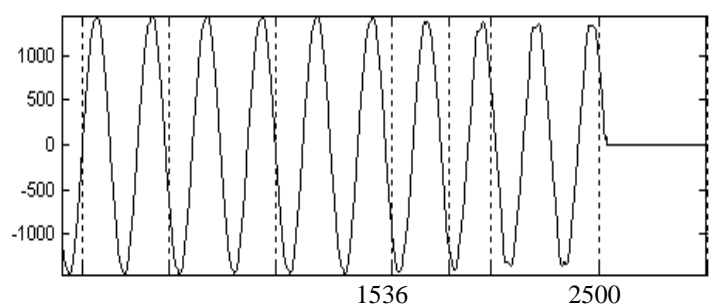

Aproximação (a2)

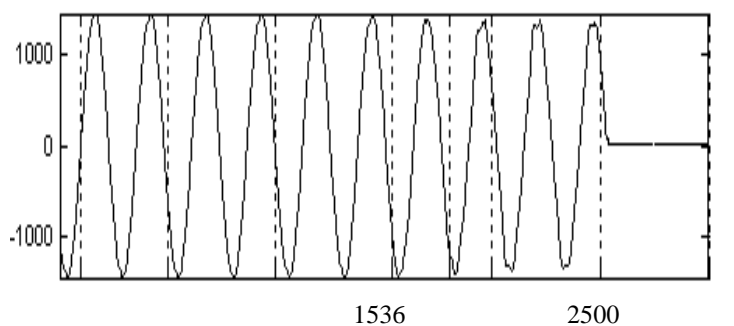

Aproximação (a3)

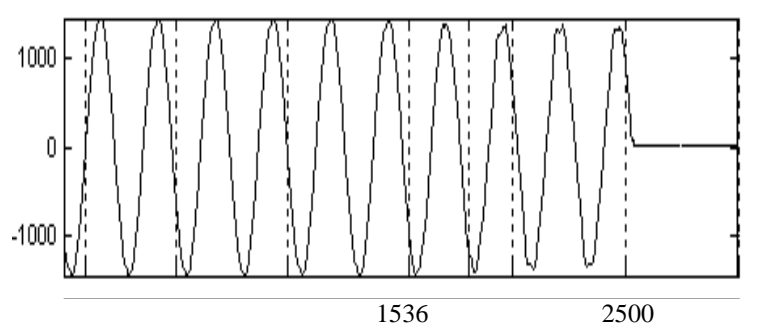

Aproximação (a4)
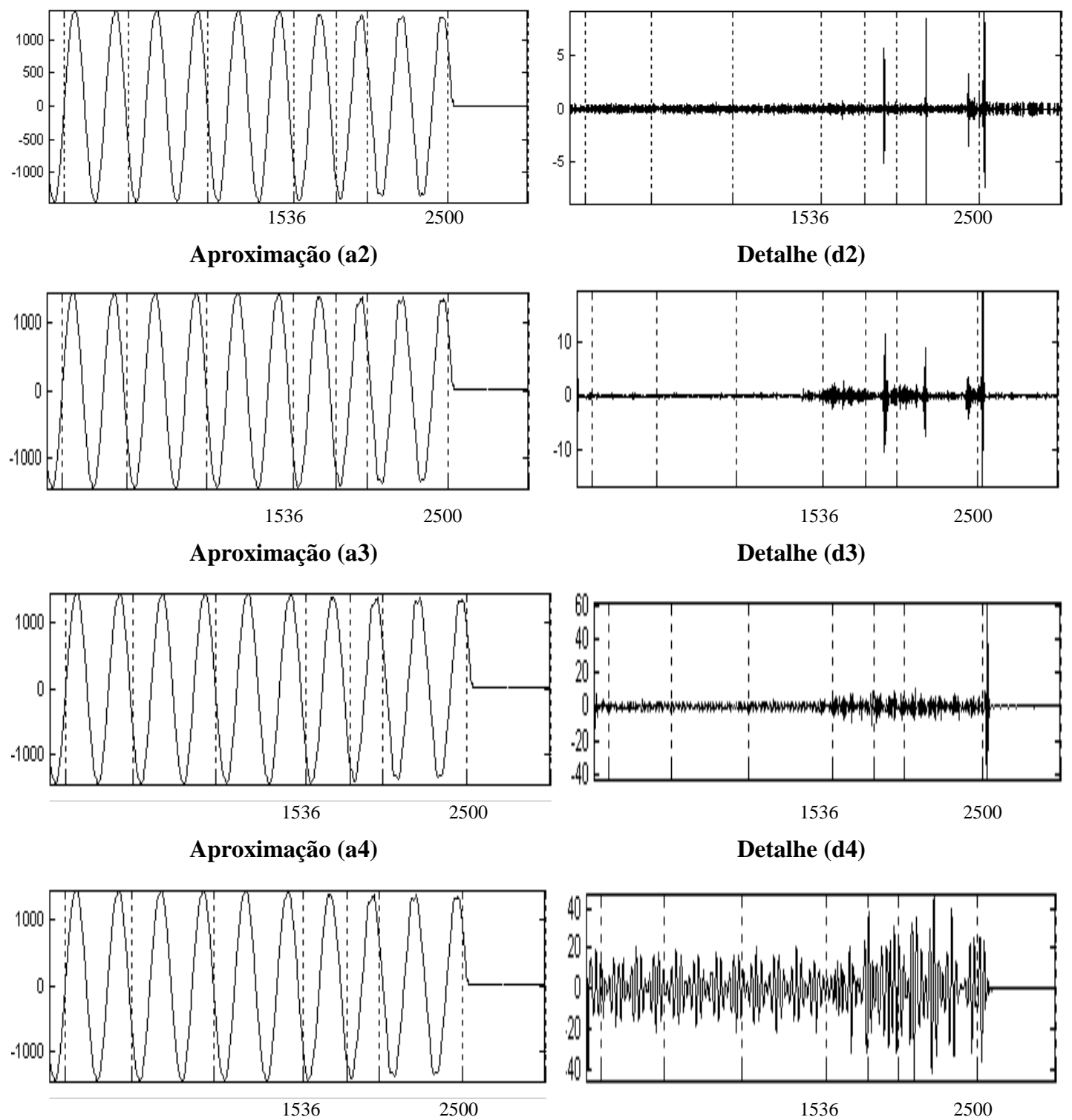

Detalhe (d2)

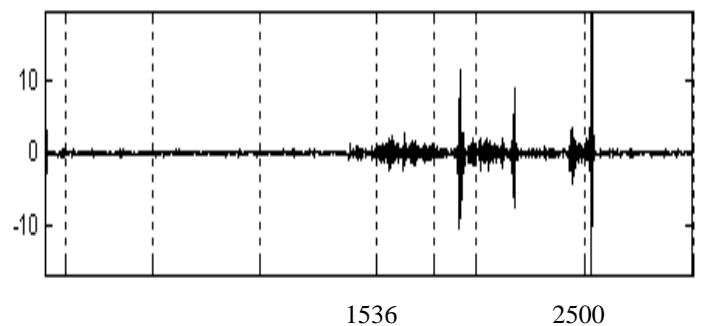

Detalhe (d3)

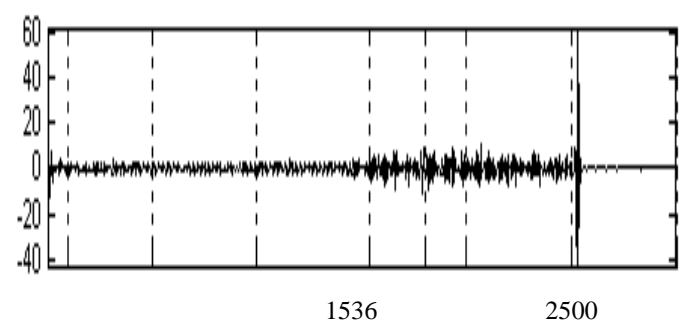

Detalhe (d4)

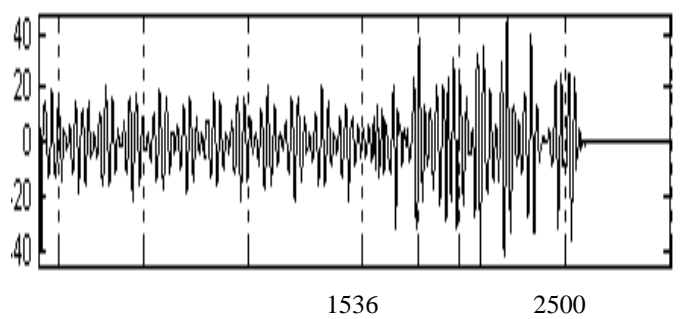

Figura 4.16 - Decomposição da Corrente Fase B (Ib), usando db4. 


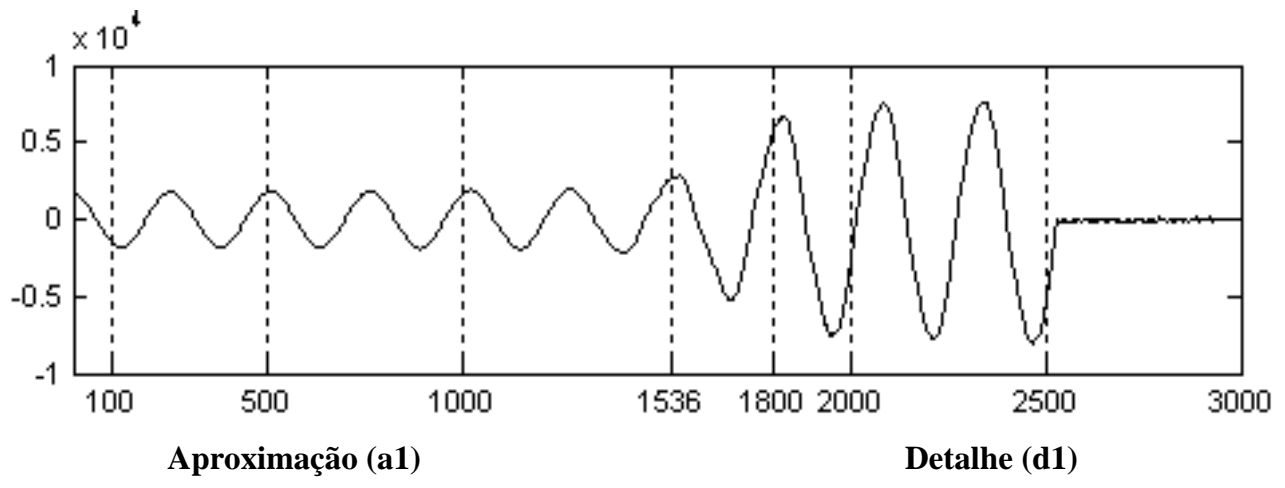

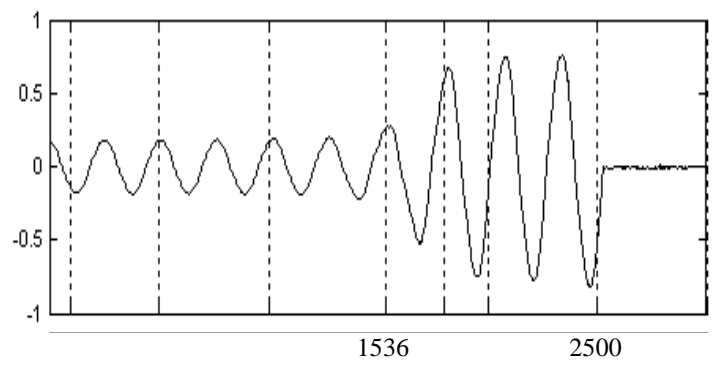

Aproximação (a2)

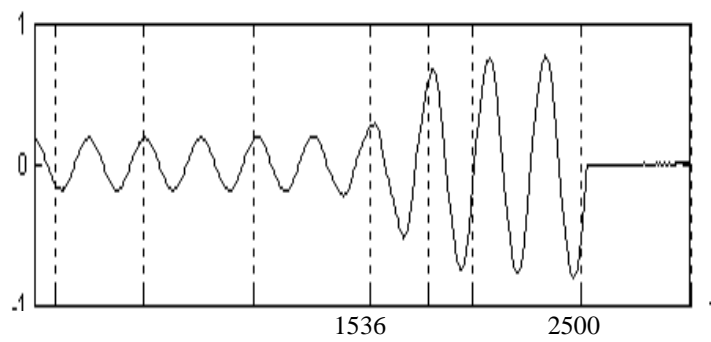

Aproximação (a3)

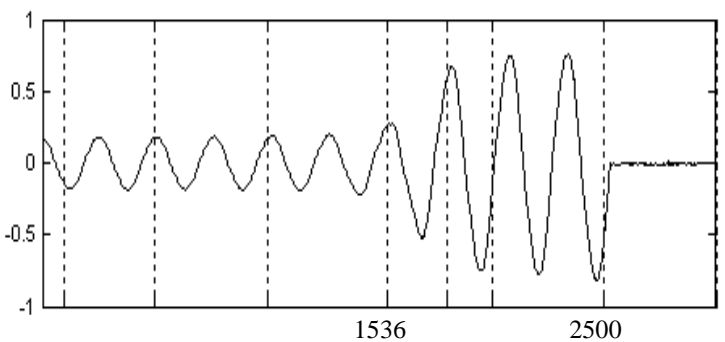

Aproximação (a4)

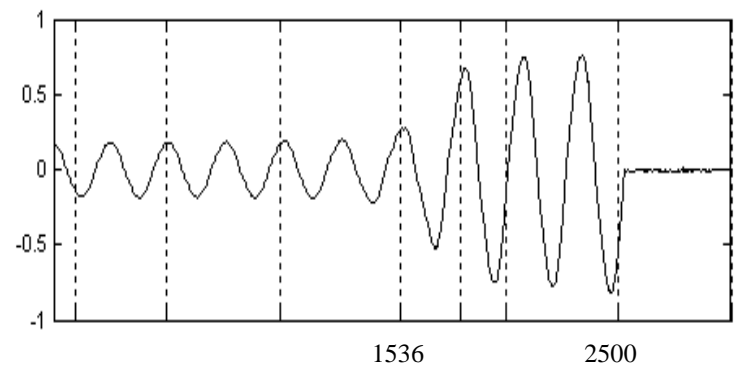

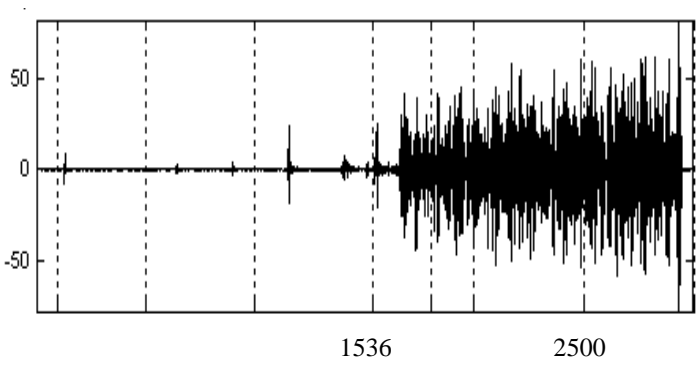

Detalhe (d2)

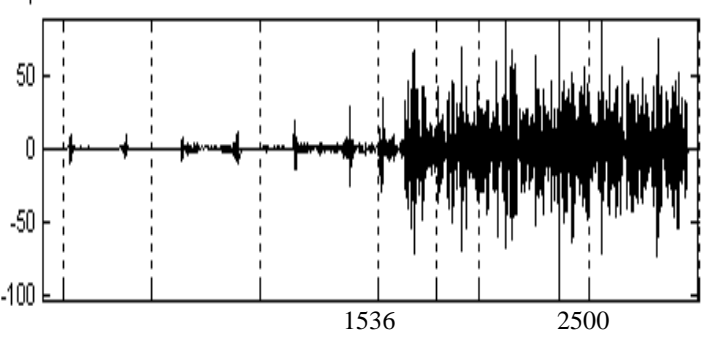

Detalhe (d3)

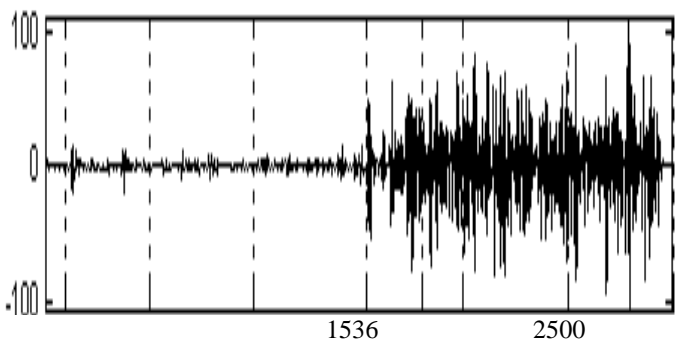

Detalhe (d4)

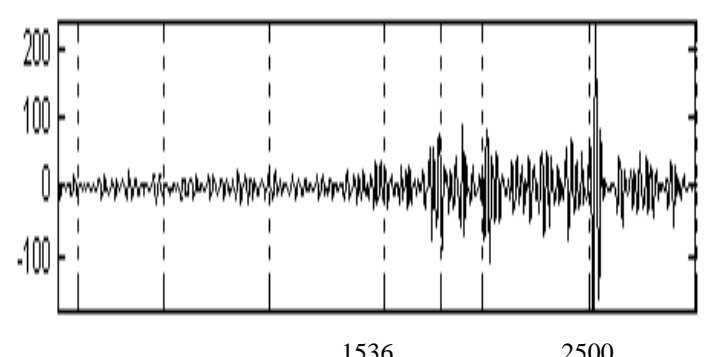

Figura 4.17 - Decomposição da Corrente Fase C (Ic), usando db4. 


\subsection{Análise de Fourier}

\subsubsection{Introdução}

Os profissionais responsáveis pela análise de sinais têm a sua disposição uma grande quantidade de ferramentas. Talvez a mais bem conhecida de todas elas seja a Transformada de Fourier, que decompõe o sinal em suas componentes (cossenos e senos) de diferentes freqüências.

Outra maneira de se pensar na Transformada de Fourier é como uma técnica matemática para transformar o sinal observado no domínio do tempo para o domínio da freqüência.

A maioria dos sinais contém numerosas características não estacionárias ou transitórias, tais como: tendências, mudanças abruptas (descontinuidades) e no início ou final de eventos, mas não tem repetitividade no tempo. Estas características são geralmente as partes mais importantes de um sinal e a Transformada de Fourier (TF) é ineficaz para detectar tais processos, necessitando uma extensão de seu conceito a "Short Time Fourier Transform" (STFT).

Variações de freqüências dependentes do tempo são muito comuns na música, voz humana, sinais sísmicos, sinais de correntes não estacionários, entre outras. Para estudar tais sinais, deve-se efetuar uma transformada capaz de obter o conteúdo de freqüência de um sinal localmente no tempo.

Existem dois métodos desenvolvidos e que apresentam tais propriedades: A Transformada de Fourier de Curta Duração (STFT) e a Transformada Wavelet TW. 


\subsubsection{Transformada de Fourier de Curta Duração (STFT)}

Num esforço para corrigir a deficiência encontrada na Transformada de Fourier, Dennis Gabor (1946) adaptou a Transformada de Fourier para analisar apenas uma pequena seção ou parte do sinal, aplicando uma técnica chamada de janelamento do sinal (Windowing). A adaptação de Gabor, chamada de Transformada de Fourier de Curta Duração, seleciona uma determinada janela e aplicam-se pesos aos valores amostrados. Estes pesos seguem uma curva gaussiana com eixo no meio da janela.

\subsubsection{Metodologia utilizada para determinação dos tempos de operação}

O sinal de entrada que será submetido ao algoritmo de cálculo de tempos consiste em "vetores" que compreendem os pontos amostrados da oscilografia das correntes e tensões de linha para cada uma das fases.

Para detectar o começo da abertura física do disjuntor procura-se pela alteração da freqüência e a geração de componentes harmônicas em diferentes janelas contendo 1 ciclo $(60 \mathrm{~Hz})$ de amostras iniciadas no primeiro pico, através da aplicação da Transformada de Fourier janelada. A Figura 4.18 ilustra a corrente da Fase C em estudo, sendo que a amostra 1536 indica a detecção do curto pelo relé.

\section{SE Sumare Corrente na Fase C}

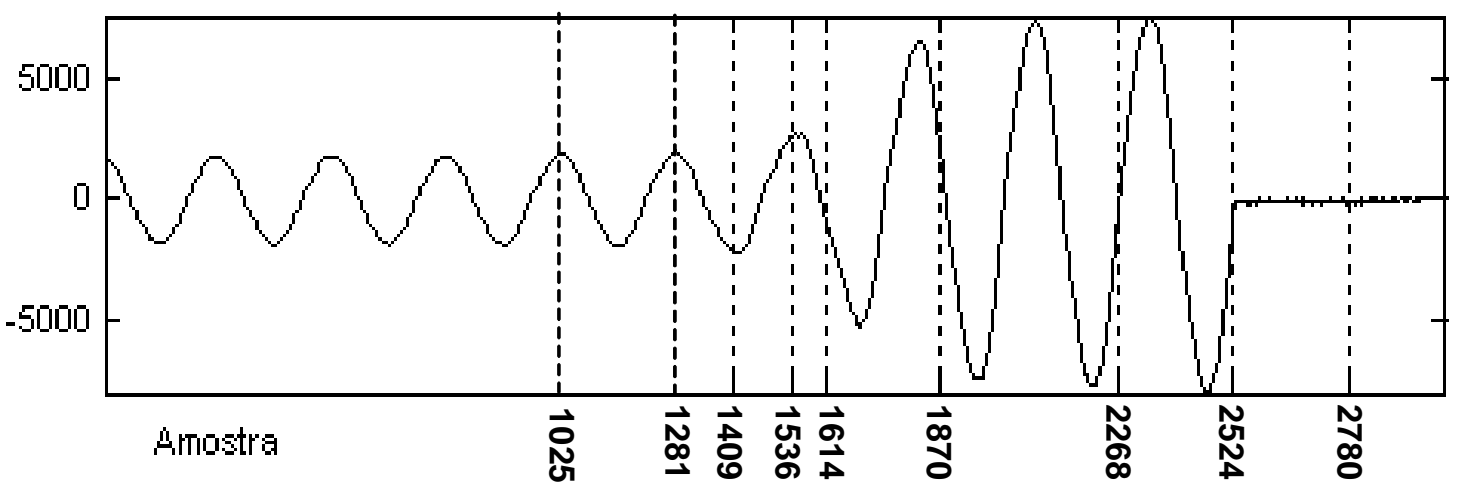

Figura 4.18 - Oscilografia da Corrente na Fase C, com intervalos de amostragem. 
Nas Figuras 4.19 até 4.24 são ilustrados os espectros de freqüência das tensões e correntes das três fases, aplicando-se a transformada de Fourier janelada (STFT) para janelas de 256 amostras ( 1 ciclo a 60Hz), portanto, uma freqüência de amostragem de 15,4 kHz. Onde pode-se observar que meio ciclo antes do tempo de disparo (tripping) do relé de proteção na amostra 1536 (0,010 segundo) começam a aparecer freqüências maiores que $60 \mathrm{~Hz}$ (cor vermelha), posteriormente a essa amostra fica mais claro observar a aparição de freqüências altas na faixa de $\mathrm{kHz}$ precisamente no momento da separação física dos contatos na operação de abertura do disjuntor, sendo mais notório este fenômeno na Fase $\mathrm{C}$ onde se originou a falta.

Pode-se observar também a mudança da energia antes e depois do disparo do disjuntor (amostra 1536), sendo que antes da operação do disjuntor tem-se a energia mais fraca (cor azul) e depois tem-se energia mais forte (cor amarelo).
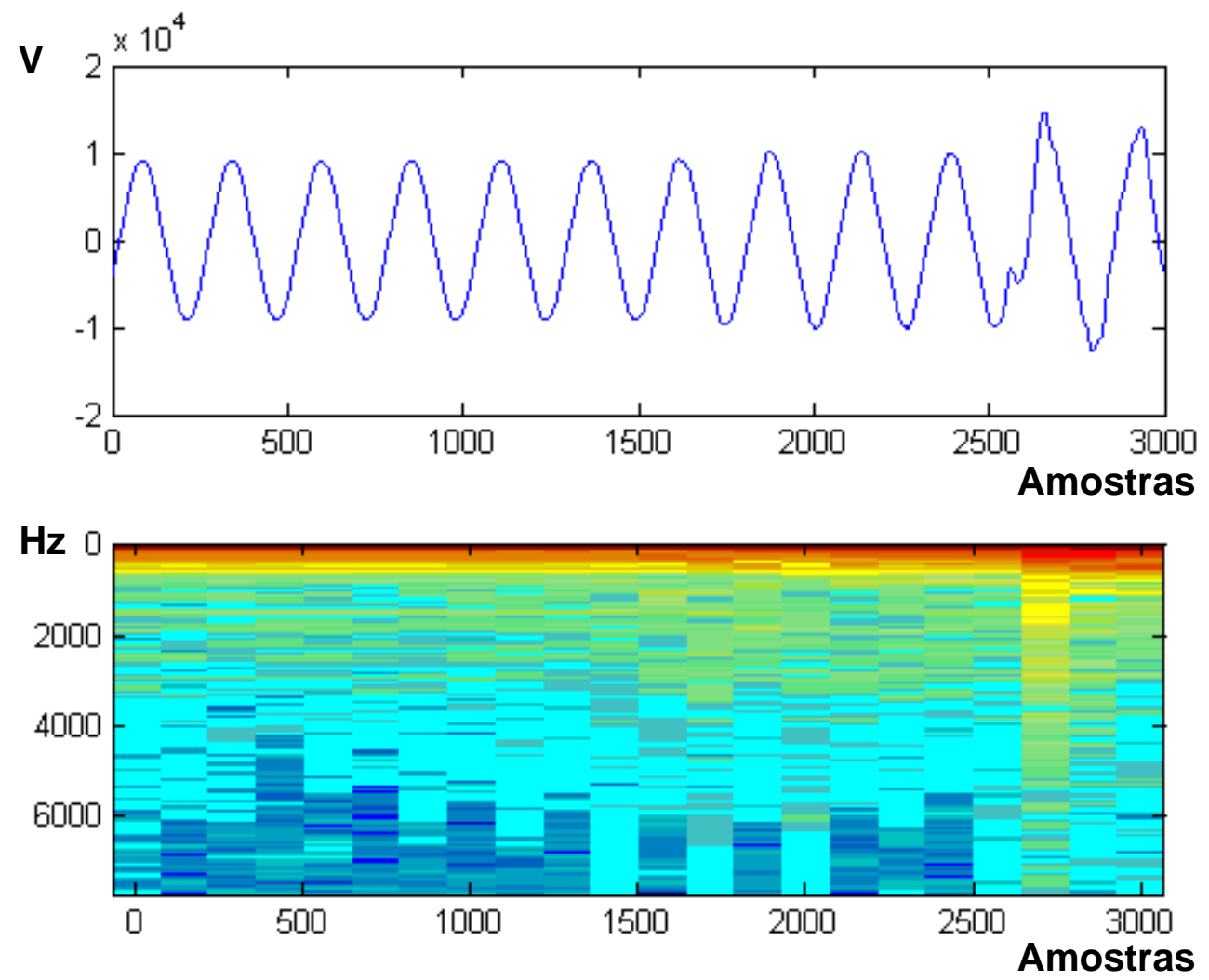

Figura 4.19 - Espectro de freqüencias da Tensão Fase A (Va), usando STFT. 

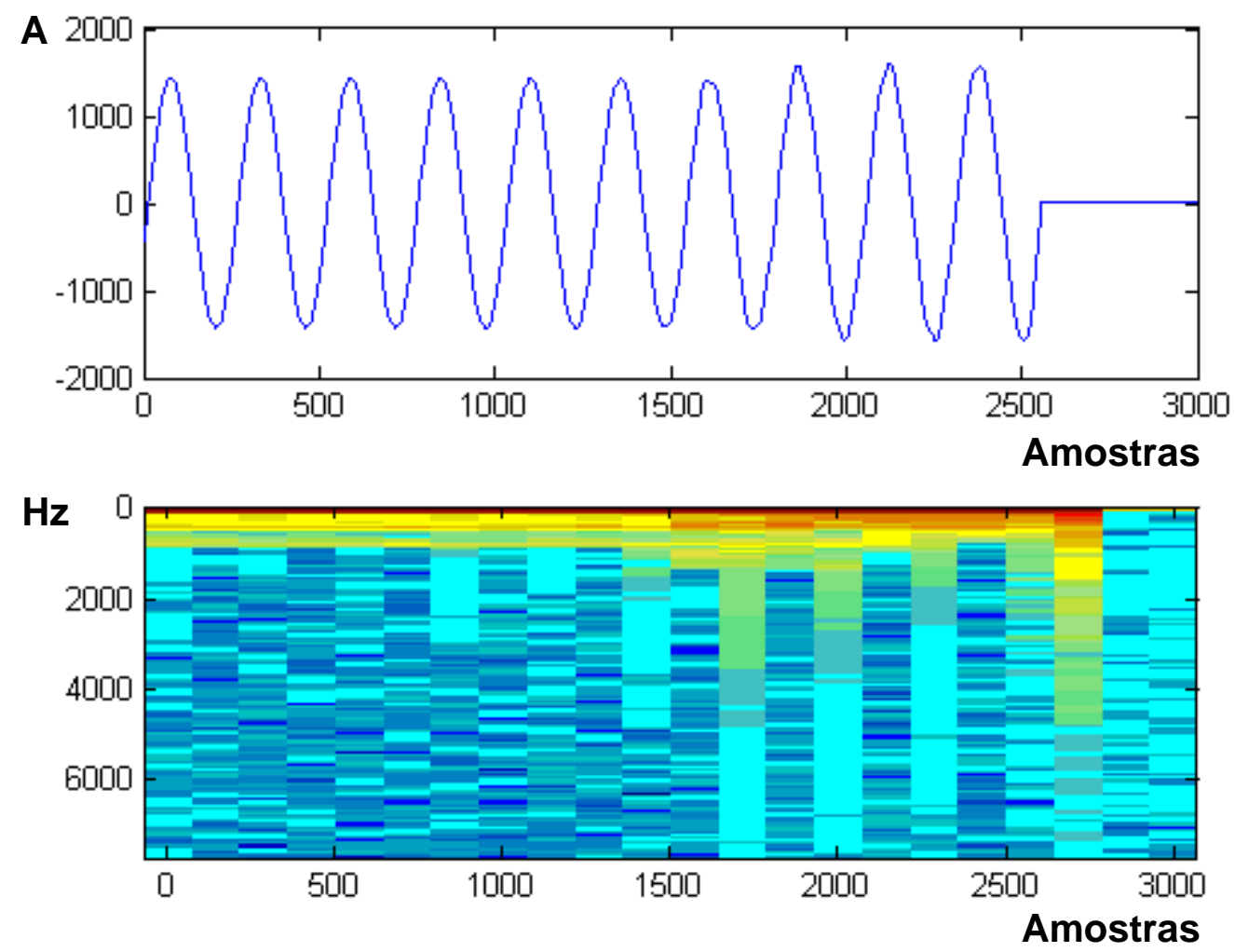

Figura 4.20 - Espectro de freqüências da Corrente Fase A (Ia), usando STFT.
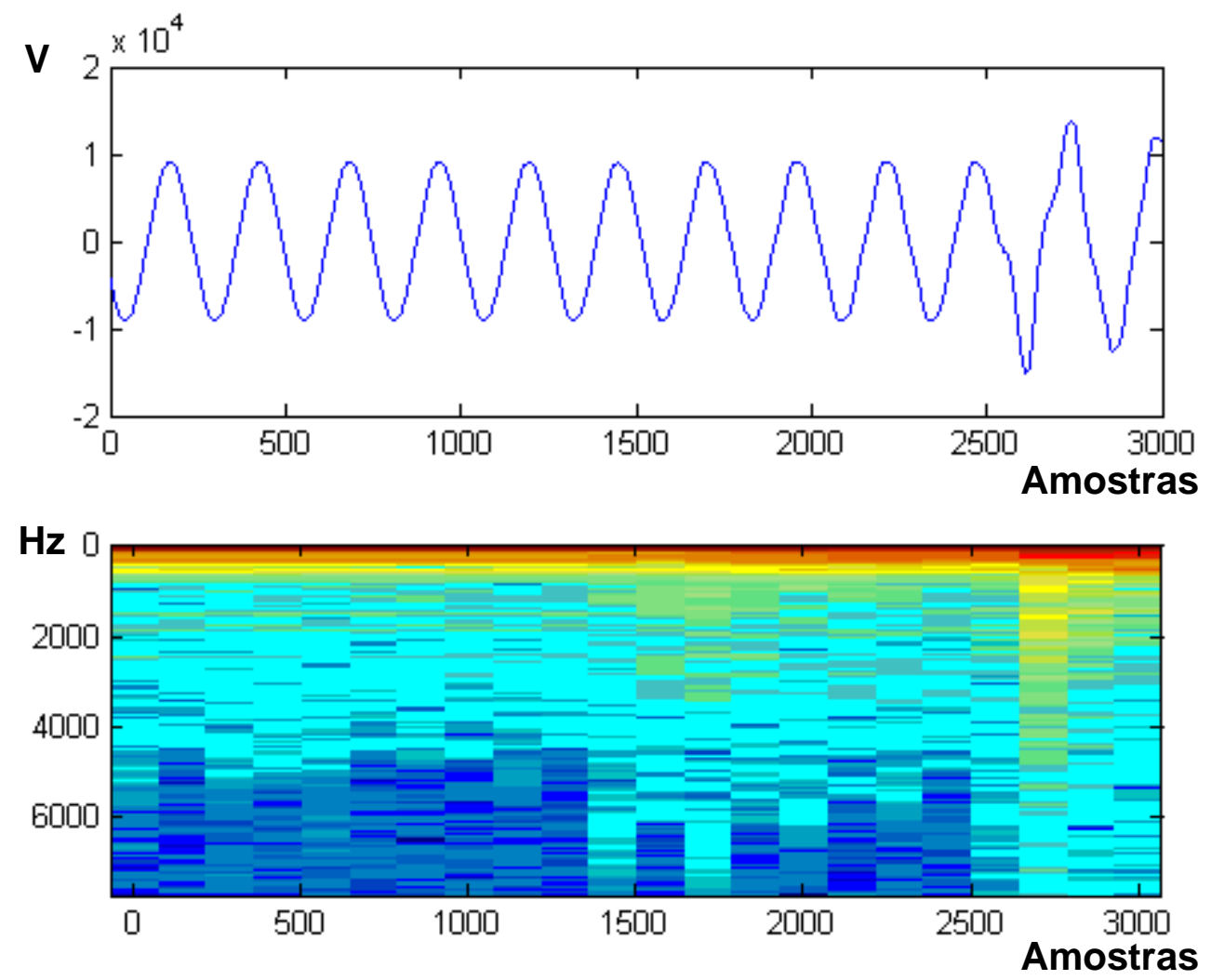

Figura 4.21 - Espectro de freqüencias da Tensão Fase B (Vb), usando STFT. 

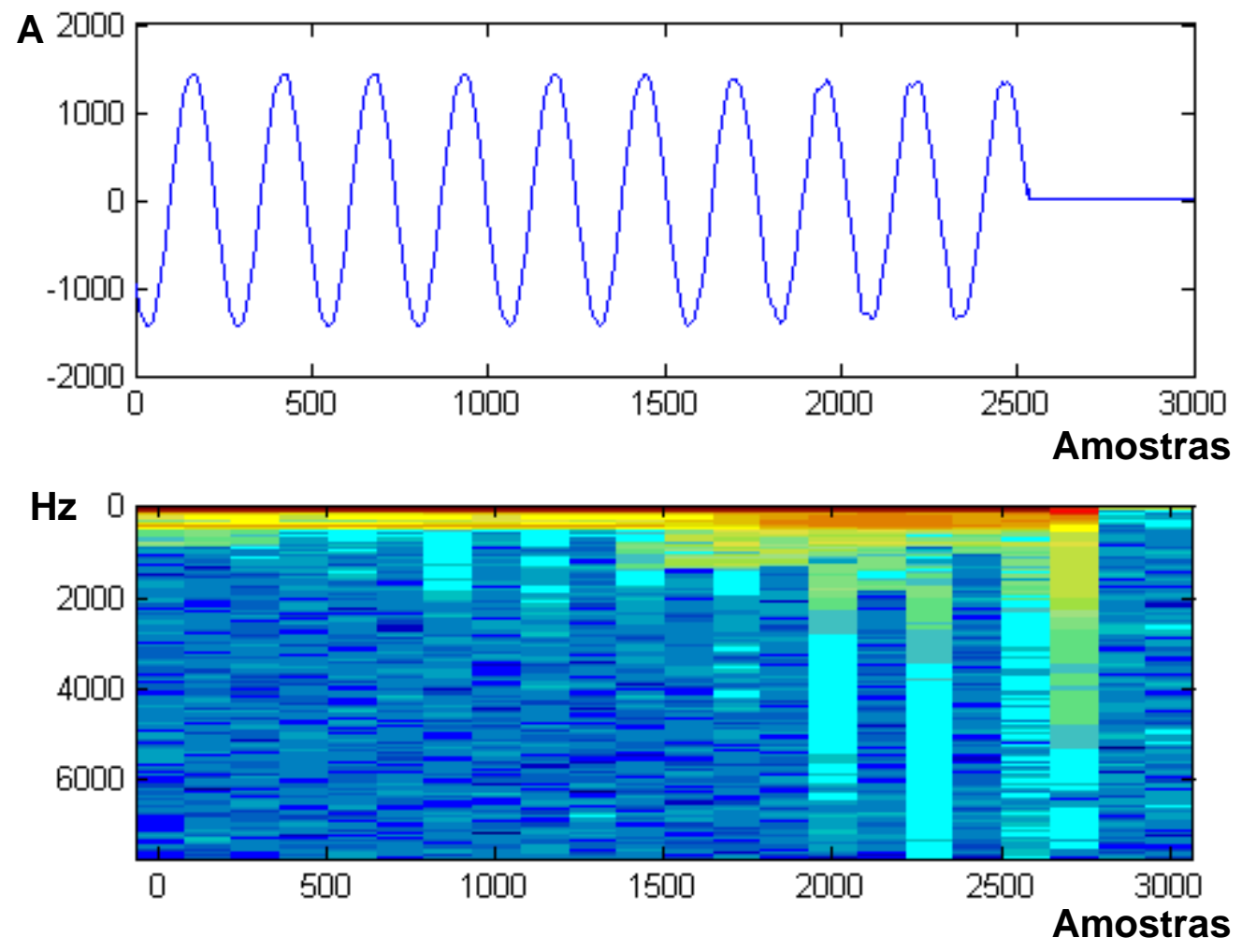

Figura 4.22 - Espectro de freqüências da Corrente Fase B (Ib), usando STFT.
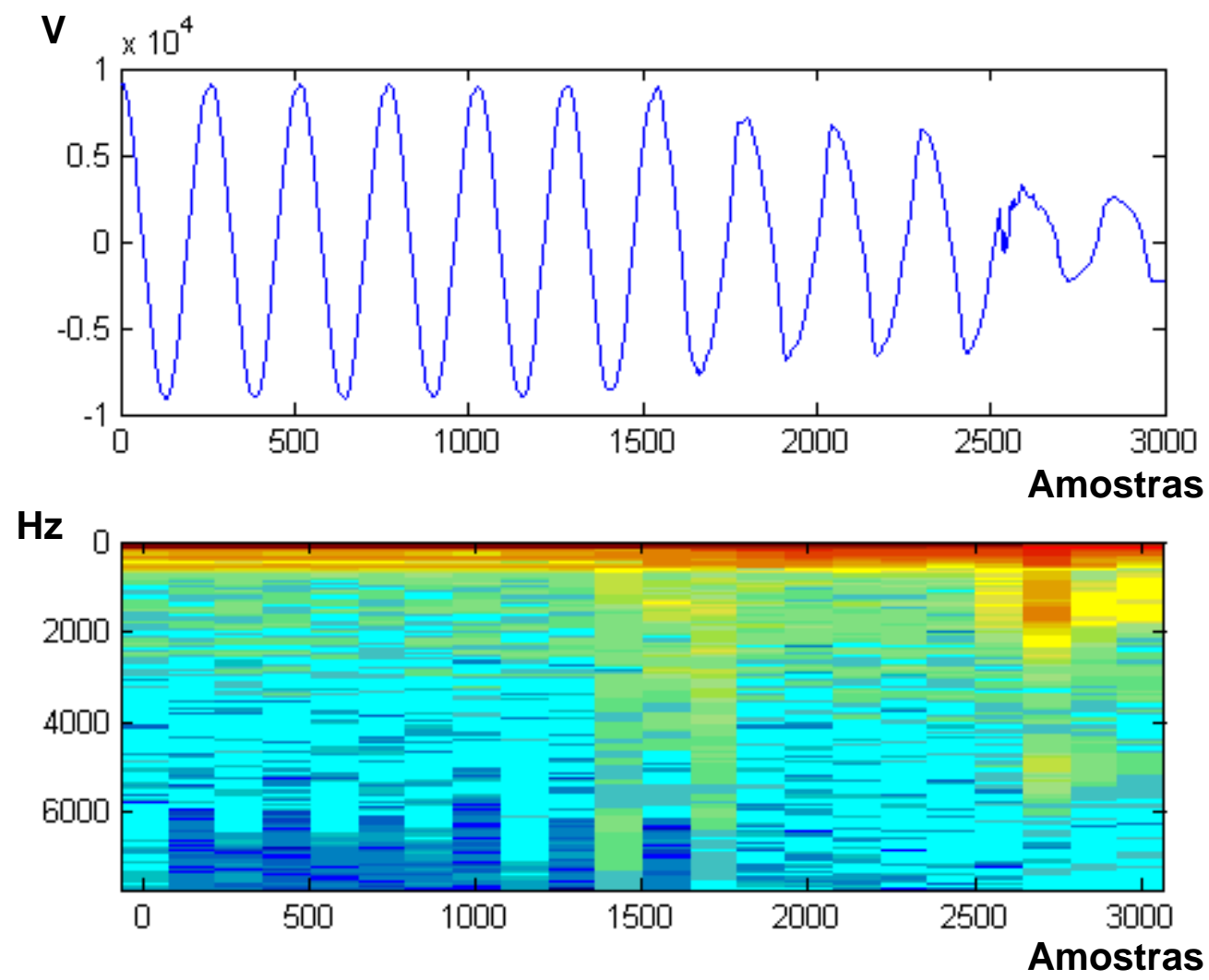

Figura 4.23 - Espectro de freqüencias da Tensão Fase C (Vc), usando STFT. 

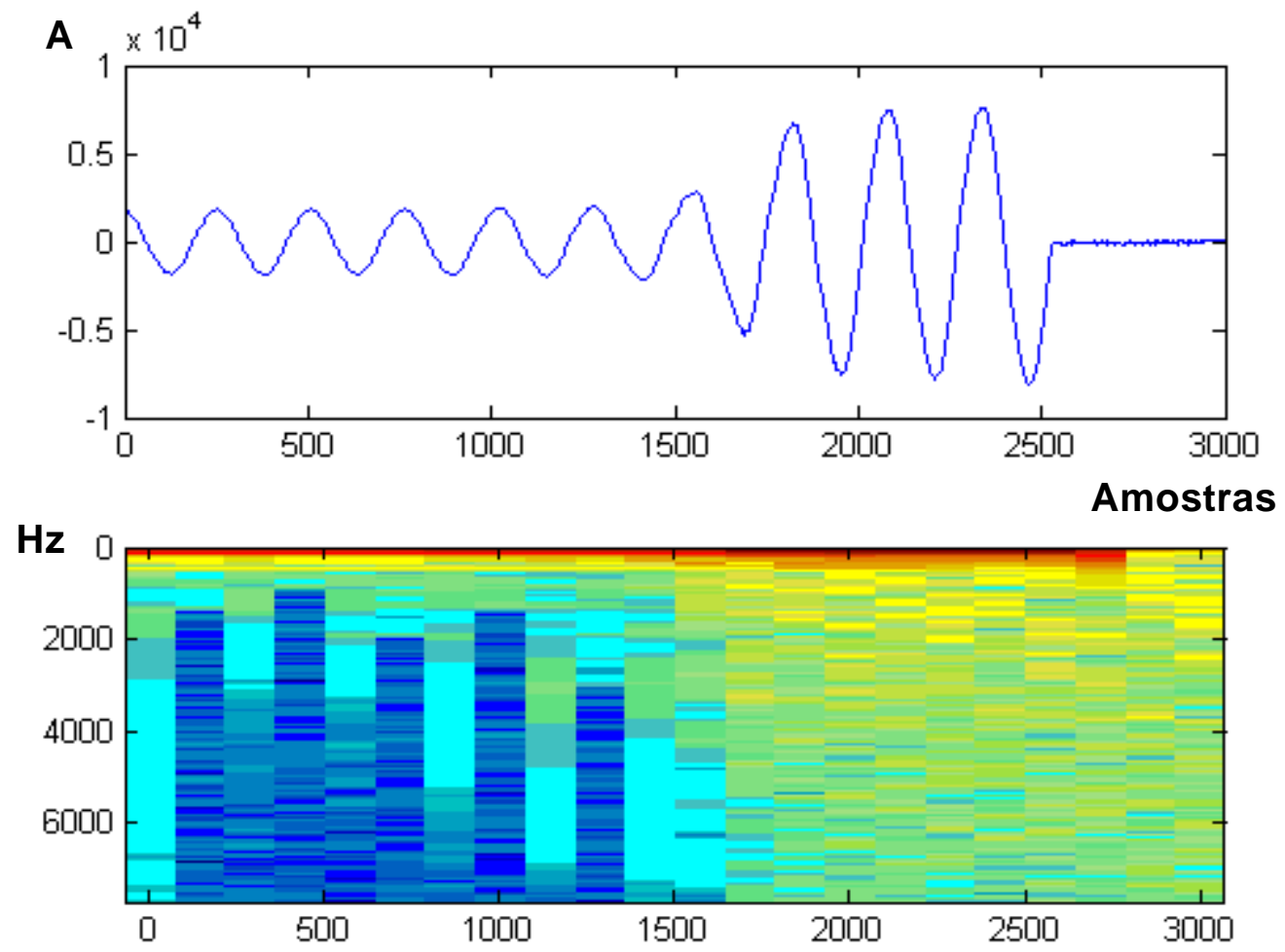

Figura 4.24 - Espectro de freqüencias da Corrente Fase C (Ic), usando STFT.

Calculando o THD (Total Harmonic Distortion) da Corrente na Fase C (Figura 4.24), em cinco ciclos compreendidos entre a amostra 950 e 2230, com intervalos de tempo de: primeiro (0,06249 a 0,07916 s), segundo $(0,07916$ a 0,09583$)$, terceiro $(0,09583$ a $0,1125)$, quarto $(0,1125$ a 0,12917$)$ e quinto ciclo $(0,12917$ a 0,14584$)$, pode-se observar que no momento da ocorrência da falta segundo e terceiro ciclo, aparecem freqüências altas, diferentes do $60 \mathrm{~Hz}$ (harmônicas), como pode-se observar nos valores identificados para cada ciclo em negrito utilizando a transformada de Fourier de curto tempo (STFT).

MC's PlotXY - Fourier chart(s). Copying date: 14/12/2004 File 200902.CFG

Variable C: Corrente -LT-Sumaré [peak] Initial Time: 0,06249 Final Time: 0,07916

Harm. Amplitude Phase

$\begin{array}{lll}0 & -4,8644 & 0,0000 \mathrm{E}+00 \\ \mathbf{1} & \mathbf{1 2 3 7 , 9} & \mathbf{7 , 7 8 4 2} \\ 2 & 8,4067 & 31,897 \\ 3 & 50,468 & 118,84 \\ 4 & 3,9767 & -10,814 \\ 5 & 7,0644 & 50,206 \\ 6 & 1,5255 & 49,126 \\ 7 & 12,626 & 119,12 \\ 8 & 1,6102 & 29,988 \\ 9 & 0,90053 & 27,009 \\ 10 & 0,81875 & 9,1188\end{array}$




$\begin{array}{lll}20 & 0,58116 & -152,71 \\ 30 & 0,4136 & 29,076 \\ 40 & 0,42605 & -37,572 \\ 50 & 1,0706 & 69,718 \\ 60 & 0,25932 & -126,57 \\ 70 & 0,52166 & 51,774 \\ 80 & 0,081785 & -164,03 \\ 90 & 0,3473 & 53,746 \\ \mathbf{1 0 0} & \mathbf{0 , 0 5 3 2 3 2} & \mathbf{1 3 0 , 6}\end{array}$

THD $=4,3363 \%$

MC's PlotXY - Fourier chart(s). Copying date: 14/12/2004 File 200902.CFG

Variable C: Corrente -LT-Sumaré [peak] Initial Time: 0,07916 Final Time: 0,09583

Harm. Amplitude Phase

$0 \quad-59,391 \quad 0,0000 \mathrm{E}+00$

$1 \quad \mathbf{1 3 4 6 , 7} \quad \mathbf{4 , 3 6 1 4}$

$2 \quad 83,832 \quad 13,963$

$3 \quad 84,545 \quad 97,372$

$4 \quad 19,334 \quad 106,99$

$5 \quad 11,39 \quad 78,013$

$6 \quad 6,9937 \quad 20,605$

$7 \quad 14,874 \quad 109,36$

$8 \quad 4,4268 \quad 45,327$

$9 \quad 2,7858 \quad 62,087$

$10 \quad 2,4462 \quad 70,196$

$20 \quad 0,20056 \quad 99,592$

$30 \quad 0,11181 \quad 51,19$

$40 \quad 1,0698 \quad 45,908$

$50 \quad 0,81938 \quad 0,7712$

$60 \quad 0,47301 \quad 122,96$

$70 \quad 0,53356 \quad 35,567$

$80 \quad 0,13618 \quad 108,33$

$90 \quad 0,43992 \quad 52,62$

$100 \quad 0,18843 \quad 99,443$

THD $=9,1133 \%$

MC's PlotXY - Fourier chart(s). Copying date: 14/12/2004 File 200902.CFG

Variable C: Corrente -LT-Sumaré [peak] Initial Time: 0,09583 Final Time: 0,1125

Harm. Amplitude Phase

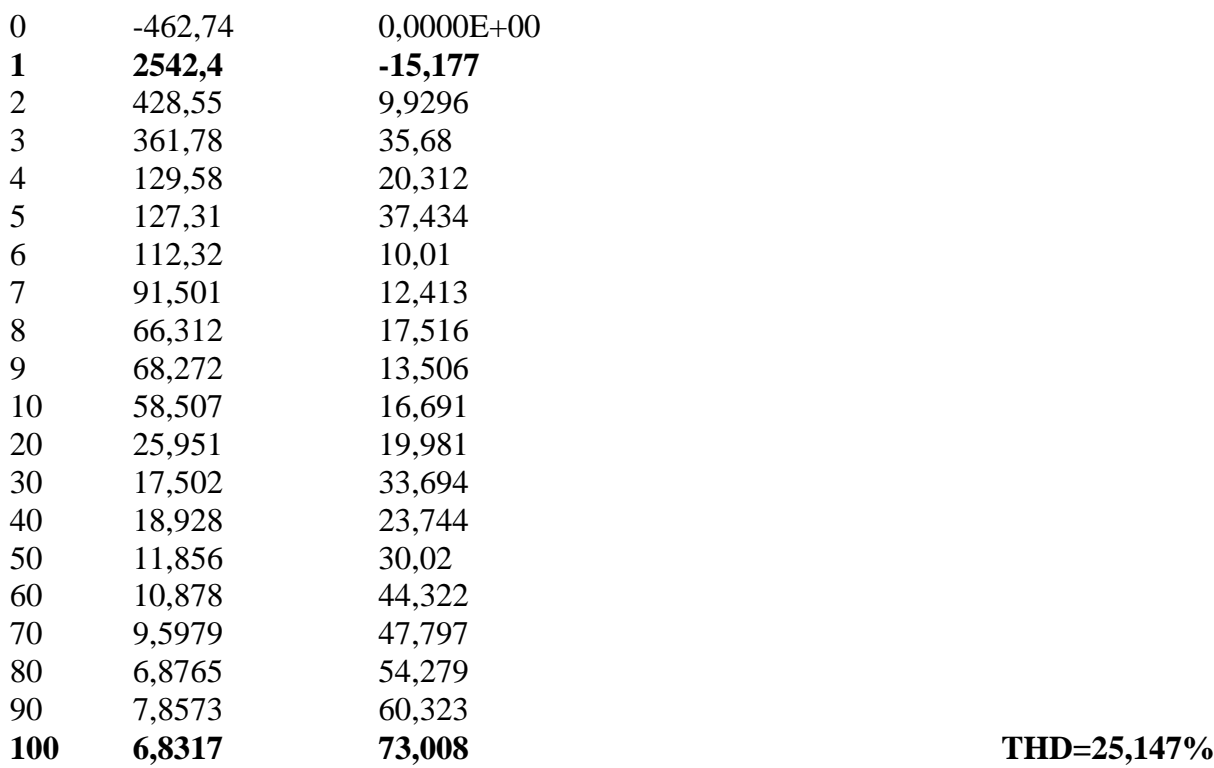


MC's PlotXY - Fourier chart(s). Copying date: 14/12/2004 File 200902.CFG

Variable C: Corrente -LT-Sumaré [peak] Initial Time: 0,1125 Final Time: 0,1292

\begin{tabular}{|c|c|c|}
\hline Harm. & Amplitude & Phase \\
\hline 0 & \multicolumn{2}{|c|}{$-0,838530,0000 \mathrm{E}+00$} \\
\hline 1 & 4565,1 & $-32,534$ \\
\hline 2 & 350,69 & 20,209 \\
\hline 3 & 433,9 & 5,2414 \\
\hline 4 & 182,93 & 17,141 \\
\hline 5 & 166,02 & $-9,0181$ \\
\hline 6 & 140,59 & $-5,9785$ \\
\hline 7 & 63,038 & 17,593 \\
\hline 8 & 69,424 & 10,164 \\
\hline 9 & 59,086 & 5,3597 \\
\hline 10 & 56,782 & 1,2063 \\
\hline 20 & 32,822 & 8,7743 \\
\hline 30 & 17,514 & 19,786 \\
\hline 40 & 15,146 & 20,403 \\
\hline 50 & 11,756 & 30,304 \\
\hline 60 & 13,956 & 41,146 \\
\hline 70 & 10,133 & 69,657 \\
\hline 80 & 9,4529 & 57,851 \\
\hline 90 & 12,027 & 83,699 \\
\hline 100 & 8,7024 & 63,494 \\
\hline
\end{tabular}

THD $=14,563 \%$

MC's PlotXY - Fourier chart(s). Copying date: 14/12/2004 File 200902.CFG

Variable C: Corrente -LT-Sumaré [peak] Initial Time: 0,1292 Final Time: 0,1458

Harm. Amplitude Phase

$\begin{array}{lll}0 & -19,312 & 0,0000 \mathrm{E}+00 \\ \mathbf{1} & \mathbf{4 9 5 6 , 3} & \mathbf{- 4 0 , 2 9 2} \\ 2 & 70,965 & -3,8644 \\ 3 & 247,21 & -18,318 \\ 4 & 35,357 & 9,3999 \\ 5 & 66,904 & -69,048 \\ 6 & 12,491 & -55,197 \\ 7 & 38,463 & 60,562 \\ 8 & 17,19 & 18,592 \\ 9 & 18,151 & -9,8694 \\ 10 & 17,65 & 21,267 \\ 20 & 11,238 & 53,26 \\ 30 & 5,1058 & -18,812 \\ 40 & 10,668 & 32,151 \\ 50 & 8,4053 & 25,157 \\ 60 & 2,189 & -87,788 \\ 70 & 2,5017 & 63,812 \\ 80 & 4,6126 & 58,437 \\ 90 & 2,7539 & 38,552 \\ \mathbf{1 0 0} & \mathbf{1 , 3 3 5 5} & \mathbf{- 1 6 7 , 5 6}\end{array}$




\section{CAPÍTULO 5}

\section{MEDIÇÕES EFETUADAS NO PROTÓTIPO}

\subsection{Introdução}

Uma vez terminada a instalação física (Hardware) do protótipo na subestação de Sumaré $440 \mathrm{kV}$ (ETEO), iniciou-se o processo de parametrização, verificação e coleta dos dados coletados pelas remotas através dos sensores instalados nos disjuntores. Neste capítulo busca-se ilustrar as informações obtidas do sistema de monitoramento do protótipo através de gráficos, telas e relatórios que permitem uma melhor manutenção preventiva dos equipamentos, assim como um melhor gerenciamento das equipes de manutenção.

\subsection{Arquitetura do Sistema de Monitoramento}

O protótipo do sistema de monitoramento está composto por um grupo de equipamentos incluindo uma Unidade de Aquisição de Dados e Controle (UAC) para a coleta e processamento dos dados, interfaces de conversão de sinais analógicos e digitais, por exemplo, (para a aquisição das correntes e tensões das fases com alta freqüência de amostragem), um computador central que processa, armazena os dados e que cumpre a função de Interface Homem Máquina (IHM), protocolos padrões de comunicação, além do conjunto de transdutores e outros dispositivos que enlaçam os diferentes componentes. Sua arquitetura geral encontra-se ilustrada na Figura 5.1. 


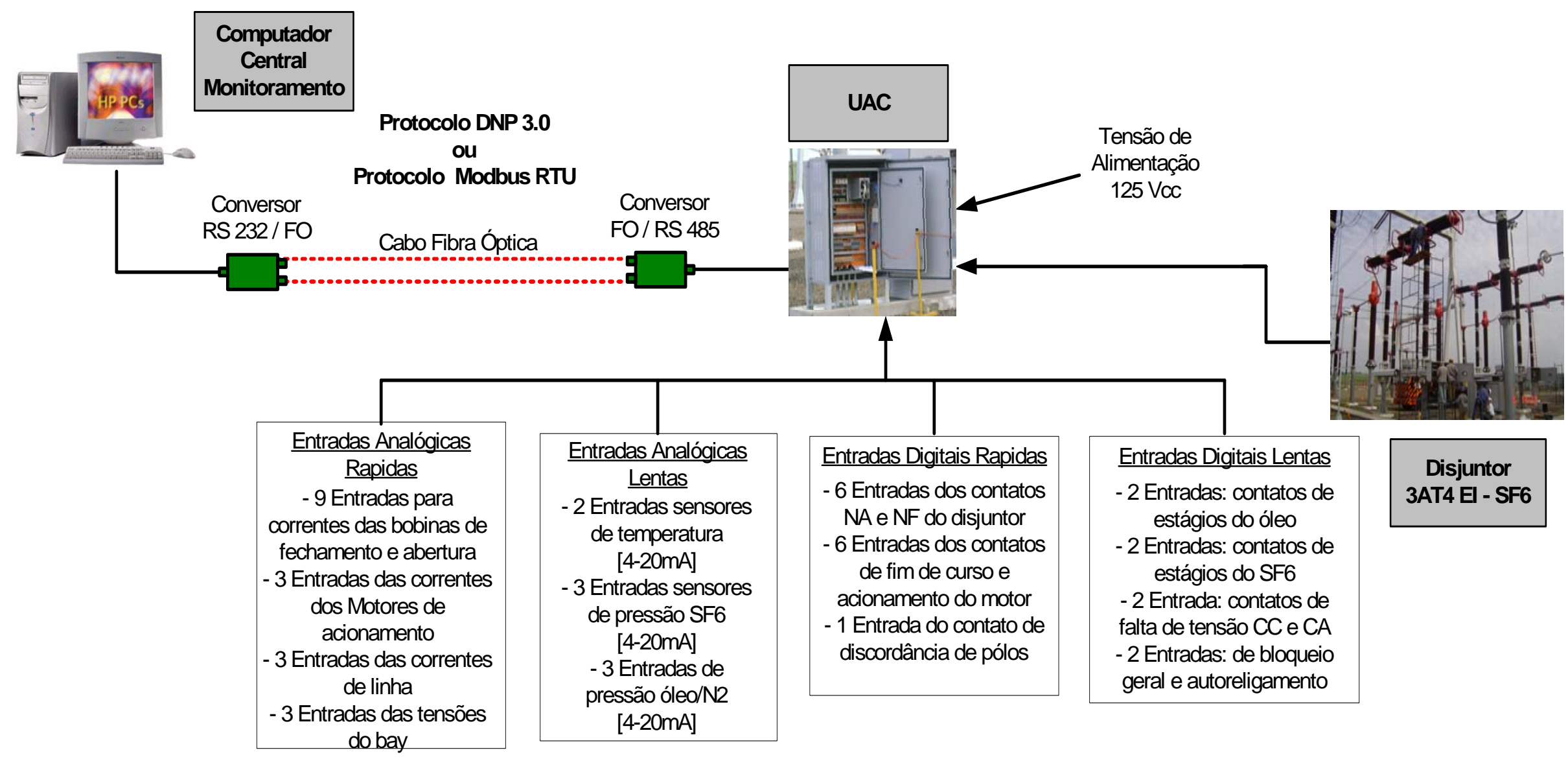

Figura 5.1 -Arquitetura geral do Sistema de Monitoramento de Disjuntores (3 fases). 


\section{a) Módulo de aquisição (UAC)}

Esta unidade está formada por uma UAC que é um micro computador PC composto por unidade de processamento, memória, saídas de comunicação e módulos de entrada/saída de dados analógicos e digitais. Estes módulos possuem características próprias e utilizam a filosofia "plug \& play", pois conectados transmitem ao módulo de processamento, informações sobre sua configuração e estado de funcionamento. Nas entradas para sinais analógicos utiliza uma taxa de amostragem de 100/110 kHz no conversor A/D com 12/16 bits de resolução, com memória tipo FIFO, e entradas digitais isoladas com níveis lógicos positivos (3 até $24 \mathrm{Vcc}$ ) e negativos (0 até 1,5Vcc). A UAC é alimentada com 120 Vca ou 125 Vcc.

Esta UAC está preparada para trabalhar em ambientes com alto nível de campo eletromagnético e suporta temperatura ambiente adequada ao histórico de temperaturas da subestação.

\section{b) Interface de sinais analógicos e digitais}

Estes módulos têm a finalidade de compatibilizar os sinais provenientes dos sensores e transdutores instalados no disjuntor com as entradas do módulo de aquisição outorgando-lhe proteção contra surtos ou alterações na linha. Estes módulos são específicos para correntes e tensões da linha, assim como para sinais digitais, tendo saídas compatíveis com as faixas de operação dos cartões de aquisição da UAC.

\section{c) Sensores}

Sensor de Temperatura.- Modelo digital Pt-100 classe B / RTD. Este sensor é fixado no próprio painel de comando do disjuntor com transmissor de temperatura com saída de 4 a 20mA, alimentação 10 a 30 Vcc, ligação a dois fios com tubo de proteção em aço inoxidável, faixa de medição de $0^{\circ} \mathrm{C}$ a $+85^{\circ} \mathrm{C}$ e uma precisão de $\pm 0,5 \%$. Um outro sensor com as mesmas características é usado 
para medição da temperatura ambiente e está instalado na proximidade do gabinete de comando de um dos pólos.

Sensores de Pressão SF6.- Modelo digital, com variação da pressão de 0 a 10 bar, sistema de dois fios, alimentação 10 a 30 Vcc, sinal de saída de 4 a 20 mA, conexão de pressão $1 / 2$ ” BSP, com precisão de $\pm 0,5 \%$ e tempo de resposta menor que $1 \mathrm{s.}$

Sensores de Pressão Óleo/N2.- Modelo digital, com variação da pressão de 0 a 400 bar, sistema de dois fios, alimentação 10 a 30 Vcc, sinal de saída de 4 a 20 $\mathrm{mA}$, conexão de pressão $1 / 2$ ” BSP, com precisão de $\pm 0,5 \%$ e tempo de resposta menor que $1 \mathrm{~s}$.

\section{d) Computador central de monitoramento}

Consiste em um microcomputador compatível com IBM PC, localizado na subestação, com freqüência de relógio de 2,4 GHz, memória RAM de 256MB, unidade de armazenamento secundaria de 40GB, monitor 17” com cartão AGP de interface gráfica, e cartões de comunicação com saída RS-232. No computador foi instalado o sistema operacional Windows 2000, um sistema SCADA (Action View), uma base de dados relacional (Oracle), assim como um programa para análise dos dados e apresentação dos resultados em forma de gráficos, tabelas, curvas, entre outros.

\section{e) Comunicação}

As necessidades de comunicação de dados do sistema de monitoramento de disjuntores, embora não envolvam um grande volume de dados, apresenta algumas peculiaridades, tais como:

Diferentes tempos de varreduras, a maior parte dos sinais digitais e analógicos é coletada a cada segundo, enquanto que alguns poucos exigem resolução de milissegundos. 
- O volume de dados a ser transmitido é na maior parte do tempo pequeno, exceto quando ocorre uma manobra do equipamento.

* Os equipamentos que coletam os dados necessitam estar sincronizados.

Fabricantes oferecem uma grande variedade de protocolos de comunicação de dados com suporte a essas funcionalidades, mas muitos deles são soluções apenas suportadas pelas linhas de produtos da empresa, o que dificulta, ou mesmo, impede a sua integração com outros equipamentos ou mesmo com o sistema SCADA.

A filosofia de sistemas abertos valoriza a adoção de interfaces e protocolos padronizados, tais como o IEC 60870-5, o DNP 3 e mais recentemente, o IEC 61850, que é também conhecido como uma extensão do UCA.2.

Equipamentos mais econômicos usualmente oferecem como alternativa o protocolo Modbus, que embora não seja um padrão amparado por uma norma, é amplamente documentado e extremamente popular na área de automação industrial, o que o transformou num padrão informal. O Modbus foi concebido para PLC (Programming Logic Controller) não sendo adequado, portanto para muitas funcionalidades típicas do setor elétrico, tais como sequenciamento de eventos e oscilografia.

Alguns fabricantes chegam a implementar adaptações no Modbus para que ele passe a suportar essas novas funcionalidades, dando origem a particularidades nem sempre compatíveis com equipamentos de outros fabricantes.

Por outro lado, equipamentos com suporte a protocolos específicos do setor elétrico tais como o IEC 60870-5 e o DNP 3, enquadram-se num outro nível de preços mais elevado, o que restringe sua aplicação.

Além disso, a norma IEC 61850 encontra-se ainda em fase de discussão e, portanto, somente uns poucos equipamentos são comercializados seguindo sua filosofia 
de objetos, e na sua maioria ainda seguem o protocolo UCA2 sugerido pelo EPRI e não a versão mais abrangente estabelecida por esse padrão IEC.

\section{f) Outros Dispositivos}

Considerando-se as distâncias consideráveis entre os equipamentos de campo e o edifício de controle, foram usados cabos de fibra óptica, com seus respectivos conversores F.O./RS-232. No caso do disjuntor do protótipo por ser de acionamento monofásico foi necessário o uso de uma boa quantidade de sensores e conseqüentemente de fontes de 125 Vcc com saídas de 12, 15 ou 24 Vcc. Assim como módulos conversores (corrente / tensão).

\subsection{Interface Homem Máquina (IHM)}

O sistema de informação para o monitoramento de equipamentos consiste em um conjunto de programas aplicativos que usam a informação contida na base de dados para realizar uma determinada tarefa como, por exemplo, visualização da curva de tendência da corrente do motor de acionamento. A base de dados é constituída por registros de grandezas físicas, elétricas e ocorrências de eventos obtidos de forma direta e indireta dos equipamentos da subestação (disjuntor) como, por exemplo, é o caso dos estados dos contatos auxiliares do disjuntor.

O sistema de monitoramento é composto de diferentes grupos de informações como: dados dos equipamentos, alarmes, curvas, medições, etc., que estão diretamente vinculadas através de telas do microcomputador para serem apresentadas ao operador.

O esquema geral do banco de dados do sistema de monitoramento é apresentado na Figura 5.2, indicando-se os respectivos blocos funcionais. 


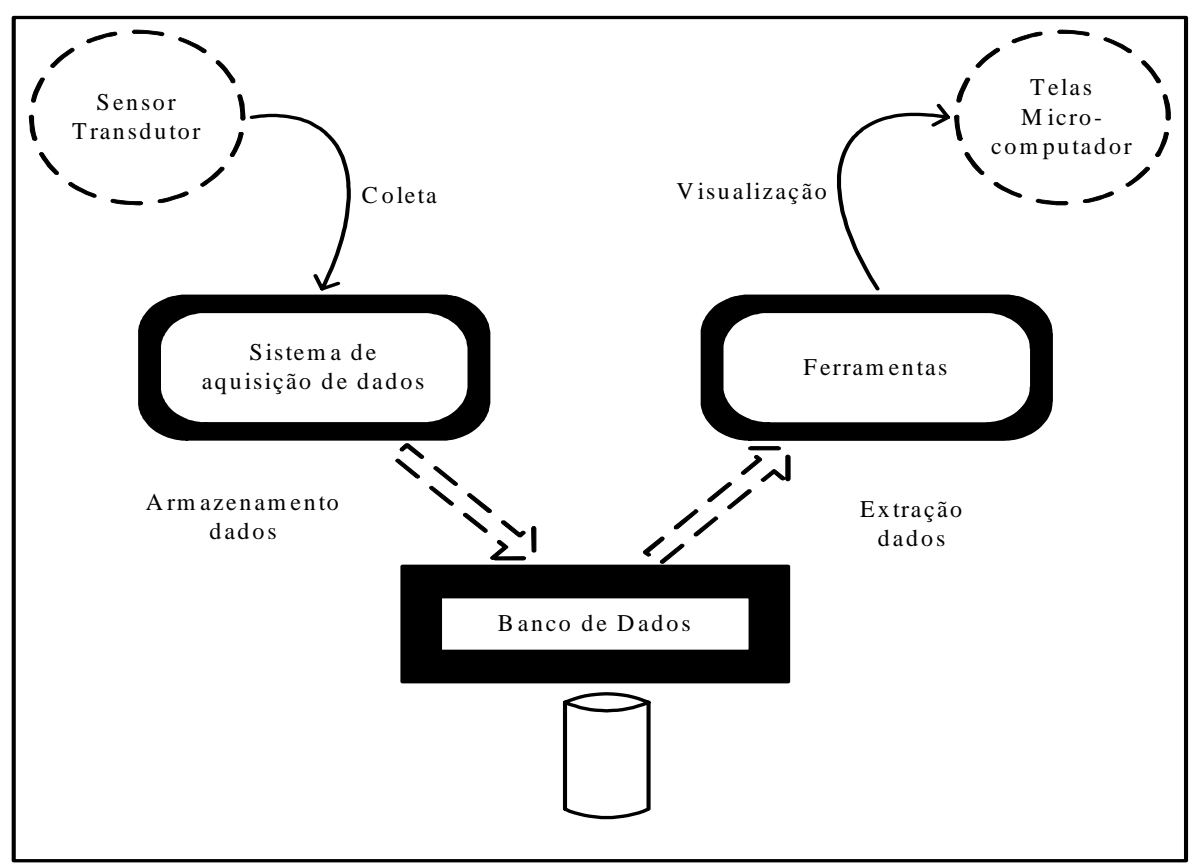

Figura 5.2 - Esquema geral do funcionamento do Sistema.

A solução de software implementada esta baseada nos programas Windows 2000, Action View e Oracle. A plataforma Windows garante a flexibilidade e facilidade na configuração e manutenção, aliada à maior compatibilidade com outros softwares, sendo este configurado para a coleta de dados como prioridade e em segundo plano para as aplicações de manutenção da base de dados.

O Oracle como sistema gerenciador do banco de dados é responsável pelo armazenamento de todas as informações e referência para todas as aplicações e análises posteriores.

A Figura 5.3 ilustra o diagrama geral de distribuição da informação e sua gestão. 


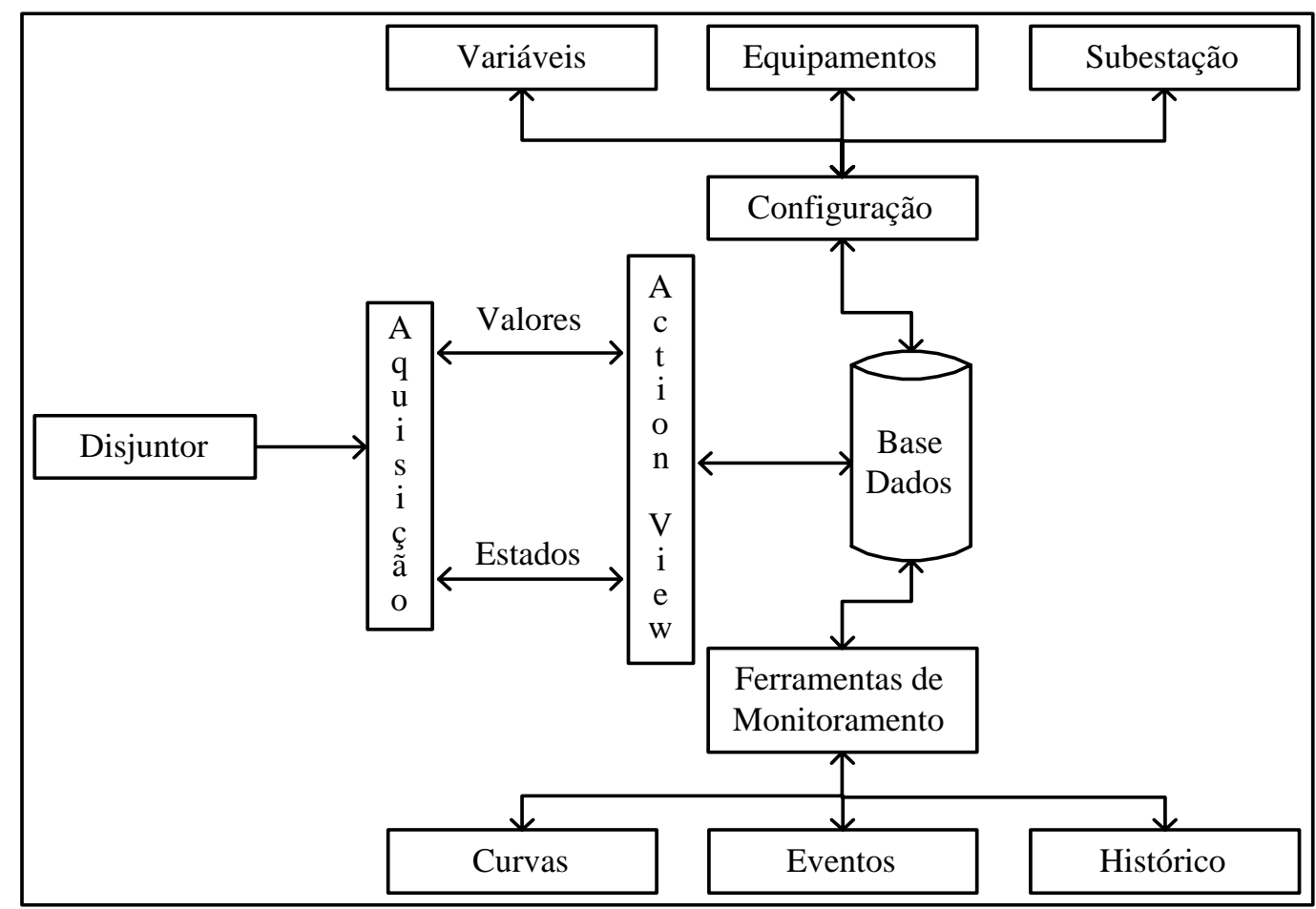

Figura 5.3 - Diagrama geral de distribuição da informação.

A Interface Homem Máquina (IHM) está constituída por uma serie de telas no computador que cumprem a função de interface entre o operador e o sistema de monitoramento.

\subsection{Telas de Interface}

\section{a) Telas de Equipamentos}

Esta ferramenta permite ao operador escolher o disjuntor ou equipamento a ser analisado, e uma vez selecionado tem-se a possibilidade de determinar qual parâmetro se deseja visualizar. A Figura 5.4 apresenta um diagrama esquemático dessa tela. 


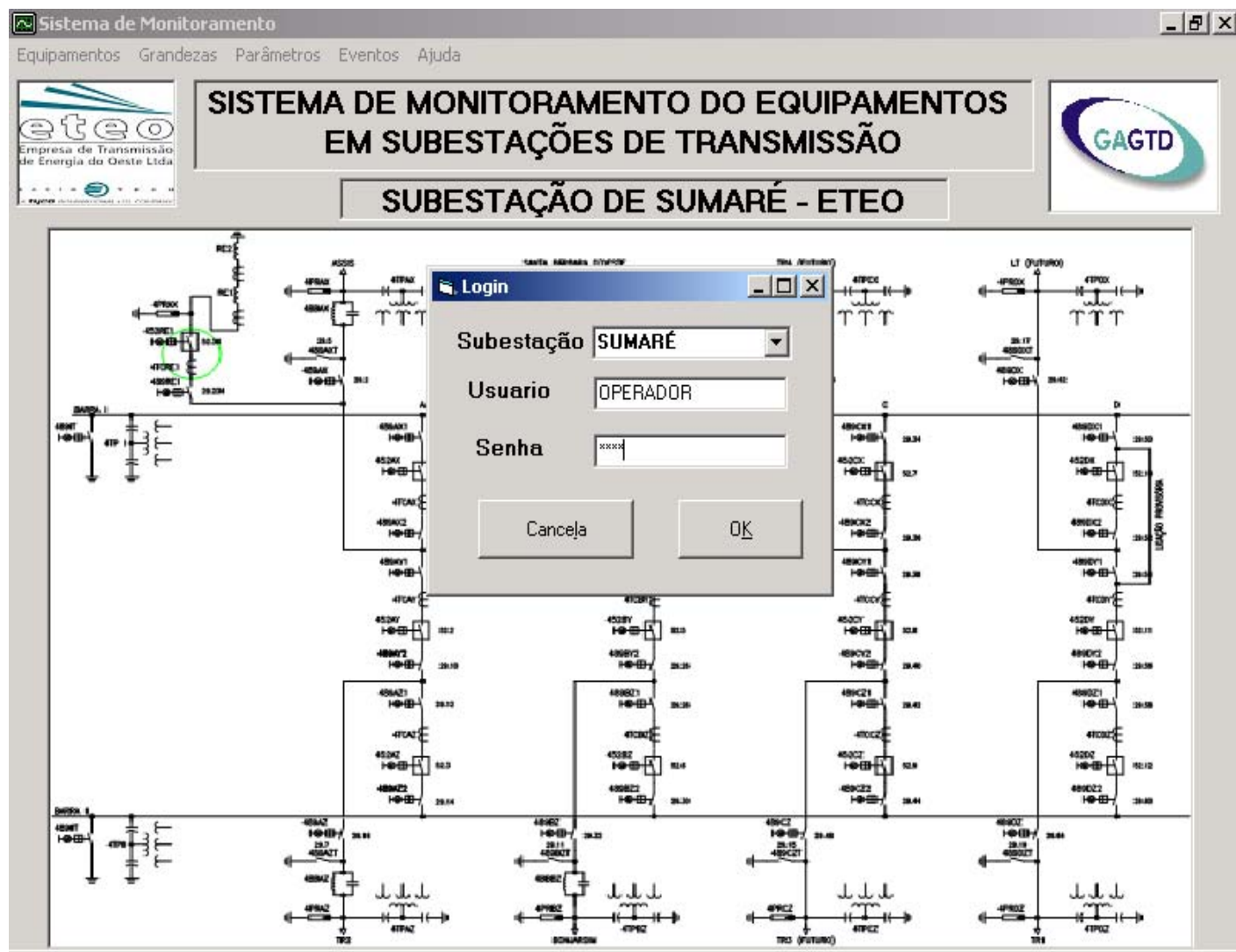

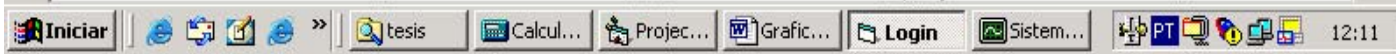

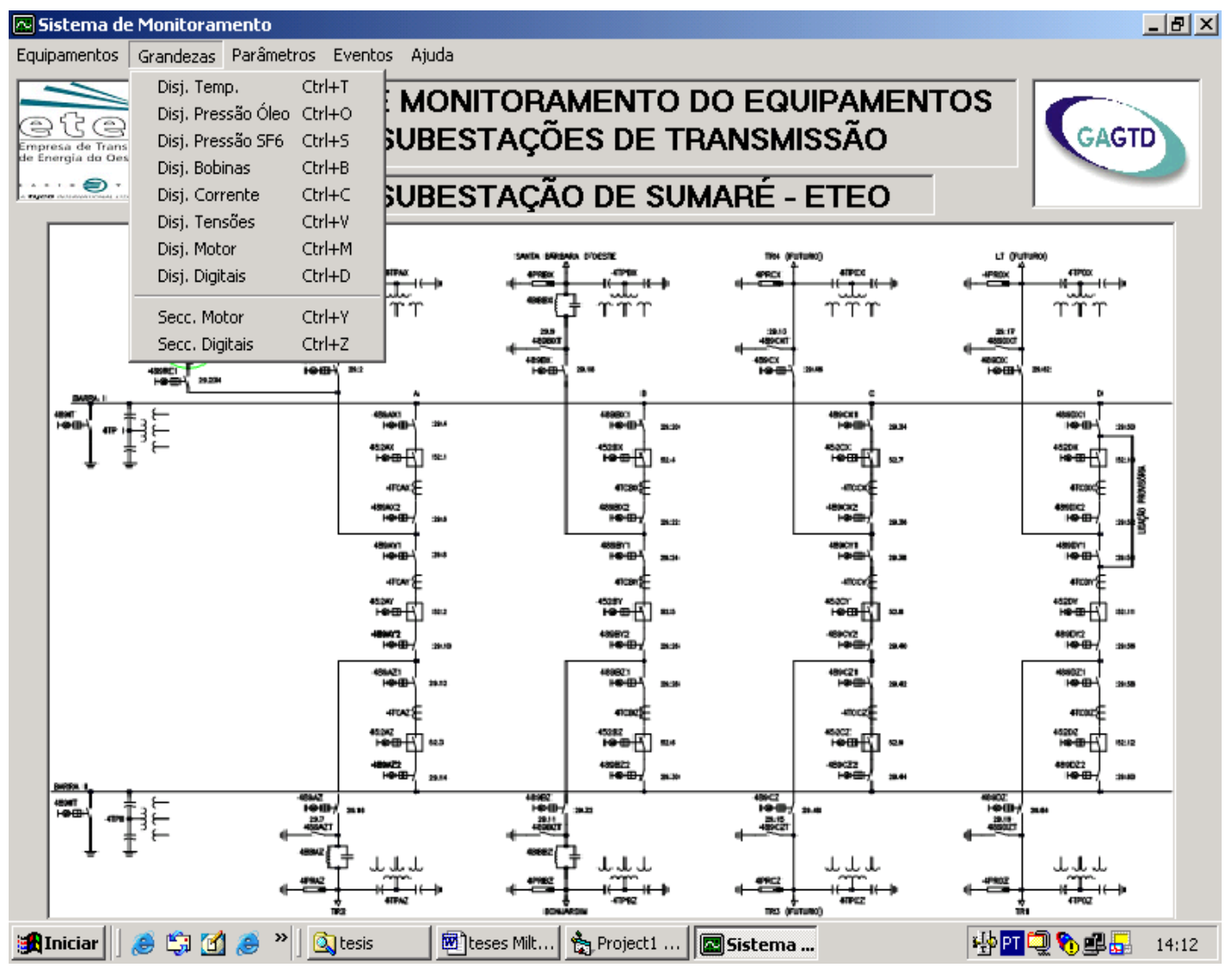

Figura 5.4 - Telas principais da ferramenta de monitoramento. 


\section{b) Telas de Parâmetros}

As diferentes variáveis monitoradas do disjuntor são apresentadas em formato de curvas (tendência) e tabelas agrupadas de acordo com sua função. Neste protótipo esses parâmetros representam as grandezas principais do disjuntor do bay do reator, disjuntor com acionamento eletro-hidráulico e isolamento a SF6 instalado na subestação Sumaré da ETEO.

Na Figura 5.5 apresenta-se a tela que é usada para selecionar a variável que se deseja visualizar.

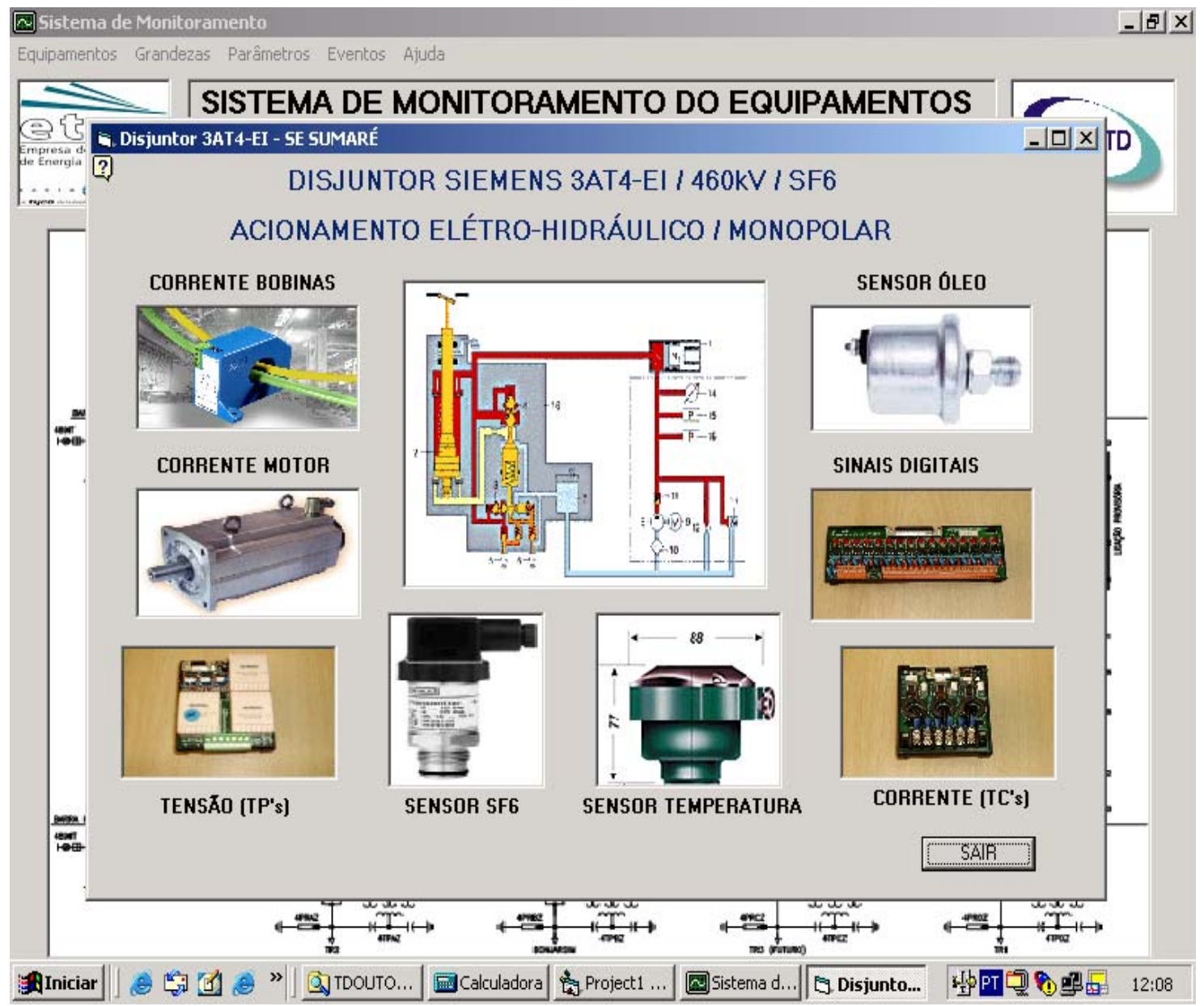

Figura 5.5. Tela de parâmetros disjuntor. 


\section{c) Telas de Variáveis}

Estas telas permitem a visualização de diferentes grandezas físicas como pressão (óleo e SF6), temperatura (interna, externa), correntes (bobinas, motores), tensões nas fases, etc; oferecendo a possibilidade de se observar graficamente sua tendência para diferentes faixas de tempo (minutos, horas, dias, etc.), tanto para uma fase isolada, como também para as três fases em forma conjunta. Além disso, é informado também o último valor medido da variável monitorada.

As telas de informação das variáveis monitoradas estão constituídas por diferentes partes:

* Valores Atuais: Texto que aparece na parte superior esquerda da tela onde são indicados os valores medidos mais recentes da variável monitorada (pressão gás SF6, pressão óleo, corrente bobinas, etc.) presentes no disjuntor (dependendo da opção selecionada), exemplo.

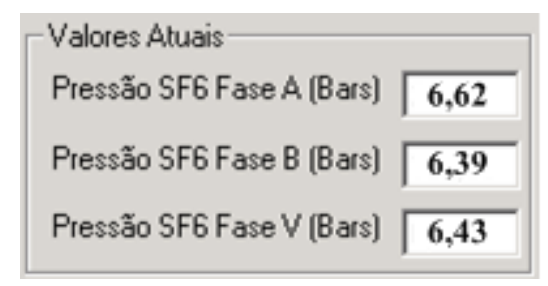

Seleção Fases: permite selecionar a fase ou fases (Azul, Branca ou Vermelha), onde se deseja monitorar uma variável determinada, bastando clicar no quadrado ao lado esquerdo do nome da fase.

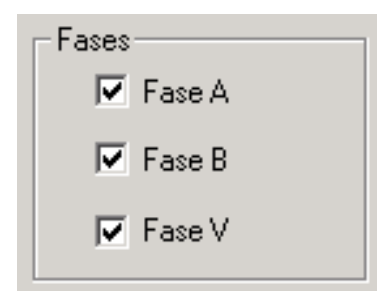

Seleção Tempo: Permite selecionar a data inicial e final na qual a grandeza selecionada terá plotadas suas amostras coletadas. Também nesta parte é possível selecionar a referência de tempo (cada minuto, cada 15 minutos ou cada 60 minutos) para a visualização da curva de tendência. 


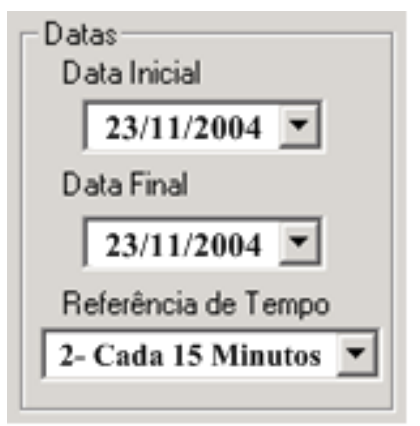

* Curva de tendência: É onde se visualiza a progressão da grandeza selecionada no intervalo de tempo especificado sendo que a cor de cada uma das grandezas é especificada na legenda. O número de amostras indica a quantidade de valores amostrados plotados para cada uma das grandezas cuja progressão é visualizada.

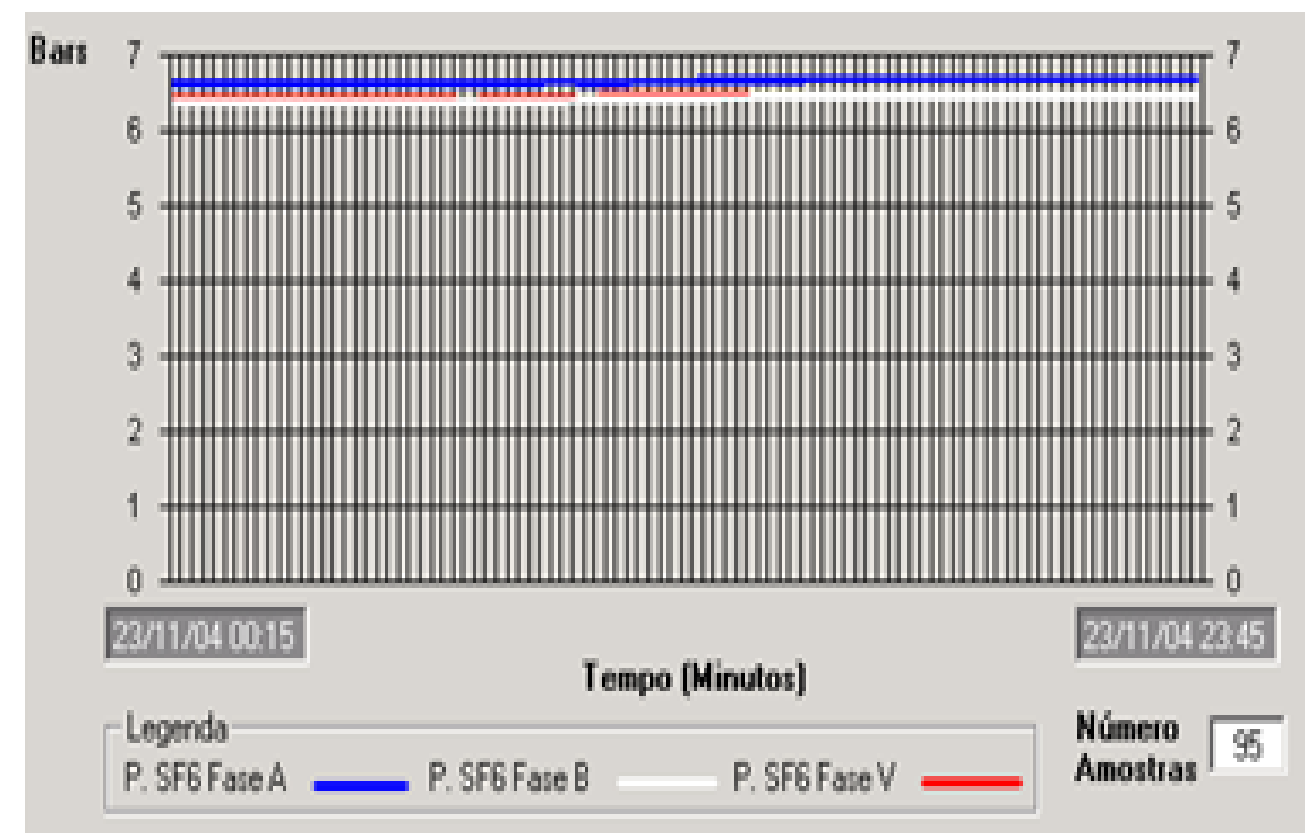

* Tabela Amostras: Esta tabela mostra os valores das amostras coletadas de uma determinada variável presentes nas três fases do disjuntor. A coluna Data_Hora indica o instante de tempo no qual foram amostradas as variáveis. É possível deslocar-se pela tabela clicando nas setas, presentes na parte inferior e direita da tabela. 


\begin{tabular}{|c|c|c|}
\hline Byte & Data_Hora & Fased BA - \\
\hline $\mathrm{Ok}$ & $14 / 05 / 200410: 15$ & 0.01 \\
\hline Ok & $14 / 05 / 200410: 30$ & 0,01 \\
\hline $0 \mathrm{k}$ & 14/05/2004 10:45 & $3,4[$ \\
\hline Ok & 14/05/2004 11:00 & 5,65 \\
\hline Ok & $14 / 05 / 200411: 15$ & 5,64 \\
\hline $0 \mathrm{k}$ & $14 / 05 / 200411: 30$ & 5,65 \\
\hline Ok & $14 / 05 / 200411: 45$ & $5,6 \mathrm{E}$ \\
\hline Ok & $14 / 05 / 200412: 00$ & $5,6 E$ \\
\hline $0 \mathrm{k}$ & $14 / 05 / 200412: 15$ & $5,6 \mathrm{E}$ \\
\hline Ok & $14 / 05 / 200412: 30$ & 5,67 \\
\hline Ok & $14 / 05 / 200412: 45$ & 5,67 \\
\hline $0 \mathrm{k}$ & 14/05/2004 13:00 & $5,6 \varepsilon$ \\
\hline Ok & $14 / 05 / 200413: 15$ & $5,7 \mathrm{C}$ \\
\hline${ }^{k}$ & 14/ก5/ากก 1.3 .3ก & 571 \\
\hline
\end{tabular}

Lista Códigos: Visualiza a lista de códigos (tag) das variáveis e equipamentos que estão sendo amostrados pelo sistema.

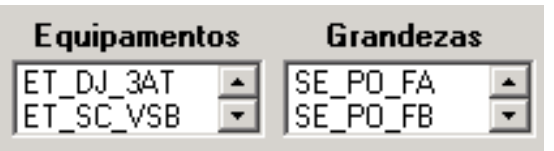

* Ícones: Cada um dos ícones realiza uma tarefa determinada:

Elementos Visualiza a lista dos códigos dos equipamentos e das variáveis monitoradas.

Limpa Limpa toda a tela.

\section{Imprimir}

Permite imprimir a tela atual.

\section{口K}

Executa a plotagem das variáveis selecionadas nos intervalos de tempo definidos.

\section{SAIR}

Permite sair desta tela e voltar a tela principal do disjuntor.

Nas seguintes figuras são ilustradas telas das medições reais efetuadas pelo sistema de monitoramento protótipo: 
Na Figura 5.6 é ilustrada a medição efetuada no dia 23/11/2004 da pressão do SF6 em cada uma das fases (A, B ou V) do disjuntor do reator na subestação Sumaré, onde pode-se observar a variação da pressão no transcurso do dia tendo-se controle sobre falhas por razões de vazamento. Além disso, nessa figura é ilustrada a comparação entre as pressões presentes nas três fases, já que o disjuntor possui acionamento monopolar (operação independente de cada fase), o qual permite parametrizar os valores máximos e mínimos da pressão de SF6 do disjuntor.

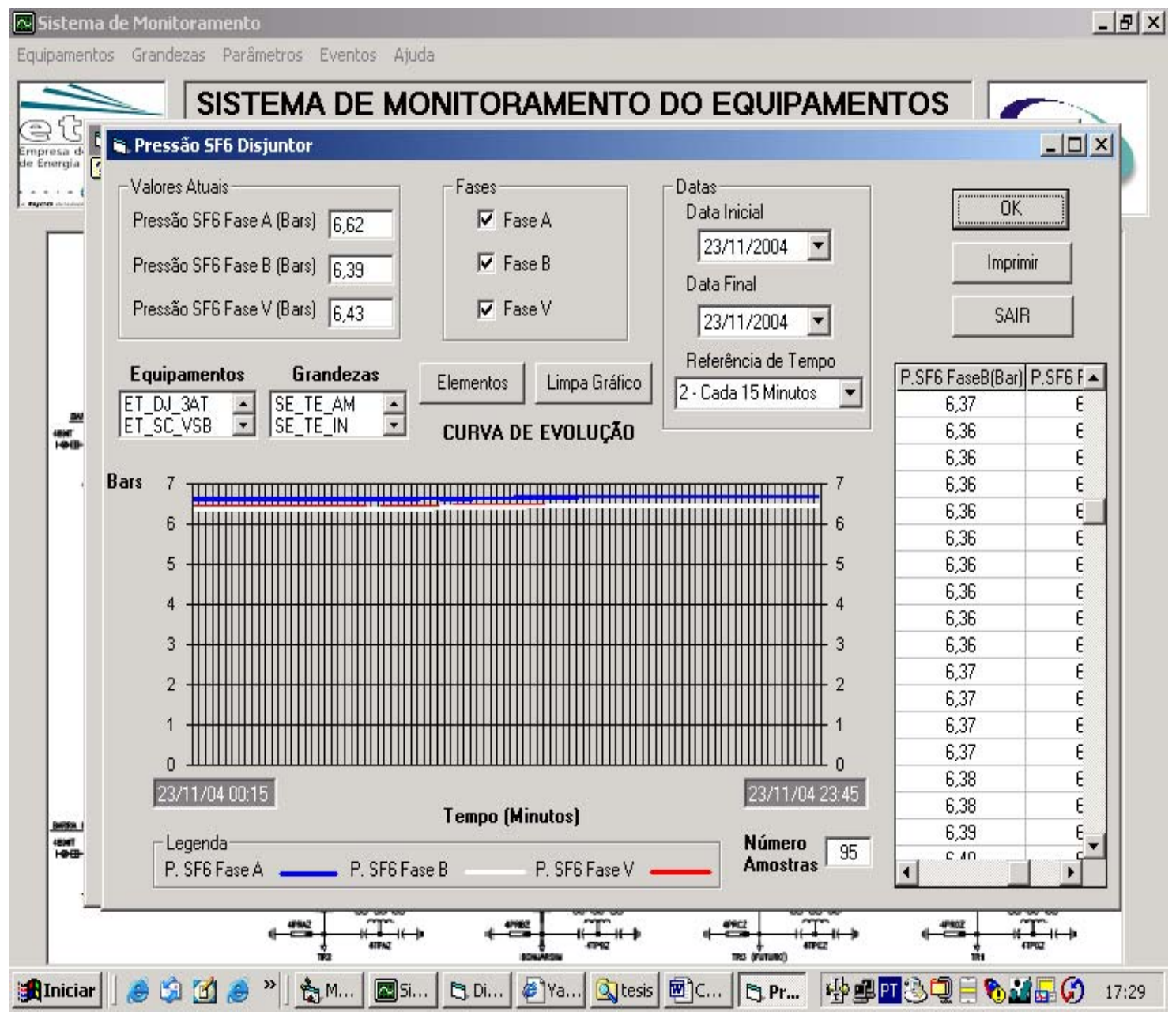

Figura 5.6 - Medição da pressão do SF6 no Disjuntor. 
Na Figura 5.7 é ilustrada a medição da pressão do óleo por fase do compressor hidráulico responsável pelo acionamento do disjuntor, no qual constatou-se problemas na pressão do óleo na fase C (Vermelha), acionando dessa forma a equipe de manutenção para sua verificação.

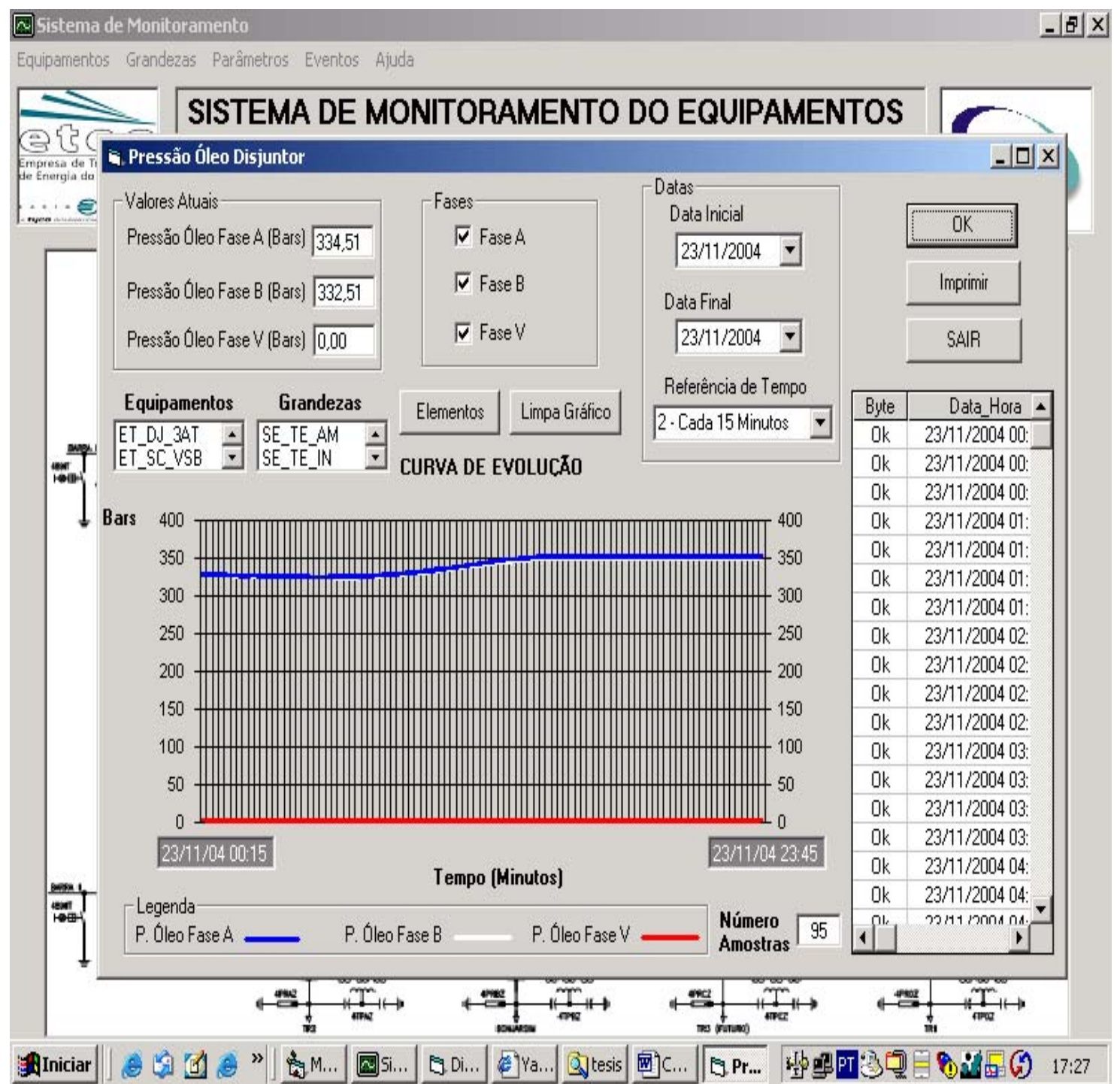

Figura 5.7 - Medição da pressão do Óleo no Disjuntor.

Na Figura 5.8 é ilustrada a variação da temperatura tanto interna do gabinete como do ambiente registrada no dia 22/10/2004. Pode-se observar que a temperatura interna é sempre maior que a temperatura do ambiente em cerca de $5^{\circ} \mathrm{C}$. É importante ressaltar que com esses valores ter-se-á um indicativo de prováveis problemas no disjuntor.

A visualização das correntes tem uma característica importante porque mediante elas pode-se calcular os tempos de operação do disjuntor, que serão comparadas com os 
dados obtidos pela aplicação de ferramentas matemáticas (Fourier, Wavelet). Além disso, o monitoramento das correntes das fases permite estimar o desgaste dos contactos principais no disjuntor, através da relação $\left(\mathrm{I}^{\mathrm{n}} \mathrm{T}\right)$.

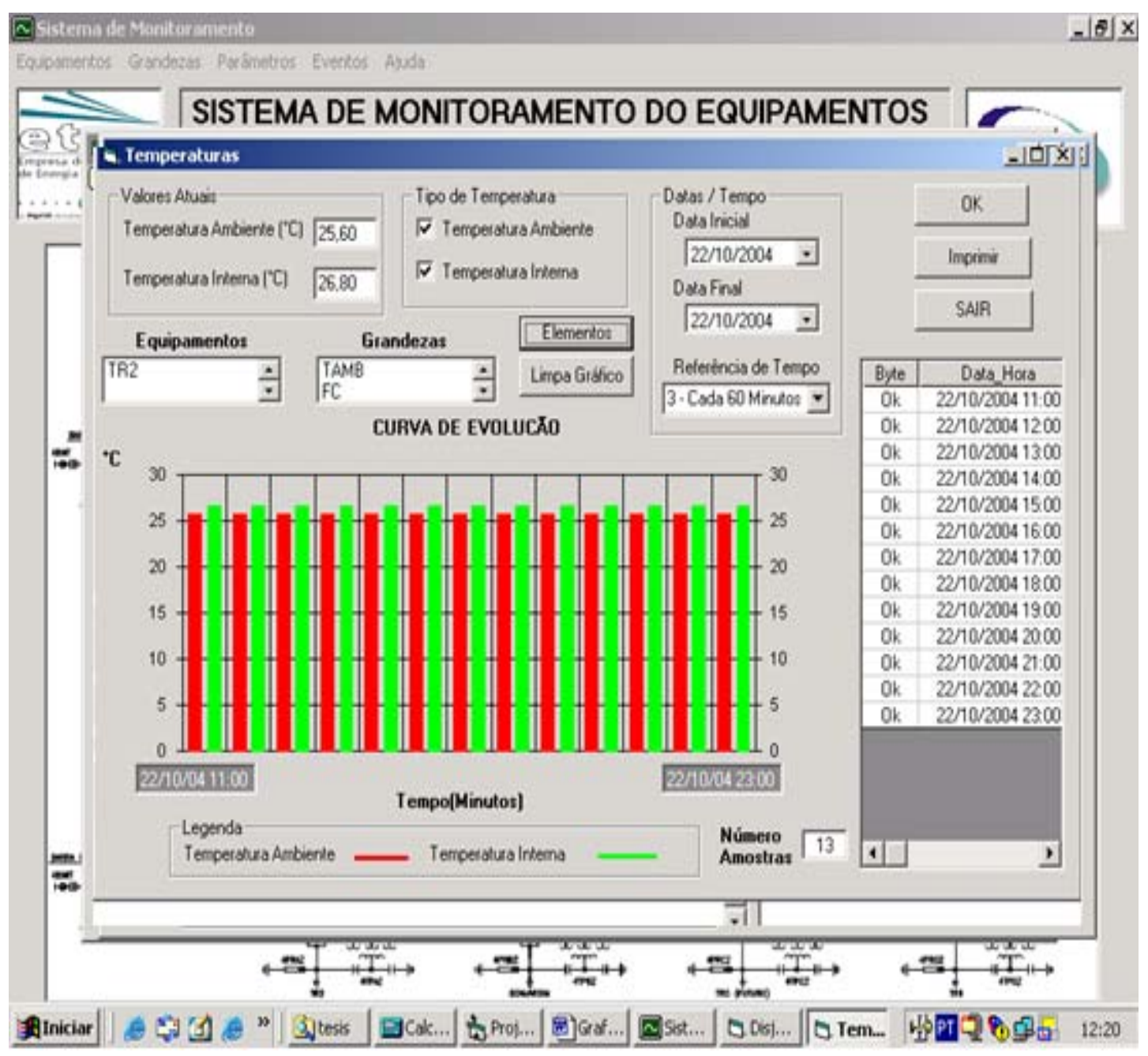

Figura 5.8 - Medição de temperatura interna e do ambiente.

A apresentação das correntes está dividida em diferentes telas de acordo com sua origem: tela das bobinas de acionamento (abertura / fechamento), tela das correntes e tensões das fases do circuito principal (por fase ou em conjunto as três fases), tela da corrente do motor (por fase ou em conjunto).

A análise da informação das medições de correntes também permitirá determinar prováveis alterações no fornecimento de energia, assim como falhas na alimentação do motor. 
Na Figura 5.9 é ilustrado o monitoramento das tensões (três fases) que chegam ao disjuntor de linha da subestação Sumaré através de sensores instalados nos TP’s, cuja informação é coletada com uma resolução de 1 amostra/ms, permitindo de essa forma observar o que acontece com a tensão no momento de operação do disjuntor.

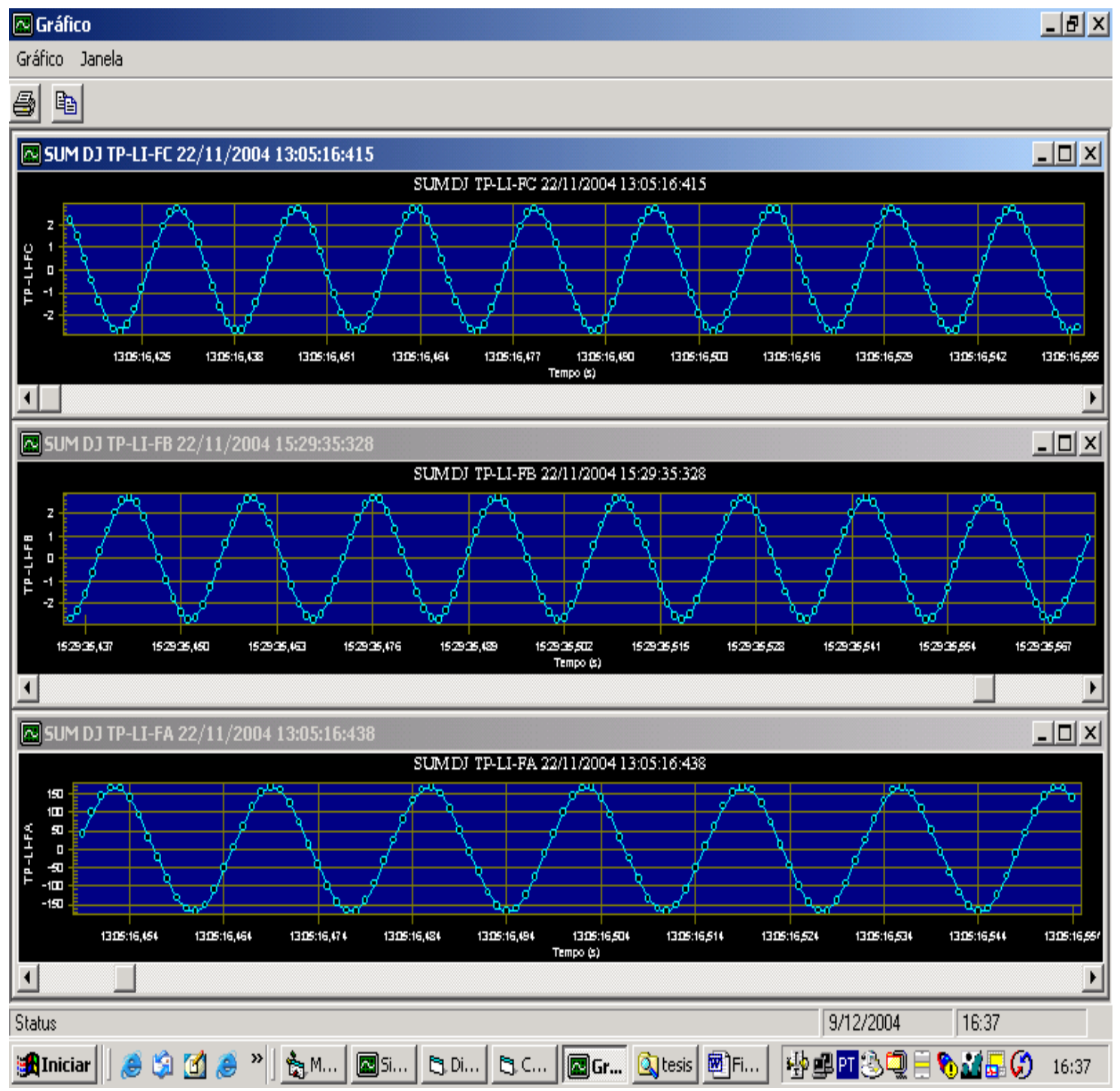

Figura 5.9 - Oscilografia das Tensões na linha que chegam ao Disjuntor.

No momento da operação do disjuntor são gerados pelo sistema de monitoramento diferentes curvas que representam as correntes presentes nas bobinas de abertura (principal e alternativa), e fechamento, motores de acionamento e circuitos de comando, assim como os pulsos dos contatos de disparo para cada uma das fases com uma resolução de amostragem de $1 \mathrm{~ms}$. 
Como pode-se observar na tela da Figura 5.10, no programa é possível selecionar a corrente de uma determinada fase, ou selecionar duas ou três fases em forma simultânea, seja a corrente do motor de acionamento, do circuito principal ou das bobinas (abertura / fechamento), com a finalidade de comparar e poder identificar alterações entre elas.

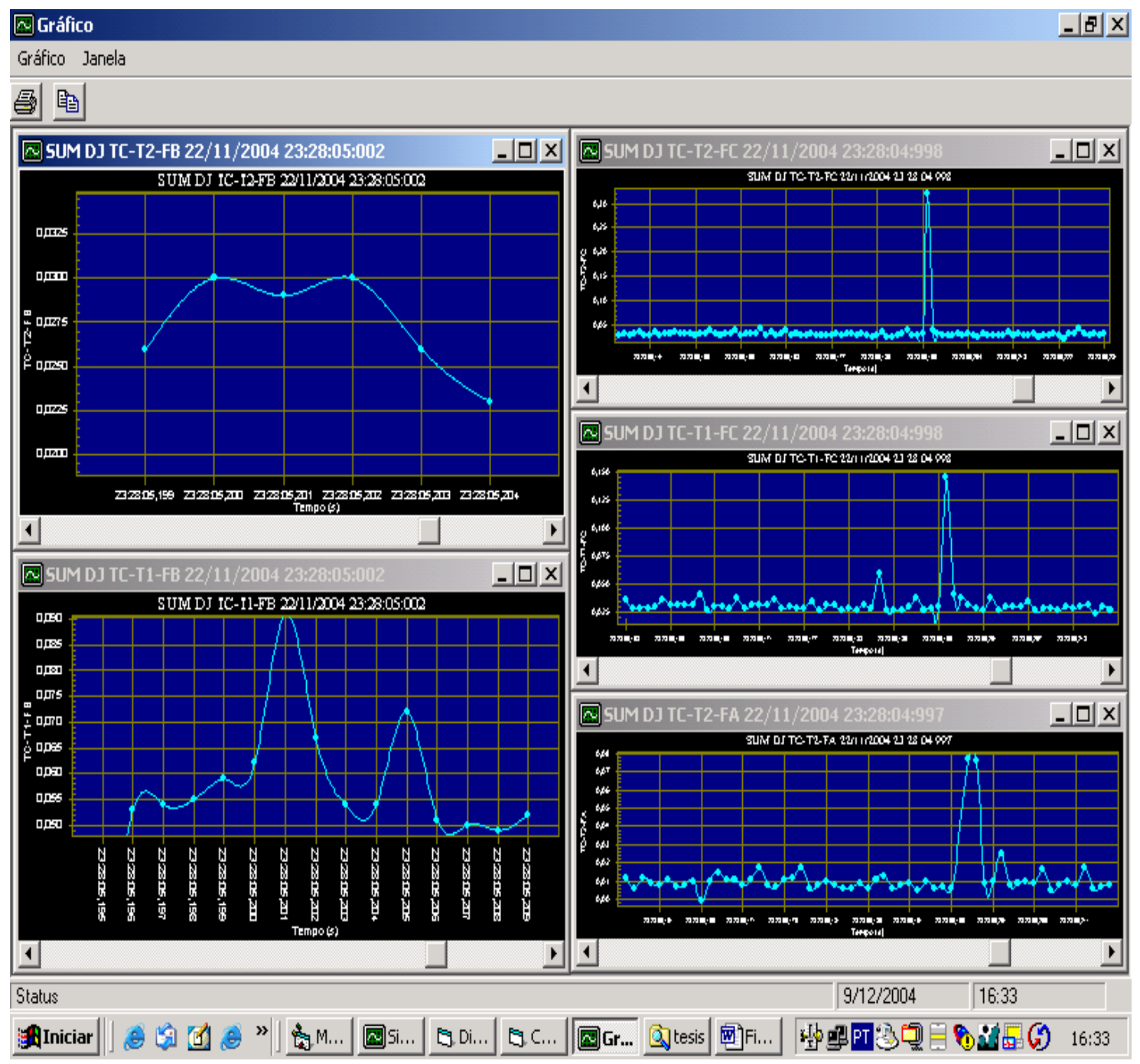

Figura 5.10 - Curvas geradas no momento da operação do Disjuntor.

A esquerda de cima para baixo:

* Corrente do motor de acionamento;

* Corrente da bobina de fechamento.

A direita de cima para baixo:

* Corrente da bobina de abertura (Fase A);

* Corrente da bobina de abertura (Fase B);

* Corrente da bobina de abertura (Fase V). 
Como trabalho paralelo ao sistema de monitoramento pode-se determinar diferentes limiares (TIM, NOI) dentro de cada uma das curvas que caracterizam a operação normal de uma determinada variável, para posteriormente ser usados como valores de referência para a ativação de um determinado alarme que possibilitará a detecção precoce de anomalias presentes no disjuntor.

Na Figura 5.11 é ilustrada a curva característica da corrente do motor de acionamento com a determinação de seus respectivos limiares.

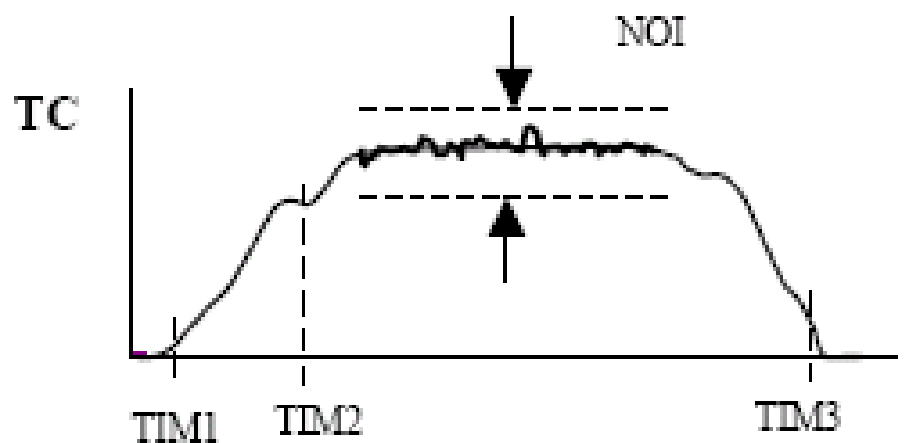

Figura 5.11 - Determinação de limiares nas curvas características do Disjuntor.

Onde:

TIM1 : $\quad$ Tempo Inicial da curva de acionamento;

TIM2 : $\quad$ Mudança da relutância da bobina de abertura;

TIM3 : $\quad$ Tempo Final da curva de acionamento;

NOI : $\quad$ Faixa de variação permitida da corrente máxima do motor.

Os valores TIM e NOI poderão ser comparados com aqueles obtidos no comissionamento do disjuntor. Variações nestes valores indicaram problemas (Ex: TIM3 maior significa tempo mais longo devido ao aumento do atrito).

Todas estas informações permitirão gerar uma base de dados com curvas de comportamento padrão das grandezas monitoradas, possibilitando estas serem comparadas com curvas obtidas do monitoramento continuo do disjuntor permitindo assim encontrar algum indício de mau funcionamento na operação do disjuntor [18]. 
O sistema de monitoramento também possui diferentes telas que servem para informar sobre o estado dos diferentes componentes do disjuntor, bem como permitir gerar relatórios do histórico de eventos podendo especificar a data inicial e final do relatório (dia, hora, minuto). Além disso, permitem selecionar as variáveis (grandezas) analógicas que estarão presentes no relatório, quer seja para uma fase isolada ou em conjunto como é ilustrada na Figura 5.12.

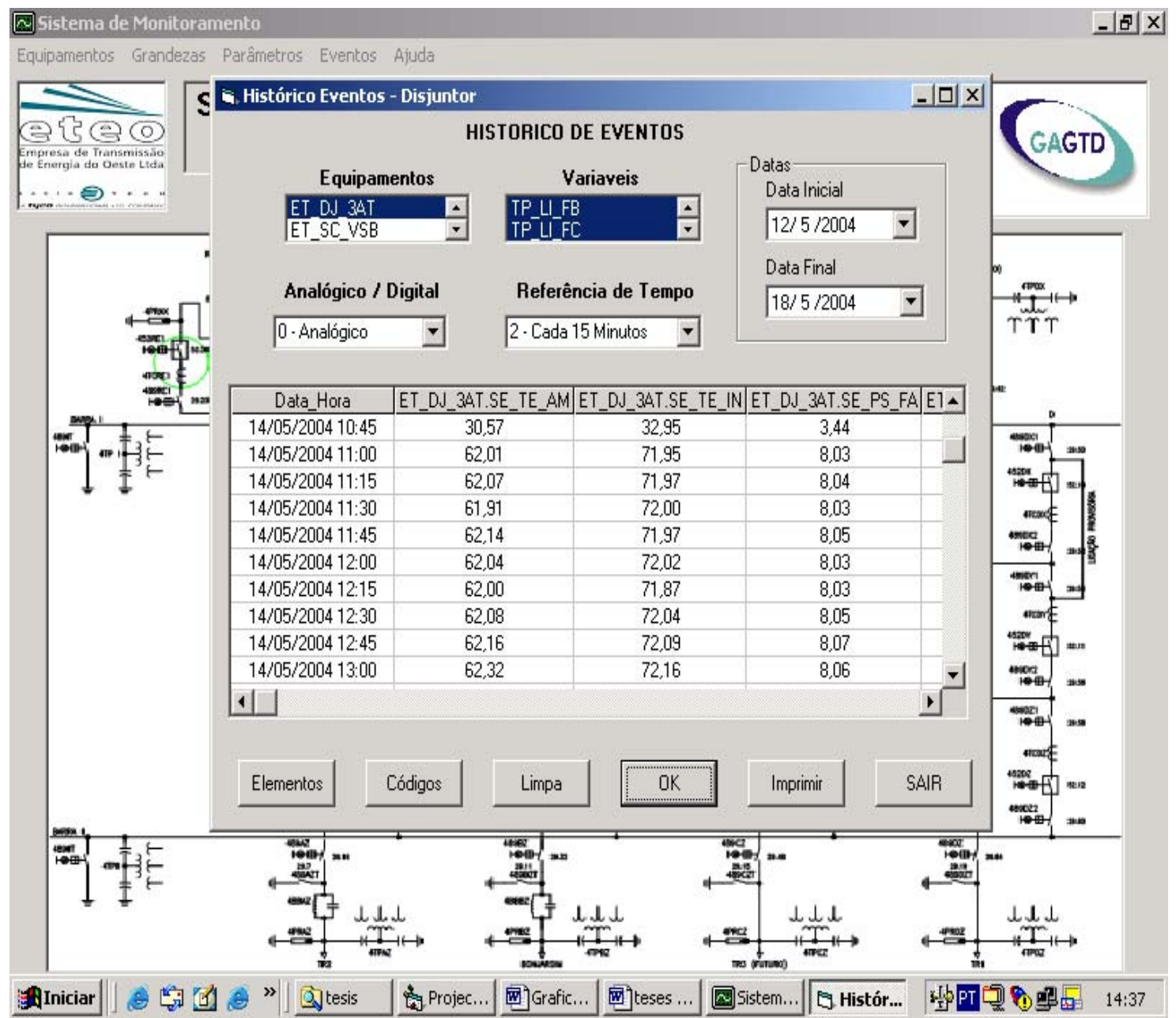

Figura 5.12 - Tela de Histórico de Eventos.

Notar que nesta tela foram selecionadas as variáveis analógicas codificadas com TP_LI_FB e TP_LI_FC (tensões das fases B e C do circuito principal) do equipamento codificado com ET_DJ_3AT (Disjuntor).

Na tela de Alarmes Figura 5.13 é ilustrada a verificação dos estado das entradas digitais (contatos) do disjuntor, coletados em 10/05/2004, cujo valor: ligado (vermelho) 
ou desligado (verde) indica o estado de um determinado alarme como, por exemplo: nível da pressão do óleo na fase B do disjuntor, cuja variação ativará um determinado contacto que a sua vez ligará um determinado esquema de proteção. Como pode-se observar nessa figura o contacto de falta de tensão no motor da fase A (parâmetro 6) encontra-se ligado o qual foi verificado pela equipe de manutenção sendo constatado que o relé de proteção desse motor estava danificado.

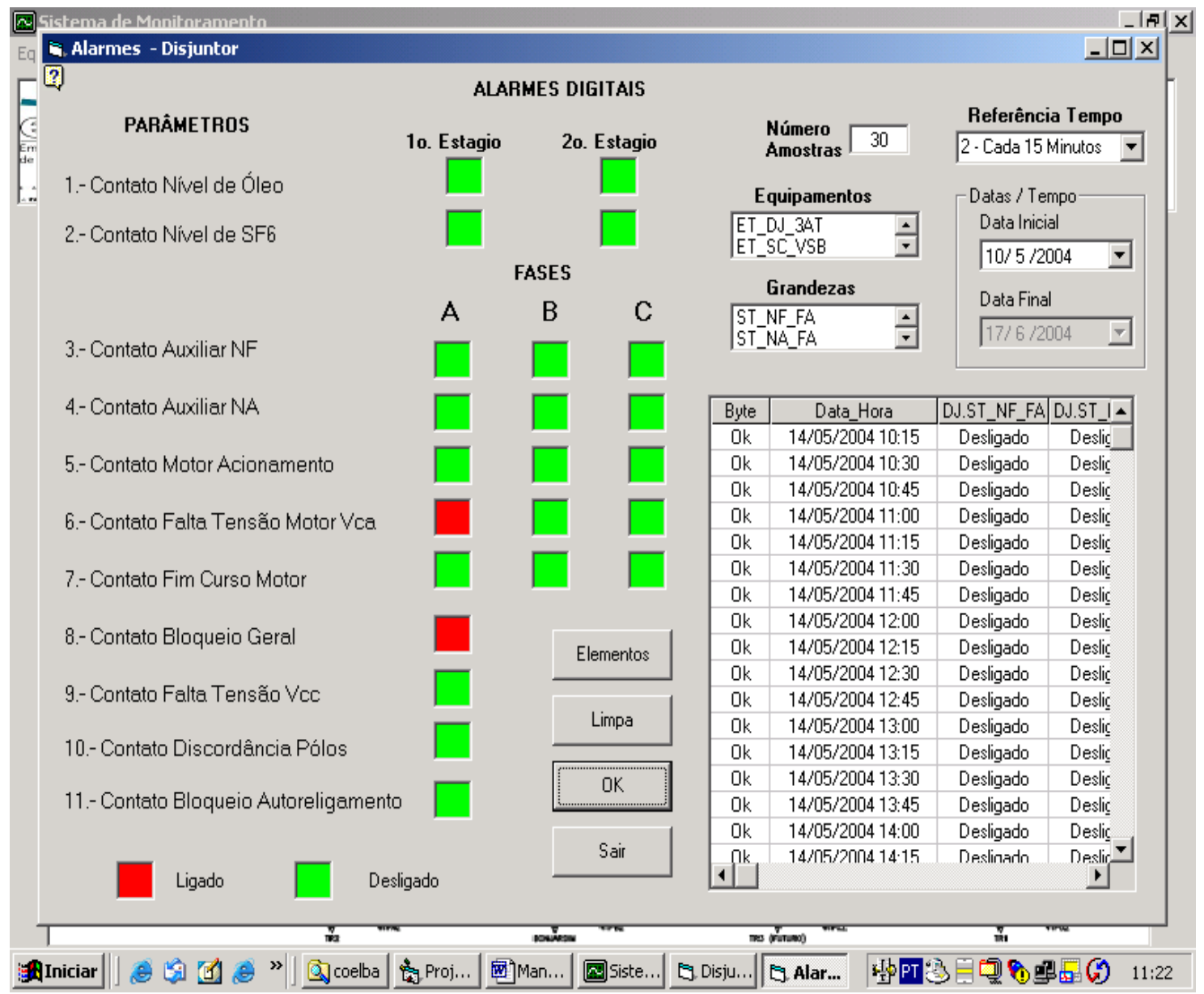

Figura 5.13 - Tela de Alarmes. 


\section{CAPÍTULO 6}

\section{COMENTÁRIOS, CONCLUSÕES, CONTRIBUIÇÕES.}

A penalização por saídas não programadas em uma subestação tem aumentado significativamente o interesse da concessionária pela segurança na abertura e fechamento de disjuntores como proteção e isolação de um para outro sistema.

Procurou-se no desenvolver deste trabalho conhecer os diferentes métodos para a cronometragem dos tempos de abertura e fechamento do disjuntor como forma de assegurar o correto funcionamento do equipamento para viabilizar a tomada de medidas que diminuam, ou mesmo eliminam, as prováveis causas que alterem esses tempos. Para uma melhor análise dos tempos de operação, faz-se necessário a utilização de alguma ferramenta extra que permita visualizar o comportamento de cada sinal envolvido. Desta forma, foram usadas ferramentas matemáticas que proporcionem os resultados esperados.

A ferramenta mais conhecida e utilizada para a análise de sinais é a Transformada de Fourier, que decompõe um sinal em ondas senoidais de diferentes freqüências. Similarmente à Análise de Fourier, a Análise Wavelet também é uma técnica matemática, onde se pode obter simultaneamente, informações tanto no domínio do tempo quanto no domínio da freqüência do sinal a ser analisado, mostrando-se um conjunto de técnicas e ferramentas de grande importância para análise de sinais que permitam determinar os tempos de operação do disjuntor.

A eficiência da TW para análise de sinais está diretamente relacionada com o comportamento das funções bases Wavelets. As Wavelets mãe escolhidas neste trabalho 
foram a db4 com sucesso, tendo oferecido, bons resultados na análise (detecção e localização) de distúrbios que ocorrem no momento da operação do disjuntor.

Como conseqüência da realização deste trabalho alguns artigos foram publicados e apresentados em congressos internacionais. A referência [37] compreende um estudo sobre um sistema de monitoramento de disjuntores implementado em duas subestações elétricas, tal trabalho, foi exposto no International Council on Large Electrical Systems Committee - CIGRE na Bósnia no 2003. A referência [38] consiste em estudos realizados para a determinação dos tempos de operação do disjuntor. Este trabalho foi exposto no IEEE Power Engineering Society General Meeting 2004, realizado nos EUA. Além de outros artigos publicados em congressos e seminários nacionais como T\&D, SNPTEE, CITENEL A CBA.

Como contribuição desta pesquisa podemos destacar:

* O entendimento e disseminação local da técnica de monitoramento de disjuntores.

* O projeto, construção e teste de um protótipo que foi instalado na SE Sumaré de ETEO, tendo apresentado um desempenho adequado.

* Identificação dos tempos notáveis na abertura do disjuntor por uma técnica não intrusiva. Determina-se por esta metodologia os tempos envolvidos no inicio e final da movimentação dos contactos principais.

* Detalhes tecnológicos como, por exemplo, o uso de sensores de efeito Hall para o monitoramento da corrente no circuito de disparo do disjuntor; modificações para a coleta de oscilografia no programa Action View.

Artigos para difusão do conhecimento em seminários e congressos conceituados. 


\section{REFERÊNCIAS BIBLIOGRÁFICAS}

[1] ANGRISANI, L., DAPONTE, P., D'APUZZO, M. and TESTA, A. “ $A$ Measurement Method Based on the Wavelet Transform for Power Quality Analysis". IEEE Transactions on Power Delivery, 13, 4, 990-998, October 1998.

[2] ALLEN, G.R.; CHEUNG, R. "Integration of protection, control and monitoring functions for transmission and distribution substations", IEEE Transactions on Power Delivery, Vol. 13, nº 1, January 1998.

[3] BARRICK, S.D; "Distributed data acquisition system for substation bus protection and monitoring”, IEEE - PES - Conference \& Exposition on Transmission \& Distribution, April 1998.

[4] BAOZHUANG, S; LI, Y; XINYU, J; HONGBIN, W; LIANGCAI, Z; "Instrumentation of online insulation monitoring of HV apparatus", Proceedings of the $6^{\text {th }}$ International Conference on Properties and Applications of Dielectric Materials, June 2000.

[5] BEAUPRÉ, J.A; LEHOUX, M; BERGER, P.A; "Advanced monitoring technologies for substations", ESMO - IEEE International Conference on Transmission \& Distribution, Construction, Operation and Live-line Maintenance, October 2000.

[6] BERGMAN, B.W.; "Circuit Breaker monitoring and diagnostic”, IEEE - PES Conference \& Exposition on Transmission \& Distribution, October 2001.

[7] BERGMAN, B.W.; "Selecting Circuit Breaker Monitoring”, IEEE Transactions on Power Systems, February 2001.

[8] CANNON, M.C; "Practical On-line Analysis For Substation Equipment Monitoring”, IEEE Winter Power Meeting, Panel Discussion, 1999.

[9] CALDERON, Y.P., "Sistema de Supervisão em Tempo Real voltado a Manutenção Preditiva de Transformadores de Potência". Dissertação de Mestrado apresentada na Escola Politécnica da USP, Junho 2004.

[10] CEA - Canadian Electricity Association, "On-line Condition Monitoring of Substation Power Equipment Utility Needs”, December 1997. 
[11] CHRISTOFOROS, N.H.; VERGHESE, G.C.; "Power system monitoring based on relay and Circuit Breaker information", IEEE Transactions on Power Systems, March 2001.

[12] CIGRE "Final Report of the Second International Enquiry on High Voltage Circuit Breaker Failures and Defects in Service”, CIGRE Technical Brochure No. 83, 1996.

[13] CORBETT, J., HIGGINS, A., and KELLEHER, C.; “A Procedure for Allocating Limited Resources to Circuit Breaker Planned Maintenance", CIGRE 02, August 2002, Session 13.

[14] COSGRAVE, J.; STANGHERLIN, S.; HUMPHRIES, J.; "Intelligent optical fiber monitoring of oil-filled circuit breaker", IEEE Proc. Generation Distribution, November 1999, Vol. 146, nº6.

[15] DUPRAZ, J.P.; SHIEMANN, A.; MONTILLET, G.F.; "Design Objectives of new digital control and Monitoring of high voltage Circuit Breaker", IEEE Transactions on Power Systems, January 2001.

[16] DUPRAZ, J.P.; WHITE, P.E.; MONTILLET, G.F.; "Strategy for Applying a Digital SF6 Monitoring Device to High Voltage Circuit Breaker", IEEE Transactions Delivery, March 2003.

[17] EPRI, “A Methodology for Assessing the Economic Justification of Retrofitting On-line Condition Monitoring to an Existing Circuit Breaker Installation", EPRI Substation Equipment Diagnostics Conference VII, New Orleans, Louisiana, Feb. 23, 1999.

[18] FROHLICH, K., STANEK, M.; "Model-Aided Diagnosis - A New Method for Online Condition Assessment of High Voltage Circuit Breakers". IEEE Transactions on Power Delivery, Vol.15, No.2, April 2000.

[19] GAOUDA, A. M., SALAMA, M. M. A., R.SULTAN, M. and CHIKHANI, A. Y. "Power Quality Detection and Classification Using Wavelet-Multiresolution Signal Decomposition”. IEEE Transactions on Power Delivery, 14, 4, 14691476, October 1999.

[20] IEEE "Guide for the selection of monitoring for Circuit Breaker", IEEE Std. C37.10.1-2000.

[21] JEFFREY, H.N.; "Electric Utility considerations Circuit Breaker Monitoring”, IEEE Transactions on Power Systems, June 2001.

[22] KIM, C. H. and AGGARWAL, R. "Wavelet transforms in power systems: Part 1 General introduction to the wavelet transforms". Power Engineering Journal, 14, 2, 81-87, April 2000. 
[23] LEE, D. S., LITHGOW, B.J., and MORRISON, R.E. "New Fault Diagnosis of Circuit Breakers". IEEE Transactions on Power Delivery, Vol. 18 No.2, April 2003.

[24] MARTINEZ, D.C., "Sistema de Supervisão em Tempo Real voltado a Manutenção Preditiva de Disjuntores". Dissertação de Mestrado apresentada na Escola Politécnica da USP - 2005.

[25] MATHWORK, Inc. Wavelet Toolbox: User's Guide, Internet, 2001.

[26] MISITI, M., MISITI, Y., OPPENHEIM, G. and POGGI, J.M. "Wavelet Toolbox: User's Guide”. Natick, MA: The Math Works, 626 p. 1997.

[27] POELT, A.; HAINES, M.; "Experiences with condition Monitoring of $H V$ Circuit Breaker”, IEEE Transactions on Power Systems, July 2001.

[28] POISSON, O., RIOUAL, P. and MEUNIER, M. "New Signal Processing Tools Applied to Power Quality Analysis". IEEE Transactions on Power Delivery, 14, 2, 561-566, April 1999.

[29] POISSON, O., RIOUAL, P. and MEUNIER, M. "Detection and Measurement of Power Quality Disturbances Using Wavelet Transform". IEEE Transactions on Power Delivery, 15, 3, 1039-1044, July 2000.

[30] PROBERT, S.A., SONG, Y.H. "Detection and Classification of High Frequency Transient using Wavelet Analysis”. IEEE Transactions on Power Delivery, 15, 3, 801-806, 2002.

[31] QINGBO, L; BAOSHENG, T; JIANG, G; “Improvement of substation maintenance”, CIRED 97, June 1997, Conference Publication $n^{0} 438$.

[32] QIU, X; WIMMER, W; “Applying object-orientation and component technology to architecture design of power system monitoring", IEEE Conference on Power System Technology, December 2000.

[33] REIS, F.F., "Uma Proposta de Algoritmo Digital para Proteção da Interligação Concessionária e Indústria operando em Sistemas de Cogeração”. Tese apresentada na Escola Politécnica da USP, Novembro 2002.

[34] SANTOSO, S., GRADY, W. M., POWERS, E. J., LAMOREE, J. and BHATT, S. C. "Characterization of Distribution Power Quality Events with Fourier and Wavelet Transforms". IEEE Transactions on Power Delivery, 15, 1, 247-254, January 2000.

[35] SANTOSO, S., POWERS, E. J., GRADY, W. M. and HOFMANN, P. "Power Quality Assessment Via Wavelet Transform Analysis". IEEE Transactions on Power Delivery, 11, 2, 924-930, April 1996. 
[36] SHIM, B; YANG, L; “An on-line insulation monitoring system of HV apparatus using a micro-computer system”, IEEE International Symposium on Electrical Insulation, April 2000, Conference Record.

[37] SILVA, M.S., JARDINI, J.A., MAGRINI, L.C., "Experience in Circuit On-line Breaker Monitoring Systems Design”, International Council on Large Electrical Systems CIGRE BHK (Sarajevo - Bosnia / Herzegovina), Setembre 2003.

[38] SILVA, M.S., JARDINI, J.A., MAGRINI, L.C., "Determination of the Circuit breaker Operation times using the Wavelet Transform", IEEE Power Engineering Society 2004 General Meeting (Denver - Colorado / EUA), Junho 2004.

[39] SMEETS, R.P.P., KERTESZ, V., et al, "Digital Testing of High Voltage Circuit Breakers”, ELECTRA No. 204, October 2002.

[40] SWEETSER, C.; BERGMAN, B., and MONTILLET, G.; "Strategies for Selecting Monitoring of Circuit Breakers", IEEE Transactions on Power Delivery, Vol. 17, No. 3, July 2002.

[41] YANG, H.T. and LIAO, C.C. "A De-Noising Scheme for Enhancing WaveletBased Power Quality Monitoring System”. IEEE Transactions on Power Delivery, 16, 3, 353-360, July 2001.

[42] YOUSSEF, A.S. "Fault Classification based on Wavelet Transformer". IEEE Transactions on Power Delivery, 531-536, 2001.

[43] YU, W., HU, X., and JI, Y., "The Application of Wavelet Singularity Detection in Fault Diagnosis of High Voltages Breakers". IECON'01 The 27 ${ }^{\text {th }}$ Annual Conference of the IEEE Industrial Electronics Society, 490-494, 2001.

[44] ZHENG, T., MAKRAM, E. B. and GIRGIS, A. A. "Power System Transient and Harmonic Studies Using Wavelet Transform". IEEE Transactions on Power Delivery, 14, 4, 1461-1467, October 1999. 


\section{APÊNDICE}

\section{ANEXO A \\ TÉCNICA DE ANÁLISE DE SINAL WAVELETS E FOURIER}

1) Introdução

Nesta parte serão tecidas considerações gerais sobre técnicas de análise de sinal: Wavelets e Fourier.

Um sinal no tempo pode ter as seguintes características: ser de duração finita ou infinita; o tempo pode ser de variação continua ou discreta (resultado da amostragem).

O mais comum, portanto é ter um sinal de duração finita e amostrado (variação de tempo discreta).

Na análise de um sinal é possível analisá-lo aos “pedaços” (duração finita / tempo discreto).

2) Transformada de Fourier

- A principal técnica desenvolvida que levaram às wavelets foi a Transformada de Fourier - TF, que surgiu da decomposição de uma função em serie de Fourier (análise de Fourier).

Esta analise estabelece que "qualquer função $2 \pi$ periódica”, $f(x)$, pode ser representada pela série.

$$
f(x)=a_{0}+\sum_{k=1}^{n}\left(a_{k} \cos (k x)+b_{k} \operatorname{sen}(k x)\right)
$$


Os valores $a, b$ são calculados por:

$a_{0}=\frac{1}{2 \pi} \int_{o}^{2 \pi} f(x) d x ; \quad a_{k}=\frac{1}{\pi} \int_{o}^{2 \pi} f(x) \cos (k x) d x ; \quad b_{k}=\frac{1}{\pi} \int_{o}^{2 \pi} f(x) \operatorname{sen}(k x) d x$

Os valores $a, b$ definem o espectro de freqüência $k$ existente na função $f(x)$.

Observar que a equação (A2) decompõe $f(x)$, e a equação (A1) recompõe $f(x)$ a partir dos valores obtidos da decomposição. Na decomposição pode-se abandonar algumas freqüências $k$, principalmente se os respectivos coeficientes $a_{k}, b_{k}$ forem pequenos com relação aos demais. Com isto, obtem-se uma função $f(x)$ "filtrada" ou "alisada".

Observar também que a "forma" das equações (A1), (A2) são similares, e que as funções $\cos (k x)$, sen $(k x)$ são usadas para decompor e recompor a função $f(x)$.

A Transformada de Fourier (TF) segue a forma da analise (serie) de Fourier. Ela consiste de duas vertentes: Na primeira o sinal em função do tempo $g(t)$ é transformada numa função das freqüências $G(f)$, determinando-se assim o espectro de freqüências do sinal. Na outra a função da freqüência é transformada na função do tempo (transformada inversa). Pode-se então usar a notação:

$$
g(t) \longleftrightarrow G(f)
$$

No caso do sinal ser infinito e a variação de tempo ser continua utiliza-se as equações a seguir:

$$
\begin{aligned}
& G(f)=\int_{-\infty}^{\infty} g(t) \ell^{-i 2 \pi f t} d t ; \quad f \in \mathfrak{R} \text { espaço real } \\
& g(t)=\int_{-\infty}^{\infty} G(f) \ell^{+i 2 \pi f t} d f ; \quad t \in \mathfrak{R} \text { espaço real } \\
& \text { onde } i=\sqrt{-1} ; f=\text { freqüência }
\end{aligned}
$$

Na prática os sinais são de duração finita ou limitado em tempo (time limited). Muitas vezes os sinais obtidos não são contínuos, ou seja, são amostras da 
função $g(t)$ colhidas com um passo de amostragem, por exemplo, 16 amostras por ciclo de $60 \mathrm{~Hz}$, ou seja, uma amostra a cada $1 \mathrm{~ms}$, ou ainda, freqüência de amostragem de 16X60=960Hz.

Na Tabela A1 estão apresentados as formulas das transformadas para as varias combinações.

Tabela A1 - Formulas de Transformadas de Fourier.

\begin{tabular}{|c|c|c|}
\hline \multirow{2}{*}{$\begin{array}{c}\text { Duração } \\
\text { Sinal }\end{array}$} & \multicolumn{2}{|c|}{ Variação do Tempo } \\
\hline & Continua & Discreta \\
\hline Infinito & $\begin{array}{l}G(f)=\int_{-\infty}^{\infty} g(t) \ell^{-i 2 \pi f t} d t ; \quad f \in \mathfrak{R} \\
g(t)=\int_{-\infty}^{\infty} G(f) \ell^{+i 2 \pi f t} d f ; \quad t \in \mathfrak{R}\end{array}$ & $\begin{array}{l}G(f)=\sum_{n=-\infty}^{\infty} g(n) \ell^{-i 2 \pi \frac{f}{S} n} ; f \in(0, S) \\
g(n)=\int_{0}^{S} \frac{1}{S} G(f) \ell^{i 2 \pi \frac{f}{s} n} d n ; \quad n \in \mathrm{Z}\end{array}$ \\
\hline Finito & $\begin{array}{l}G\left(\frac{k}{T}\right)=\int_{0}^{T} g(t) \ell^{-i 2 \pi\left(\frac{k}{T}\right) t} d t ; \quad k \in \mathrm{Z} \\
g(t)=\sum_{k=-\infty}^{\infty} \frac{G\left(\frac{k}{T}\right)}{T} \ell^{+i 2 \pi \frac{k}{T} t} ; t \in(0 ; T) \\
\text { Nota: } T \text { período }\end{array}$ & $\begin{array}{l}G\left(\frac{k}{N}\right)=\sum_{n=0}^{N-1} g(n) \ell^{-i 2 \pi \frac{k}{N} n} ; k \in \mathrm{Zn} \\
g(n)=\frac{1}{N} \sum_{k=0}^{N-1} G\left(\frac{k}{N}\right) \ell^{+i 2 \pi \frac{k}{N} n} ; n \in \mathrm{Zn} \\
f \longrightarrow \frac{k}{N} ; N=\text { no. de amostras }\end{array}$ \\
\hline
\end{tabular}

Muitas vezes está sinal é composto de varias partes. Neste caso divide-se a função em pedaços (janelas) e calcula-se a transformada. É a Transformada de Fourier de Curta Duração - Short Time Fourier Transform - STFT. É costume aplicar em cada secção do sinal uma função peso de forma a colocar menor ênfase nos extremos que no meio da secção. Se este peso for uma Gaussiana então aparece a denominação Transformada de Gabor. O termo Windowed Fourier Transform - WFT também é usado nestes casos.

Se os valores são amostrados uniformemente pode-se simplificar a quantidade de contas através de matrizes esparsas. É o Fast Fourier Transform - FFT. 
Aplicação nesta tese:

O sinal “corrente no disjuntor” pode ser dividido nas seguintes secções:

Pré-defeito

$\checkmark$ Com curto - até início de separação dos contatos principais

$\checkmark$ Início da separação até o contato móvel atingir a posição final

$\checkmark$ Contatos abertos até a interrupção da corrente numa passagem por zero.

3) Transformada Wavelet

3.1) Geral

A Transformada Wavelet - WT é uma técnica que sucede a Transformada de Fourier permitindo uma melhor análise dos sinais. [2]

O conceito tem certa similaridade com a Transformada de Fourier. Ou seja, uma função $f(x)$ pode ser decomposta em: uma série similar à equação (A1) exceto que, as funções seno e cosseno são substituídas por "Wavelets". Na Figura A1 são mostradas algumas das funções Wavelets $(\phi(x))$ denominadas “mãe” para análise de sinais discreto (amostras).
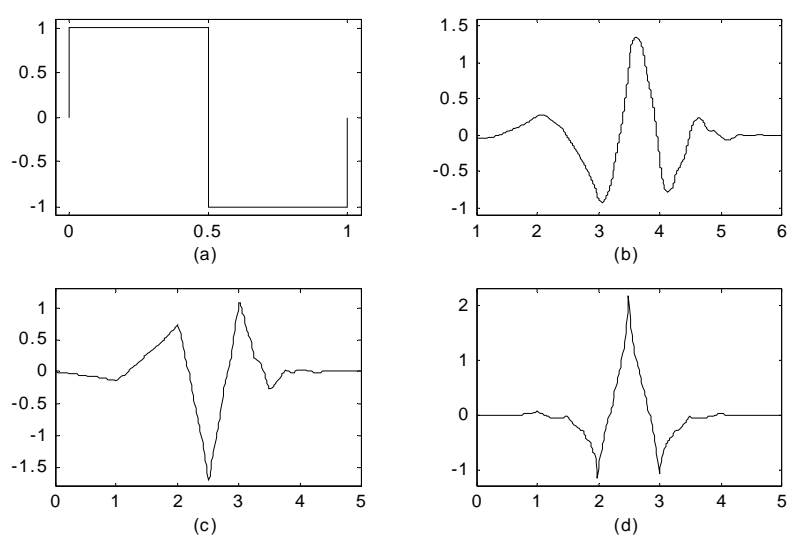

Figura A1 - Wavelets mãe: Haar (a), db4 (b), sym3 (c) e coif1 (d).

Notar que elas têm uma duração determinada, ou seja, valores diferentes de zero apenas numa janela. 
Para os Wavelets é estendido o conceito de família, ou seja:

- dada uma função $\phi(x)$ "wavelets mãe"

- existe uma família dada por $\frac{1}{\sqrt{a}} \phi\left(\frac{x-b}{a}\right)$

obtidas a partir de $\phi$, atribuindo-se valores para $a$ e $b$. Notar que " $a$ " "escala" a função e " $b$ " "translada” a função.

Para decompor uma função $\mathrm{f}(\mathrm{x})$ em uma série de Wavelets é preciso calcular os coeficientes.

$C W T(a, b)=\frac{1}{\sqrt{a}} \int_{-\infty}^{\infty} f(x) \phi\left(\frac{x-b}{a}\right) d x$

Neste caso CWT é a Transformada Wavelets Contínua - CWT.

Usa-se também a notação (A6) a seguir para a eq (A5):

$C W T(a, b)=\left\langle f, \phi_{a b}\right\rangle$

Para recompor a função $f(x)$ partindo da CWT aplica-se (A7).

$f(x)=\frac{1}{c_{\phi}} \int_{-\infty}^{\infty} \int_{a>0}^{\infty} C W T(a, b) \frac{1}{\sqrt{\alpha}} \phi\left(\frac{x-b}{a}\right) d a d b$

Sendo $c_{\phi}$ uma constante. Notar que a mesma função $\phi$ é usada na decomposição e recomposição do sinal, similarmente a Transformada de Fourier.

3.2) Escala e Translação

A) Escala

Nas Figuras A2 e A3 são mostrados estes efeitos. Se estivesse sendo falado sobre segmentos de senóides, por exemplo, o efeito do fator de escala é facilmente observado, onde a diminuição do fator de escala " $a$ " contrai o gráfico da função: 

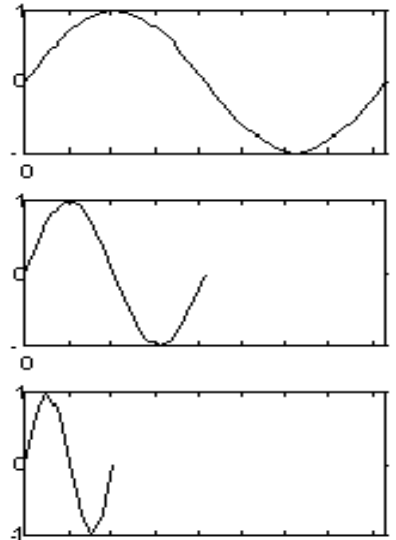

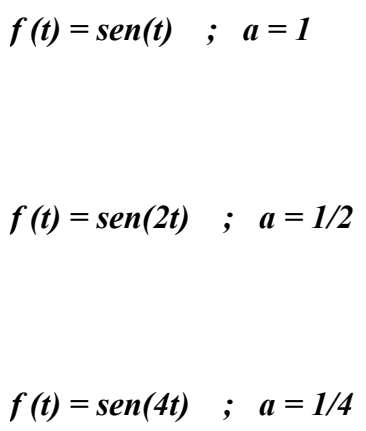

$f(t)=\operatorname{sen}(4 t) \quad ; \quad a=1 / 4$

Figura A2 - Exemplo do fator de escala em uma função seno(t/a)

O fator de escala trabalha da mesma forma com as Wavelets. Quanto menor o fator de escala, mais “contraída” será a Wavelet. A Figura A3 ilustra o fator de escala atuando com funções Wavelets.
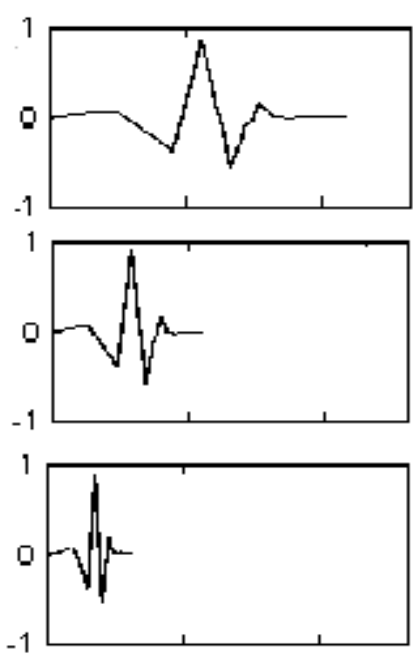

$$
f(t)=\phi(t) \quad ; a=1
$$$$
f(t)=\phi(2 t) \quad ; a=1 / 2
$$

$$
f(t)=\phi(4 t) \quad ; a=1 / 4
$$

Figura A3 - Exemplo do fator de escala em uma função Wavelet.

\section{B) Translação}

Transladar uma Wavelet significa atrasá-la ou adiantá-la no eixo das abscissas, que é o que se faz matematicamente quando escreve-se $f(x-k)$ como um atraso na função $f$ de um fator $k$, como pode ser visto abaixo na Figura A4. 

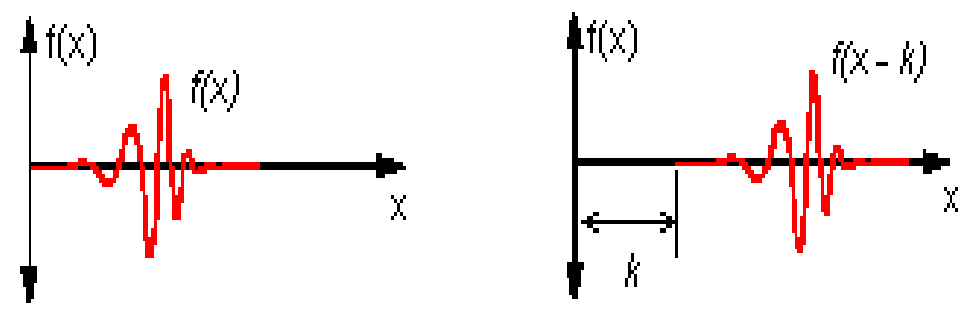

Figura A4 - Translação aplicada a uma Wavelet.

C) Decomposição e Recomposição da função

Para a decomposição da função $f(x)$ na série wavelets deve-se proceder da seguinte forma (cálculo de $C W T(a, b))$ :

i) - Alinhar uma Wavelet definida pelos parâmetros $(a, b)$ com uma secção inicial do sinal original;

ii) - Calcular o coeficiente $C W T(a, b)$ equação (A5). Notar que o valor $C W T(a, b)$ representa o quão intimamente relacionado está a Wavelet com a secção do sinal. Entre os coeficientes calculados, os maiores valores de CWT significam uma maior similaridade do sinal com a Wavelet. O resultado irá depender da forma da Wavelet escolhida (Figura A5).

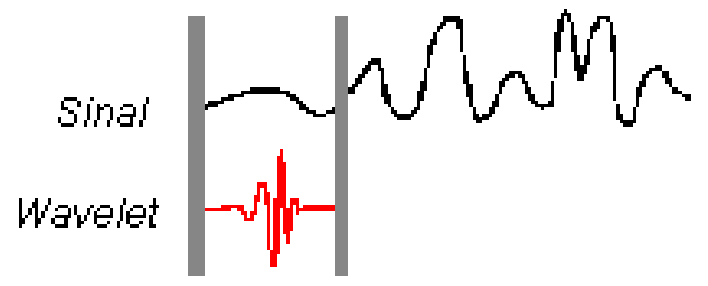

Figura A5 - Cálculo do fator CWT de relação entre a Wavelet e o sinal.

iii) - Efetuar uma "translação” da Wavelet, como mostrado na Figura A6, e repetir os passos i) e ii) até que se tenha coberto todo o sinal. 


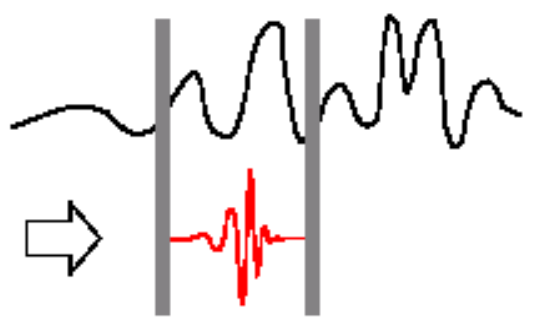

Figura A6 - Translação da função Wavelet

iv) - "Escalar" (dilatar/contrair) a Wavelet, como ilustrado na Figura A7, e repetir os passos de i) a iii).

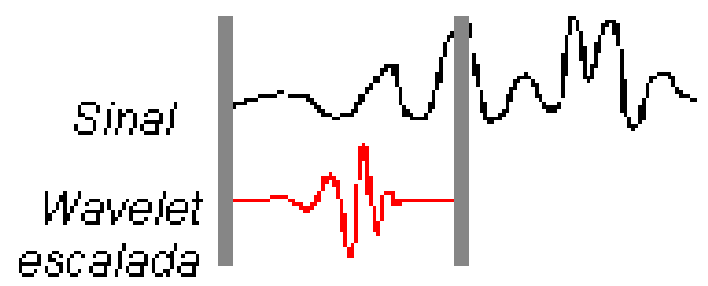

Figura A7 - Exemplo de escalamento da função Wavelet para o prosseguimento nos cálculos

v) - Repetir os passos de i) a iv) para todas as escalas.

Terminado o processo descrito acima, obtem-se os coeficientes para representação do sinal.

Neste ponto é importante notar que ao variar " $b$ ” desloca-se a janela dos pontos da função $f(x)$ a ser analisado. Variando " $a$ " observa-se melhor detalhes da função $f(x)$ variando a largura de janela.

Para a recomposição a partir dos valores CWT procede-se de forma similar.

3.3) Variantes da Transformada Wavelet Contínua

A DPWT Transformada Wavelet de Parâmetros Discretos consiste em fazer em (A5) $a=a_{0}{ }^{m}$, e $b=m b_{0} a_{0}{ }^{m}$, onde $a_{0}, b_{0}$ são os intervalos de amostragem e $m, n$ números inteiros. Neste caso tem-se:

$$
\begin{gathered}
\phi(m, n)=a_{0}^{-\frac{m}{2}} \phi\left(a_{0}^{-m} x-n b_{0}\right) \\
D P W T(m, n)=a_{0}^{-\frac{m}{2}} \int f(x) \phi\left(a_{0}^{-m} x-n b_{0}\right) d x
\end{gathered}
$$


Notar que $f$ e $\phi$ são variáveis contínuas porém, as freqüências são discretas. Do ponto de vista eficiência computacional pode-se adotar $a_{0}=2$ e $b_{0}=1$, o que resulta numa dilatação de $2^{-m}$ e numa translação de $2^{m} n$.

A DTWT Transformada Wavelet de Tempo Discreto é obtida discretizando o valor de $x \operatorname{com} x=k t$, e utilizando intervalo de amostragem $t=1$ (A10).

$$
\operatorname{DTWT}(m, n)=a_{0}^{-\frac{m}{2}} \sum_{k} f(k) \phi\left(a_{0}^{-m} k-m b_{0}\right)
$$

Neste caso, tanto o tempo como as freqüências são variáveis discretas.

Finalmente a DWT - Transformada Wavelet Discreta é obtida discretizando a Wavelet $\phi$ e fazendo $a_{0}=2$ e $b_{0}=1$

$$
\operatorname{DWT}(m, n)=2^{-\frac{m}{2}} \sum_{k} f(k) \phi\left(2^{-m} k-n\right)
$$

Ela tem uma correspondência com a Transformada de Fourier Discreta.

\section{4) Decomposição por filtros [3]}

Para este objetivo são definidas duas funções: $\phi$ escalamento e $\psi$ função Wavelet. A função escalamento $\phi$ é definida pela equação (A12).

$$
\phi(x)=\sum_{k=0}^{M-1} c_{k} \phi(2 x-k)
$$

onde $c_{k}$ são coeficientes diferentes dependente da Wavelet considerada, e $M$ é o número de coeficientes não nulos da Wavelet.

Na Tabela A2 a seguir estão definidos alguns coeficientes: 
Tabela A2. Coeficientes de Transformadas Wavelets.

\begin{tabular}{|l|c|c|c|c|}
\hline Wavelet & $\mathrm{c}_{0}$ & $\mathrm{c}_{1}$ & $\mathrm{c}_{2}$ & $\mathrm{c}_{3}$ \\
\hline Haar & 1,0 & 1,0 & & \\
\hline \multirow{2}{*}{ Daubechies 4 } & 0,683 & 1,183 & 0,316 & $-0,183$ \\
& $\frac{1}{4}(1+\sqrt{3})$ & $\frac{1}{4}(3+\sqrt{3})$ & $\frac{1}{4}(3-\sqrt{3})$ & $\frac{1}{4}(1-\sqrt{3})$ \\
\hline
\end{tabular}

A função Wavelet $\psi$ é definida por:

$$
\psi(x)=\sum_{k}(-1)^{k} c_{1-k} \phi(2 x-k)
$$

Nota: As funções $\phi, \psi$, são complementares de “mesma origem”, devem possuir propriedades matemáticas específicas (ex. ortogonalidades) que não serão aqui discutidas. Detalhes podem ser obtidos em [3], [2].

\section{4) Algoritmo Mallat Pirâmide (Análise Multi Resolução)}

Tomando-se um conjunto finito de $N$ pontos de um sinal, onde $N=2^{m}$ e passando estes dados por 2 funções convolução (A13); (A12) cria-se saídas com metade das amostras originais. Estas convoluções são “filtros”.

- metade das saídas são produzidas por um filtro "passa baixa” definido pela eq. (A12). A saída produzida é dada por:

$$
a_{i}=\frac{1}{2} \sum_{j=1}^{N} c_{-2 i+j+1} f_{j} \quad i=1, \ldots . . N / 2
$$

- a outra metade é produzida por um filtro "passa alta” definido pela eq. (A13). Esta saída é dada por:

$$
d_{i}=\frac{1}{2} \sum_{j=1}^{N}(-1)^{j+1} c_{-j+2+2 i} f_{j} \quad i=1, \ldots . . N / 2
$$

Lembrando que: $N$ é número de amostras, $c$ são coeficientes; $f$ é a função entrada, e $i$ a ordem de decomposição. 
A saída $a_{i}$ é denominada “aproximação" e a saída $d_{i}$ é denominada "detalhe”. Conceitualmente $a_{i}$ contém as freqüências baixas e $d_{i}$ as freqüências altas.

Na Figura A8 mostra-se graficamente a primeira decomposição da função de entrada.

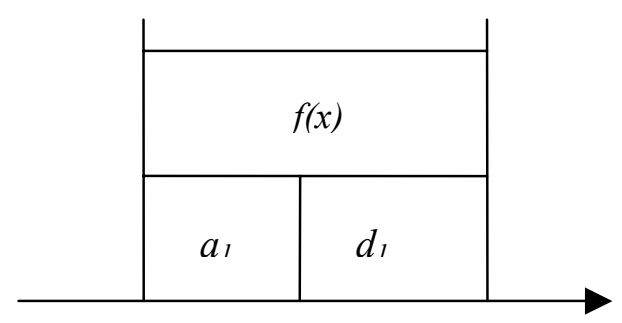

Figura A8 - Decomposição da Função

Aplicando-se a mesma técnica em $a_{l}$ atinge-se o segundo nível de decomposição criando-se $a_{2}, d_{2}, \ldots$ e assim sucessivamente obtendo-se o conjunto $a_{n}, d_{1}, d_{2}, \ldots d_{n}$ que pode ser usado depois para recomposição do sinal. A Figura A9 indica os vários níveis de decomposição.

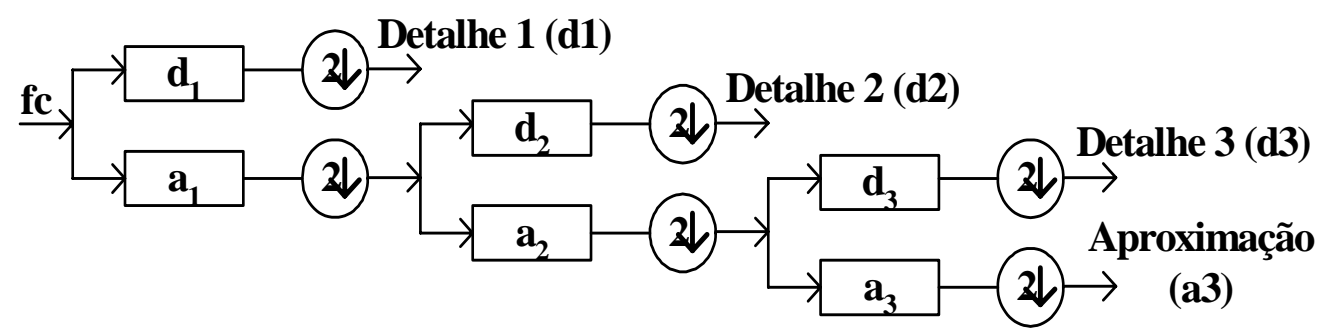

Figura A9 - Decomposição em 3 níveis.

O símbolo $2 \downarrow$ indica que o número de amostras cai a metade.

Exemplo: Para um melhor entendimento considere-se para $\psi$ a função Haar. Os valores $a_{i}$ obtidos com a eq (A14) resultam na semi-soma de duas amostras sucessivas (ver exemplo numérico mais a frente), ou seja, é uma média, já os valores $b_{i}$ eq (A15) resultam na semi diferença de duas amostras consecutivas (variação).

Via de regra qualquer que seja a Wavelet os valores $a_{i}$ representam uma espécie de “média ponderada móvel” e os valores $b_{i}$ diferenças ponderadas. Desta forma $a_{i}$ resulta 
numa versão "filtrada” da função (denominada “aproximação”) e $b_{i}$ as variações desta função (denominado “detalhe”).

De posse dos valores $a_{i}, b_{i}$ pode-se reconstruir o sinal pela transformação inversa à decomposição descrita.

A transformação inversa devido ao filtro passa baixa é dada por:

$$
f_{j}^{L}=\sum_{i=1}^{N / 2} c_{i-2 j+4} a_{i} \quad i=1 \ldots . . N
$$

Notar que esta equação duplica os valores de saída de filtro passa baixa:

$$
f_{j}^{H}=\sum_{j=1}^{N / 2}(-1)^{j} c_{2 j-1-i} b i
$$

A função é, pois composta das parcelas relativas ao filtro passa baixa e passa alta sendo, portanto:

$$
f=f^{L}+f^{H}
$$

No caso de se ter, por exemplo, duas decomposições:

$$
f=a^{(2)}+d^{(1)}+d^{(2)}
$$

Na Figura A10 mostra-se a saída do Matlab usando a função mãe Haar com os gráficos de aproximação e detalhe da primeira decomposição, sendo usadas 16 amostras. 


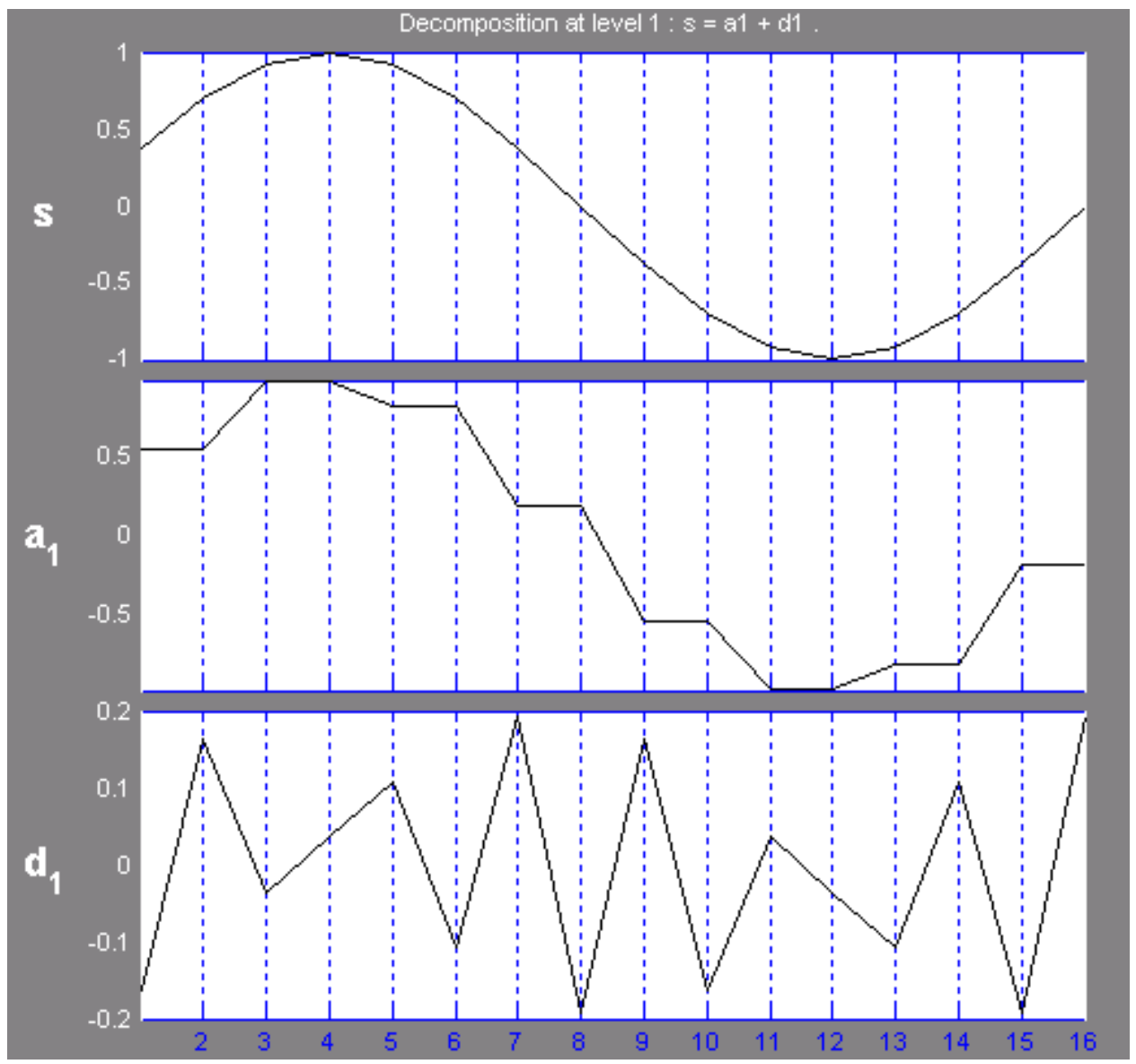

Figura A10 - Transformada Wavelet Haar usando Matlab.

3.5) Forma matricial do algoritmo

Sejam as matrizes (função de entrada, aproximação e detalhe).

$$
f(x)=\left[\begin{array}{l}
f(0) \\
f(1) \\
f(N-1)
\end{array}\right] \quad a=\left[\begin{array}{l}
a_{0} \\
a_{1} \\
a_{\frac{N}{2}-1}
\end{array}\right] \quad d=\left[\begin{array}{l}
d_{0} \\
d_{1} \\
d_{\frac{N}{2}-1}
\end{array}\right]
$$

Considere também uma função Wavelet definida por 4 coeficientes $\left(c_{0}, c_{1}, c_{2}, c_{3}\right)$.

Então: 


$$
\begin{aligned}
& \bar{G}=\sqrt{2}\left|\begin{array}{cccccccc}
c_{0} & c_{1} & c_{2} & c_{3} & & & & 0 \\
0 & 0 & c_{0} & c_{1} & c_{2} & c_{3} & & 0 \\
0 & . . & & & c_{0} & c_{1} & \ldots & 0
\end{array}\right| \\
& \bar{H}=\sqrt{2}\left|\begin{array}{cccccccc}
c_{3} & -c_{2} & c_{1} & -c_{0} & & . . & & 0 \\
0 & 0 & c_{3} & -c_{2} & c_{1} & -c_{0} & & 0 \\
0 & \ldots & & & c_{3} & -c_{2} & \ldots & 0
\end{array}\right|
\end{aligned}
$$

A matriz $a$ e $d$ são obtidas por:

$$
\begin{aligned}
& a=\bar{G} f \\
& d=\bar{H} f
\end{aligned}
$$

A transformação inversa é obtida utilizando as matrizes:

$$
\begin{gathered}
G=\sqrt{2}\left|\begin{array}{cccc}
c_{3} & c_{1} & & 0 \\
& c_{2} & c_{0} & 0 \\
& c_{3} & c_{1} & 0 \\
0 & & & c_{2}
\end{array}\right| \\
H=\sqrt{2}\left|\begin{array}{cccc}
-c_{0} & -c_{2} & & 0 \\
0 & c_{1} & c_{3} & 0 \\
0 & -c_{0} & -c_{2} & 0 \\
& & & c_{1}
\end{array}\right|
\end{gathered}
$$

Resultando:

$$
f=G a+H d
$$

\subsection{Exemplo numérico}

Seja uma função cujos valores iniciais são zeros depois 2;4;5;9;0;0;0.

Para a sua decomposição e depois recomposição será usada a Wavelet Haar aplicandose, pois as equações (A14) a (A18). A Haar tem 2 coeficientes $c_{0}=1$ e $c_{1}=1$ e pode ser 
calculada com as formulas matriciais do item anterior excluindo os valores c2; c3 e trocando $\sqrt{2}$ por $1 / 2$ nas matrizes $\bar{G}, \bar{H}$ e 1 nas matrizes $\mathrm{G}$, H. Assim tem-se:

$$
a=\left[\begin{array}{l}
0 \\
0 \\
3 \\
7
\end{array}\right]=1 / 2\left[\begin{array}{cccccccc}
1 & 1 & 0 & 0 & 0 & 0 & 0 & 0 \\
0 & 0 & 1 & 1 & 0 & 0 & 0 & 0 \\
0 & & & & 1 & 1 & & \\
0 & & & & & & 1 & 1
\end{array}\right]\left[\begin{array}{l}
0 \\
0 \\
0 \\
0 \\
2 \\
4 \\
5 \\
9
\end{array}\right]
$$

Notar por exemplo que: $a_{3}=(2+4) / 2$, ou seja, os valores a são médias de 2 pontos sucessivos

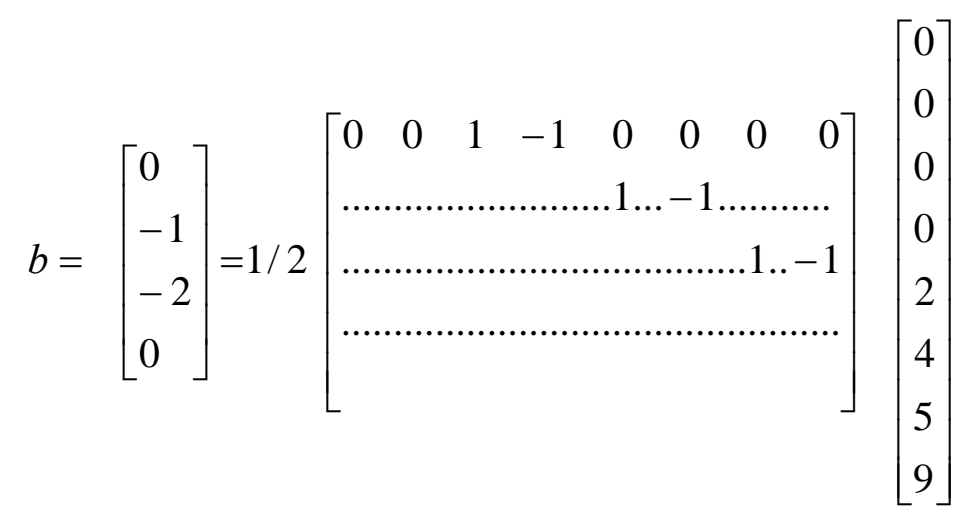

Notar que: $b_{3}=(5-9) / 2$, ou seja, a semidiferença.

Para a recomposição tem-se

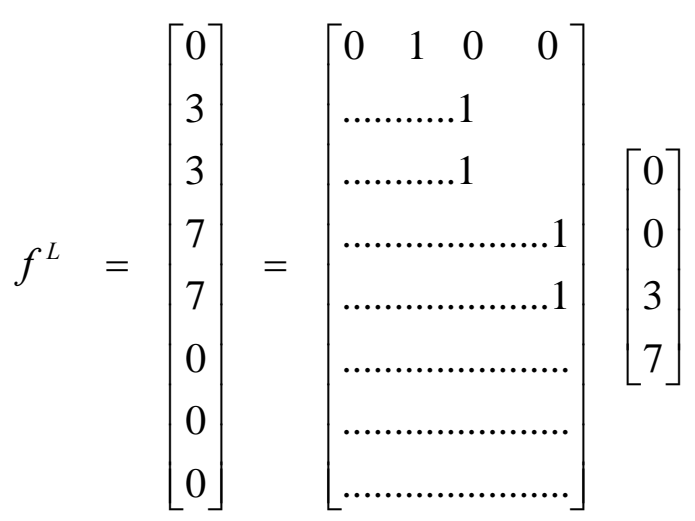

Examinado $f_{2}^{L_{2}} f^{L_{3}}$ observa-se que esta operação duplica o numero de amostras replicando valores. 


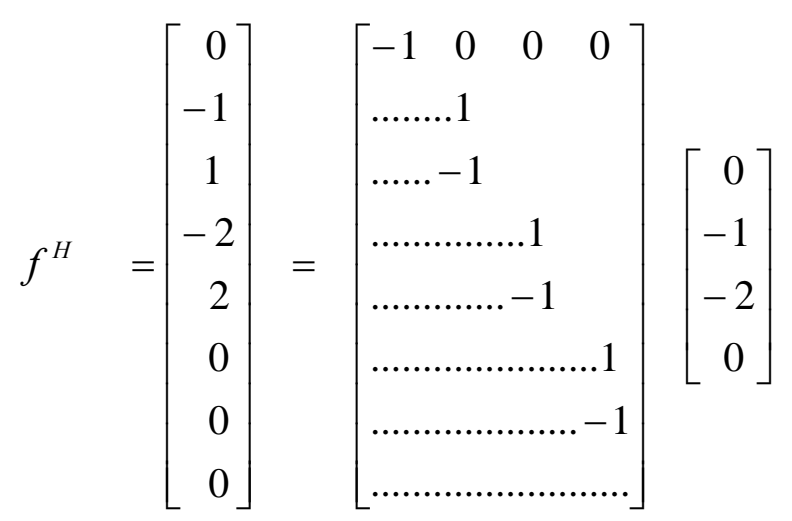

A recomposição $f(x)$ resulta na soma dos resultados de $f^{\mathrm{L}}$ e $f^{H}$ acima.

Por exemplo:

$$
\begin{aligned}
& f(2)=3-1=2 \\
& f(3)=3+1=4 \\
& f(4)=7-2=5 \\
& f(5)=7+2=9
\end{aligned}
$$

Como eram os valores iniciais a menos de um deslocamento de posição

$$
f(2) \text { recomposto }=f(5) \text { inicial }
$$

\section{7) Aplicação nesta tese}

Dado os sinais de correntes e tensões nas três fases, aplica-se a decomposição do sinal em diferentes níveis.

Os valores de $d_{l}$, detalhes da primeira decomposição, indicarão o instante de ocorrência do curto ( $1^{\text {a }}$ variação) e depois o início de abertura dos contatos, quando aparecerão altas freqüências devido ao arco interno.

A interrupção ao passar a corrente por um zero, estando os contatos abertos completam a identificação dos instantes. 
[1] Graps, A. "Na Introduction to Wavelets”. IEEE Computational Science and Engineering, Summer 1995, vol. 2 n².

[2] Chan, Y. T. “Wavelets Basics” Kluwer Academic Publishers, 1995.

[3] Edwards, T. "Discrete Wavelet Transforms: Theory and Implemetation” Stamford University, September, 1991. 